\title{
ipen
}

AUTARQUIA ASSOCIADA À UNIVERSIDADE DE SÃO PAULO

ESTUDO DA ADSORÇÃO DE ÍONS METÁLICOS EM CAULINITA PARA ÁGUA DE REUSO

Giovanni Del Sordo Filho

Dissertação apresentada como parte dos requisitos para obtenção do Grau de Mestre em Ciências na Área de Tecnologia Nuclear - Aplicações

Orientador:

Prof. Dr. Paulo Sergio Cardoso da Silva 


\title{
INSTITUTO DE PESQUISAS ENERGÉTICAS E NUCLEARES
}

Autarquia associada à Universidade de São Paulo

\section{ESTUDO DA ADSORÇÃO DE ÍONS METÁLICOS EM CAULINITA PARA ÁGUA DE REUSO}

\author{
Giovanni Del Sordo Filho
}

Dissertação apresentada como parte dos requisitos para obtenção do Grau de Mestre em Ciências na Área de Tecnologia Nuclear - Aplicações

Orientador:

Prof. Dr. Paulo Sergio Cardoso da Silva

Versão Original

Versão Original disponível no IPEN

São Paulo

2015 


\section{AGRADECIMENTOS}

Aos meus pais, Ivanize Silva Del Sordo e Giovanni Del Sordo, minha irmã Vanessa Silva Del Sordo, ao inestimável apoio, incentivo e pela inspiração de caráter.

Agradeço ao Dr. Paulo Sérgio Cardoso da Silva, pela oportunidade, orientação, paciência, durante todo o período dos estudos. Muito Obrigado.

À Dra. Marycel Elena Barboza Cotrim pelas análises por ICP-OES.

À Dra. Sônia Maria Oliveira pelas análises por difração de raios-X.

Ao Dr. Marcos Antônio Scapin pelas análises por fluorescência de raios-X.

A Carolina Fernanda da Silva pela imensa ajuda e incentivo dado, muito obrigado!

A minha irmã Yale, e aos sobrinhos Bruno e Ayanni, pelo imenso apoio e por acreditarem, muito agradecido!

A Maria da Conceição Saraceni e Silvana Saraceni, pelo apoio dado na construção da minha formação, muito obrigado!

A Kátia Cristina A. Miranda, pelo imenso apoio dado no "período de realização do trabalho", muito obrigado!

Aos amigos, Alberto, Emerson e Regiane, pelo apoio e incentivo dado, muito obrigado!

Ao Instituto de Pesquisas Energéticas e Nucleares e aos colegas do CRPq. 
Para minha mãe Ivanize Silva Del Sordo Quem tanto amo e a quem tudo devo!!! 


\section{ESTUDO DA ADSORÇÃO DE ÍONS METÁLICOS EM CAULINITA PARA APLICAÇÃO EM ÁGUA DE REÚSO}

Giovanni Del Sordo Filho

\section{RESUMO}

A demanda crescente por água tem feito de seu reúso planejado um tema atual e de grande importância, já citada na Agenda 21, que recomendou implementação de políticas de gestão dirigidas para o uso e reciclagem de efluentes, integrando proteção de saúde pública de grupos de risco com práticas ambientais adequadas. De acordo com as Resoluções CONAMA n 357 e 420 os efluentes somente podem ser descartados em corpos d’água se os seus parâmetros característicos se situarem de acordo com o balizamento dado para cada classe de corpo de água.

Íons metálicos podem ser removidos de soluções aquosas por diferentes processos sendo a adsorção em argilas um método que pode ser considerado efetivo e barato quando comparado aos demais.

Neste estudo foi avaliada a capacidade de adsorção dos íons metálicos $\mathrm{Cr}^{3+}$, $\mathrm{Zn}^{2+}, \mathrm{Cd}^{2+}, \mathrm{Pb}^{2+}, \mathrm{Cu}^{2+}$ e $\mathrm{Ni}^{2+}$ em solução utilizando-se caulinita comercial com a finalidade de reúso e/ou descarte. A caracterização mineralógica e química das amostras comerciais obtidas indicou que aquela denominada "caulinita $C$ " foi a que mais se adequou ao estudo visto que apresenta elevado teor de pureza mineralógica, baixos teores de elementos traço, e maior capacidade de troca catiônica.

O estudo da remoção dos íons em solução indicou que o aumento razão adsorvente:adsorvato aumenta a eficiência de adsorção. $\mathrm{O}$ estudo da influência do pH indicou que a maior adsorção ocorre em pH levemente alcalino, pH 8. E o estudo do tempo de contato indicou que o equilíbrio de adsorção é atingido em menos de trinta minutos para todos os íons, exceto para o Ni. A análise das isotermas de adsorção indicou que a caulinita empregada neste estudo é adequada principalmente à remoção dos íons Zn (II), Cu (II) e PB (II). 


\title{
METAL ION ADSORPTION STUDY IN KAOLINITE FOR APPLICATIONS IN WATER REUSE
}

\section{Giovanni Del Sordo Filho}

\begin{abstract}
The growing demand for water has made its planned reuse a current topic of great importance, as already mentioned in Agenda 21, which recommended a management policy implementation directed to the use and recycling of waste, integrating public health protection of risk groups with appropriate environmental practices. According to the 357 and 420 CONAMA Resolutions, effluents can only be dropped into water bodies if their characteristic parameters are located in accordance with the marks given for each body of water class.

Metal ions can be removed from aqueous solutions by different processes being clay adsorption a method that can be considered effective and cheap when compared to others.

In this study, the commercial kaolinite adsorption capacity was evaluated for the metal ions $\mathrm{Cr}^{3+}, \mathrm{Zn}^{2+}, \mathrm{Cd}^{2+}, \mathrm{Pb}^{2+}, \mathrm{Cu}^{2+}$ and $\mathrm{Ni}^{2+}$ in solution with the purpose of reuse and / or disposal. The mineralogical and chemical characterization of commercial samples obtained indicated that the one called "kaolinite $C$ " was the one most suited to the study because of its high purity mineral content, low levels of trace elements, and higher cation exchange capacity.

The study of ions removal in solution indicated that the increment in the dsorbent: adsorbate ratio increases the adsorption efficiency. The influence of $\mathrm{pH}$ indicated that most of the adsorption occurs in a slightly alkaline $\mathrm{pH}, \mathrm{pH}$. The study of the contact time indicates that the adsorption equilibrium is reached in less than thirty minutes for all ions except for $\mathrm{Ni}$. The analysis of adsorption isotherms indicated that the kaolinite used in this study is suitable for the ion removal mainly of $\mathrm{Zn}$ (II), $\mathrm{Cu}$ (II) and $\mathrm{Pb}(\mathrm{II})$.
\end{abstract}


SUMÁRIO

1 - INTRODUÇÃO

Página

2 - OBJETIVO

2.1 - Objetivo geral

2.2 - Objetivos específicos 29

3 - MATERIAIS E MÉTODOS 30

3.1 - Amostragem 30

3.2 - Metodologia 30

3.2.1 - Fluorescência de raios-X (FRX) 30

3.2.2 - Difração de raios-X (DRX) 31

3.2.3 - Análise por ativação neutrônica instrumental 32

3.2.4 - Absorção Atômica com forno de grafite 36

3.2.5 - Espectrometria com emissão óptica com plasma indutivamente acoplado 37

3.3 - Caracterização das argilas $\quad 39$

3.3.1 - Mineralógica 39

3.3.1.1 - Difração de raios-X 39

3.3.2 - Química 40

3.3.2.1 - Fluorescência de raios-X 40

3.3.2.2 - Ativação neutrônica instrumental 40

3.3.2.3 - Dissolução das amostras de caulinita 40

3.3.3 - Teor de umidade, matéria orgânica e perda ao fogo 41

3.3.4 - Ativação das argilas $\quad 42$

3.3.4.1 - Ativação térmica $\quad 42$

3.3.4.2 - Ativação ácida $\quad 42$

3.3.5 - Capacidade troca catiônica 43

3.4 - Estudo da adsorção $\quad 45$

3.4.1 - Efeito da proporção 45

3.4.2 - Efeito do $\mathrm{pH} \quad 46$

3.4.3 - Efeito do tempo de contato 47

3.5 - Medidas das concentrações nas soluções 47

3.5.1 - Absorção atômica com forno de grafite 47

3.5.2 - Espectrometria de emissão óptica com plasma indutivamente acoplado $\quad 50$

4 - RESULTADOS E DISCUSSÃO 51

4.1 - Caracterização mineralógica das argilas 51

4.1.1 - Difração de raios-X $\quad 51$

4.2 - Caracterização química das argilas $\quad 54$

4.2.1 - Fluorescência de raios-X $\quad 54$

4.2.2 - Ativação Neutrônica Instrumental 55

4.2.3 - Teor de umidade, matéria orgânica e perda ao fogo 57

4.2.4 - Capacidade de troca catiônica $\quad 60$

4.3 - Resultados estudo da adsorção $\quad 61$

4.3.1 - Efeito da proporção $\quad 61$

4.3.2 - Efeito do $\mathrm{pH} \quad 65$

4.3.3 - Efeito do tempo de contato $\quad 70$

4.3.4 - Isotermas de Langmuir, Freundlich e (D-R) 75

5 - CONCLUSÃO

REFERÊNCIAS

$\begin{array}{ll}\text { ANEXOS } & 96\end{array}$ 


\section{LISTA DE TABELAS}

Tabela 1. 1 - Fontes naturais e antropogênicas de alguns metais pesados para o ambiente.

Tabela 3.1 - Elementos determinados por ativação neutrônica, radioisótopo formado na ativação, energia dos raios gama utilizados na espectrometria gama, meias-vidas e tempo de decaimento. $-35$

Tabela 3.2 - Concentrações das soluções que foram utilizadas nos testes de adsorção em caulinita.

Tabela 3.3 - Concentrações das soluções utilizadas na construção da curva de calibração para determinação de $\mathrm{Cd}$ e $\mathrm{Pb}$ pela técnica de GFAAS. 48

Tabela 3.4 - Parâmetros de determinação de $\mathrm{Cd}$ e $\mathrm{Pb}$ ajustados para análise. $-50$

Tabela 4.1 - Comparação das características químicas e teores dos óxidos em \%.------54

Tabela 4.2 - Concentrações obtidas por análise de ativação nêutronica.------------------56

Tabela 4.3 - Resultados de teor de umidade, matéria orgânica e perda ao fogo.---------57

Tabela 4.4 - Resultados da capacidade de troca catiônica das três amostras, após o tratamento térmico.

Tabela 4.5 - Resultados da capacidade de troca catiônica das três amostras, após tratamento ácido. $-61$

Tabela 4.6 - Íons com os respectivos tempos de equilíbrio.--------------------------------75

Tabela 4.7 - Constantes das isotermas obtidas com os dados experimentais $-82$ 


\section{LISTA DE FIGURAS}

Figura 1.1 - Fluxograma das etapas do reuso de água--------------------------------------19

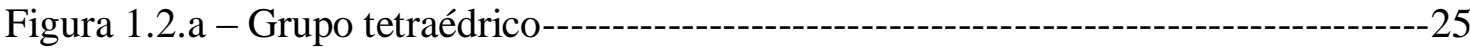

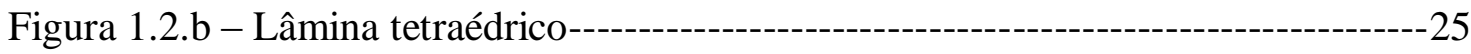

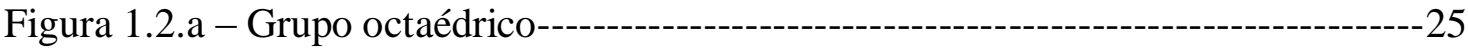

Figura 1.2.a - Lâmina octaédrica---------------------------------------------------------------25

Figura 1.3.a - Estrutura de um argilomineral do Tipo 1:1-------------------------------26

Figura 1.3.b - Estrutura de um argilomineral do Tipo 2:1--------------------------------26

Figura 3.1 - Ilustração dos três materiais adquiridos e utilizados neste trabalho.-------30

Figura 3.2 - Processo esquemático da formação de um radionuclídeo artificial

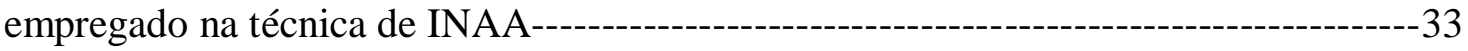

Figura 3.3 - Partes básicas de um ICP OES-----------------------------------------------------38

Figura 3.4 - Identificação do ponto de viragem da titulação com azul de metileno pelo aparecimento da aura azul clara em torno da argila difundida no papel--------------------43

Figura 3.5 - Montagem do arranjo experimental utilizado para a determinação da capacidade de troca catiônica pelo método do Azul de Metileno--------------------------44

Figura 3.6 - Indicação experimental do ponto de viragem para a determinação da CTC

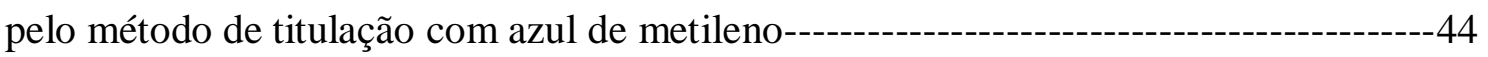

Figura 3.7 - Equipamento de GFAAS modelo AAnalyst 800 da Perkin Elmer.---------47

Figura 3.8 - Curva de calibração para Cd obtida por GFAAS------------------------------48

Figura 3.9 - Curva de calibração para Pb obtida por GFAAS-------------------------------49

Figura 4.1 - Difratograma 1 referente à amostra de Caulinita A---------------------------51

Figura 4.2 - Difratograma 2 referente à amostra de Caulinita B---------------------------52

Figura 4.3 - Difratograma 3, referente a amostra de Caulinita C---------------------------53

Figura 4.4 - Termograma 1, referente a amostra CA----------------------------------------57 
Figura 4.5 - Termograma 2, referente a amostra CB------------------------------------------58

Figura 4.6 - Termograma 3, referente a amostra CC-----------------------------------------58

Figura 4.7 - Gráfico da concentração de íons de zinco na solução-------------------------62

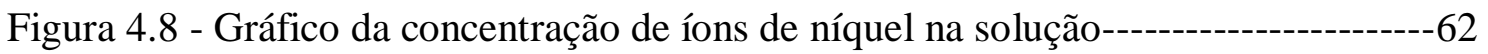

Figura 4.9 - Gráfico da concentração de íons de cobre na solução-------------------------63

Figura 4.10 - Gráfico da concentração de íons de cromo na solução----------------------63

Figura 4.11 - Gráfico da concentração de íons de cádmio na solução---------------------64

Figura 4.12 - Gráfico da concentração de íons de chumbo na solução--------------------64

Figura 4.13 - Gráfico do efeito do pH para o íon de cádmio 0,2 mg.L ${ }^{-1}$.-----------------65

Figura 4.14 - Gráfico do efeito do pH para o íon de cádmio $8 \mathrm{mg} . \mathrm{L}^{-1}$.-------------------66

Figura 4.15 - - Gráfico do efeito do pH para o íon de chumbo 0,5 mg.L -1 $^{----------------66}$

Figura 4.16 - Gráfico do efeito do pH para o íon de chumbo 18 mg.L ${ }^{-1}$-------------------66

Figura 4.17 - Gráfico do efeito do pH para o íon de cromo $0,1 \mathrm{mg} \cdot \mathrm{L}^{-1}-----------------67$

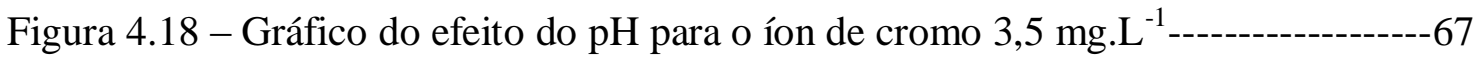

Figura 4.19 - Gráfico do efeito do pH para o íon de cobre 12 mg.L-1

Figura 4.20 - Gráfico do efeito do pH para o íon de cobre 37 mg.L ${ }^{-1}$.-------------------68

Figura 4.21 - Gráfico do efeito do pH para o íon de zinco 65 mg.L ${ }^{-1}$.--------------------68

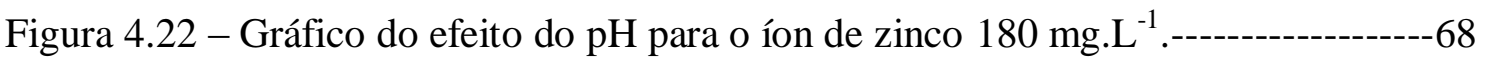

Figura 4.23 - Gráfico do efeito do pH para o íon de níquel $25 \mathrm{mg} \cdot \mathrm{L}^{-1}$.-------------------69

Figura 4.24 - Gráfico do efeito do pH para o íon de níquel 75 mg.L - $^{-1}$-------------------69

Figura 4.25 - Gráfico do efeito do tempo de contato para o íon de cádmio $0,2 \mathrm{mg} . \mathrm{L}^{-1} .70$

Figura 4.26 - Gráfico do efeito do tempo de contato para o íon de cádmio $8 \mathrm{mg} . \mathrm{L}^{-1}$.--71

Figura 4.27 - Gráfico do efeito do tempo de contato para o íon de chumbo $0,5 \mathrm{mg} . \mathrm{L}^{-1}$.-- 
Figura 4.28 - Gráfico do efeito do tempo de contato para o íon de chumbo $18 \mathrm{mg} . \mathrm{L}^{-1} .71$

Figura 4.29 - Gráfico do efeito do tempo de contato para o íon de cromo 3,5 mg.L $\mathrm{L}^{-1} .-72$

Figura 4.30 - Gráfico do efeito do tempo de contato para o íon de cromo $0,1 \mathrm{mg} \cdot \mathrm{L}^{-1}-{ }_{-12}$

Figura 4.31 - Gráfico do efeito do tempo de contato para o íon de cobre $12 \mathrm{mg} . \mathrm{L}^{-1}$.---72

Figura 4.32 - Gráfico do efeito do tempo de contato para o íon de cobre $37 \mathrm{mg} . \mathrm{L}^{-1}$.---73

Figura 4.33 - Gráfico do efeito do tempo de contato para o íon de zinco $65 \mathrm{mg} . \mathrm{L}^{-1}$.---73

Figura 4.34 - Gráfico do efeito do tempo de contato para o íon de zinco $180 \mathrm{mg} . \mathrm{L}^{-1}$---73

Figura 4.35 - Gráfico do efeito do tempo de contato para o íon de níquel $25 \mathrm{mg} . \mathrm{L}^{-1}$---74

Figura 4.36 - Gráfico do efeito do tempo de contato para o íon de níquel 75 mg.L ${ }^{-1}$---74

Figura 4.37 - Isotermas de Langmuir (A), Freundlich (B) e Dubinin-Radushkevich (C),

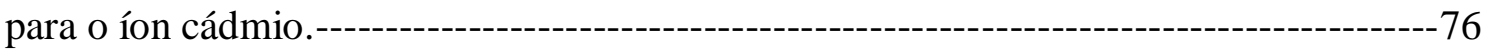

Figura 4.38 - Isotermas de Langmuir (A), Freundlich (B) e Dubinin-Radushkevich (C),

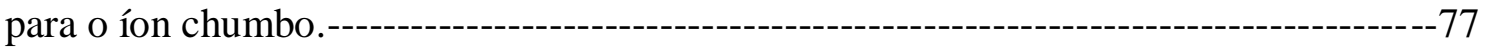

Figura 4.39 - Isotermas de Langmuir (A), Freundlich (B) e Dubinin-Radushkevich (C),

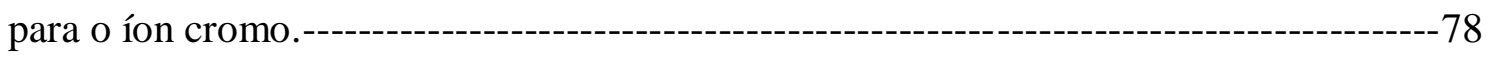

Figura 4.40 - Isotermas de Langmuir (A), Freundlich (B) e Dubinin-Radushkevich (C),

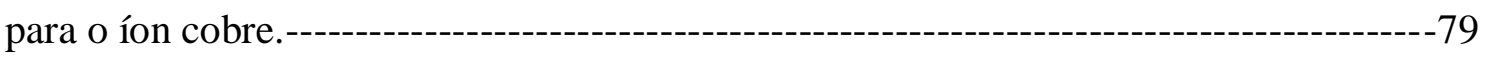

Figura 4.41 - Isotermas de Langmuir (A), Freundlich (B) e Dubinin-Radushkevich (C),

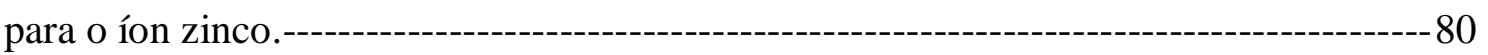

Figura 4.42 - Isotermas de Langmuir (A), Freundlich (B) e Dubinin-Radushkevich (C),

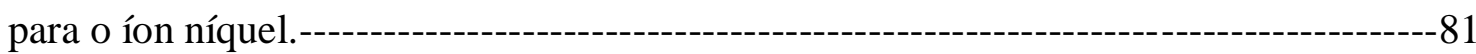




\section{LISTA DE ABREVIATURAS E SIGLAS}

CONAMA - Conselho Nacional do Meio Ambiente

ICP-OES - Emission Spectrometry with Inductively Coupled Plasma Source

(Espectrometria de Emissão Óptica com Plasma Indutivamente Acoplado)

GFAAS - Graphite Furnace Atomic Absorption Spectrometry (Absorção Atômica com

Forno de Grafite)

INAA - Instrumental Neutron Activation Analysis (Análise por Ativação Neutrônica Instrumental)

CTC - Capacidade de Troca Catiônica

FRX - Fluorescência de Raios-X

DRX - Difração de Raios-X

D-R - Dubinin-Radushkevich

PVC - Policloreto de vinila

IBAMA - Instituto Brasileiro do Meio Ambiente

IAEA - International Atomic Energy Agency (Agência Internacional de Energia Atômica)

ABNT - Associação Brasileira de Normas Técnicas

$\mathbf{v} / \mathbf{v}$ - Volume por volume

IGc - Instituto de Geociências

USP - Universidade de São Paulo

CQMA - Centro de Química e Meio Ambiente

IPEN - Instituto de Pesquisas Energéticas e Nucleares

STM-2 - Syenite, Table Mountain

AAM - Adsorção de azul de metileno

LAN - Laboratório de Ativação Neutrônica

LAQA - Laboratório de Análises Química e Ambiental

CA - Caulinita A

CB - Caulinita B 
CC - Caulinita C

$\boldsymbol{\%} \mathbf{U}$ - Teor de umidade

\%MO - Matéria orgânica

\%PF - Perda ao fogo 


\section{1 - INTRODUÇÃO}

A possibilidade de escassez de água num futuro próximo tem feito com que seu uso seja cada vez mais planejado e novas técnicas de reuso sejam desenvolvidas e colocadas em prática.

Modernamente, as práticas de reuso foram introduzidas como um recurso adicional no tratamento de despejos industriais, de modo a permitir a reciclagem interna específica não potável e a consequente economia de água, bem como a redução de custos operacionais e tarifários (CAVALCANTI, 2012).

O despejo descontrolado, sem um prévio tratamento desses efluentes, contribui para a exposição de metais tóxicos, um risco à saúde da população.

A toxidade, bioacumulação, biomagnificação e a impossibilidade de destruição, tornam tais metais um perigo presente, assim, é de extrema importância o monitoramento em vários compartimentos, por meio do conhecimento das suas concentrações para avaliação da qualidade ambiental. De uma forma geral, a avaliação é realizada comparando-se os valores de concentrações de um determinado elemento contra uma faixa de valores estabelecidos como "basais" ou estabelecidos em legislação como valores seguros para um determinado compartimento ambiental (MESTER, STURGEON, 2003; HILL, 2010).

A Resolução CONAMA 357 lista alguns metais tóxicos com padrões de emissão e de qualidade definidos, dentre os quais podemos destacar: cádmio, chumbo, cobre, cromo, níquel e zinco, que serão objeto deste estudo.

Denominam-se metais tóxicos, àqueles que possuem densidades altas quando comparados com os metais leves, superior a $5 \mathrm{~g} / \mathrm{cm}^{3}$. Também são definidos como elementos químicos com número atômico maior do que o ferro (26) (LEE, 2006).

Os metais tóxicos são utilizados em processos industriais nas suas formas elementares, bem como seus sais ou como compostos organometálicos.

O cádmio tem massa atômica 112,4 g.mol ${ }^{-1}$, número atômico 48 e densidade 8,6 $\mathrm{g} / \mathrm{mL}$. Os acetatos, cloretos e sulfatos de cádmio são altamente solúveis em água enquanto que os óxidos e carbonatos são praticamente insolúveis sendo, no entanto, solúveis no $\mathrm{pH}$ gástrico. Apresenta alta toxidade para os seres vivos, porém, apresenta 
baixa concentração natural, sendo assim, sua principal fonte de contaminação são ocasionadas pelas ações humanas (ALLOWAY, 1995b). Pode ser encontrado adsorvido por atração eletrostática em sítios com carga negativa das argilas, matéria orgânica e óxidos hidratados, adsorvidos ou coprecitados com óxidos, hidróxidos de ferro, manganês e possivelmente alumínio, precipitados com carbonatos, bicarbonatos e fosfatos, complexados à matéria orgânica, fixado no interior da rede cristalina da argila ou ainda em solução, na forma iônica ou complexada (ADRIANO, 1986). O cádmio tem boa resistência à corrosão o que lhe confere aplicações em ligas com chumbo, cobre e estanho e em galvanoplastia. Além disso, o cádmio pode ser utilizado como estabilizante em plásticos do tipo PVC (policloreto de vinila), cerâmicas, esmaltes, pigmentos e em reatores nucleares (LEE, 2006).

O chumbo tem massa atômica de 207,19 g.mol ${ }^{-1}$, número atômico $82 \mathrm{e}$ densidade 11,3 g/mL. Sulfetos, óxidos e oxalatos de chumbo são insolúveis, nitratos e cloratos são solúveis enquanto que sulfatos e cloretos são muito pouco solúveis. $\mathrm{O}$ chumbo geralmente ocorre como $\mathrm{Pb}^{+2}$ e é encontrado em silicatos substituindo o $\mathrm{K}^{+}$ou em carbonatos, substituindo $\mathrm{Ca}^{+2}$, pois apresenta características químicas semelhantes ao grupo dos metais alcalinos terrosos, o que determina sua habilidade em deslocar tais elementos (KABATA-PENDIAS, 2001). Suas principais fontes naturais são erupções vulcânicas, erosão e aerossóis oriundos da água do mar e o seu principal minério é a galena $(\mathrm{PbS})$. Atividades antropogênicas tais como mineração, fundição, produção de baterias, fungicidas e pigmentos estão entre fontes muito relevantes de chumbo as quais afetam profundamente a qualidade ambiental.

O cobre na forma pura tem uma coloração marrom avermelhada com alta ductilidade e maleabilidade, massa atômica de 63,54 g.mol ${ }^{-1}$, número atômico 29 e densidade $8,94 \mathrm{~g} / \mathrm{cm}^{-3}$.

Os estados de oxidação mais comuns são $0,+1$ e +2 . O Cu (0) é bastante estável porém solúvel em soluções de ácido sulfúrico e nítrico. O Cu (I) é um íon instável em ambientes oxidantes e o $\mathrm{Cu}$ (II) é o estado de oxidação mais abundante e mais estável deste elemento em ambientes oxidantes hidrofílicos. As utilizações mais importantes do cobre são sua aplicação em fios e cabos para transmissão de energia elétrica. Também possui várias aplicações na indústria eletrônica, tubos para água, vasos e recipientes, cobertura e revestimento em construções, conservantes de madeira, fungicidas, como 
pigmentos e anti-incrustante, agentes em tintas, como aditivos nutricionais para pecuária, e aditivos para fertilizantes. $\mathrm{O}$ cobre é um elemento importante em ligas metálicas, sendo mais conhecidos o latão (cobre e zinco) e o bronze (cobre e estanho) (ELLINGSEN et al., 2007).

O cromo tem massa atômica 52 g.mol ${ }^{-1}$, número atômico 24 e densidade 7,2 $\mathrm{g} / \mathrm{mL}$. É um metal que ocorre predominantemente nas formas $\mathrm{Cr}$ (III) e $\mathrm{Cr}$ (VI), mas ele pode ocorrer também em todos os estados de oxidação entre -2 e +6 , sendo o +3 o mais estável e a forma hexavalente a de maior toxidade. As indústrias metalúrgica, química e de refratários são as principais consumidoras de $\mathrm{Cr}$ que também é extensivamente empregado na galvanoplastia, na fabricação de tintas artísticas e anticorrosivas, explosivos, indústria gráfica, cerâmicas e em revestimentos obtidos por eletrodeposição.

O níquel tem massa atômica $58,71 \mathrm{~g} \cdot \mathrm{mol}^{-1}$, número atômico 28 e densidade 8,9 $\mathrm{g} / \mathrm{mL}$. Existe principalmente nos estados de oxidação $0,+1$ e +2 . Os sais de $\mathrm{Ni}$ de ácidos fortes são solúveis em água enquanto que os sais de ácido fraco são insolúveis. O níquel elementar não é um problema de poluição de água por não ser solúvel, porém, seus sais são altamente solúveis, gerando um alto risco de contaminação. As aplicações do níquel variam muito, desde ligas metálicas para aços inoxidáveis, galvanoplastia, fundição, catalisadores, soldagem e cunhagem. Ele pode ser encontrado também em equipamentos eletrônicos tais como baterias $(\mathrm{NiCd})$, em tintas e cerâmicas. Devido a sua ampla aplicação, há uma introdução considerável desde elemento no ambiente.

O zinco possui massa atômica 65,38 g. $\mathrm{mol}^{-1}$, número atômico 30 e densidade $7,13 \mathrm{~g} / \mathrm{mL}$. O estado de oxidação mais estável é o +2. É um elemento anfótero e em pH intermediário forma hidróxidos de baixa solubilidade enquanto que em valores mais extremos de $\mathrm{pH}$ a solubilidade aumenta formando íons zinco em $\mathrm{pH}$ baixo e o íon zincato $\mathrm{Zn}(\mathrm{OH})_{4}{ }^{-2} \mathrm{em} \mathrm{pH}$ alto. $\mathrm{O}$ zinco é intensivamente utilizado na indústria galvânica, de tintas, cerâmicas, farmacêuticas, de inseticidas e muitas outras (LEE, 2006; CAVALCANTI, 2012).

A Tabela 1.1, apresenta as principais fontes, tanto naturais quanto antropogênicas que podem contribuir com a adição de metais tóxicos no ambiente. 
TABELA 1.1 - Fontes naturais e antropogênicas de alguns metais tóxicos para o ambiente.

\begin{tabular}{|c|c|c|}
\hline Elemento & Natural & Antropogênica \\
\hline $\begin{array}{c}\mathrm{Cd} \\
\left(* * 65^{\circ}\right)\end{array}$ & $\begin{array}{l}\text { Minérios de } \mathrm{Zn} \text { e } \mathrm{Pb} \\
\text { rochas fosfáticas }\end{array}$ & $\begin{array}{l}\text { Resíduos de mineração, } \\
\text { galvanoplastia, indústria de } \\
\text { pilhas }\end{array}$ \\
\hline $\begin{array}{c}\mathrm{Pb} \\
\left(* * 36^{\circ}\right)\end{array}$ & Mineral galena & $\begin{array}{l}\text { Indústrias de baterias, } \\
\text { encanamento, gasolina, } \\
\text { carvão, pigmentos }\end{array}$ \\
\hline$\underset{\left(* * 25^{\circ}\right)}{\mathrm{Cu}}$ & $\begin{array}{l}\text { Sulfetos óxidos } \\
\text { Carbonatos }\end{array}$ & $\begin{array}{l}\text { Galvanoplastia, ligas } \\
\text { metálicas, esgoto } \\
\text { doméstico e industrial, } \\
\text { resíduo de mineração, } \\
\text { defensivos agrícolas }\end{array}$ \\
\hline $\begin{array}{c}\mathrm{Cr} \\
\left(* * 21^{\circ}\right)\end{array}$ & $\begin{array}{l}\text { Mineral cromitas } \\
\text { Solos de serpentina }\end{array}$ & $\begin{array}{l}\text { Galvanoplastia, ligas } \\
\text { metálicas, esgoto } \\
\text { industrial, produtos } \\
\text { anticorrosivos }\end{array}$ \\
\hline $\begin{array}{c}\mathrm{Ni} \\
\left(* * 22^{\circ}\right)\end{array}$ & Solos de serpentina & $\begin{array}{c}\text { Ligas metálicas, indústrias } \\
\text { de bateria, resíduo } \\
\text { industrial, produção de } \\
\text { óleos vegetais }\end{array}$ \\
\hline $\begin{array}{c}\mathrm{Zn} \\
\left(* * 24^{\circ}\right)\end{array}$ & $\begin{array}{c}\text { Minerais (sulfetos, óxidos, } \\
\text { silicatos) }\end{array}$ & $\begin{array}{l}\text { Ligas metálicas, } \\
\text { pigmentos, galvanoplastia, } \\
\text { resíduo industrial, } \\
\text { encanamentos }\end{array}$ \\
\hline
\end{tabular}

Fonte. MALAVOLTA, 1994.

* Desde 1993 a lei 7823/93 estabeleceu a obrigatoriedade de adição de 22\% de etanol anidro à gasolina, tornando desnecessária a adição de chumbo-tetraetila.

** Abundância relativa na crosta terrestre (LEE, 2006).

Segundo HESPANHOL (2002), importância especial ao reuso da água foi dada já na Agenda 21, a qual recomendou aos países participantes da ECO 92 a implementação de políticas de gestão dirigidas para o uso e reciclagem de efluentes, integrando proteção de saúde pública de grupos de risco, com práticas ambientais adequadas.

No capítulo 21 - “Gestão ambientalmente adequada de resíduos líquidos e sólidos", Área Programática B - "Maximizando o reuso e a reciclagem ambientalmente dequadas", é estabelecido, como um dos objetivos básicos: "vitalizar e ampliar os sistemas nacionais de reuso e reciclagem de resíduos". 
A prática de uso de águas residuárias também é associada às seguintes áreas programáticas incluídas nos capítulos 14 - "Promovendo a agricultura sustentada e o desenvolvimento rural", e 18 - "Proteção da qualidade das fontes de águas de abastecimento - Aplicação de métodos adequados para o desenvolvimento, gestão e uso dos recursos hídricos", visando à disponibilidade de água "para a produção sustentada de alimentos e desenvolvimento rural sustentado" e "para a proteção dos recursos hídricos, qualidade da água e dos ecossistemas aquáticos".

A Constituição do Brasil de 1988 dedicou vários artigos a recursos hídricos, e todo o Capítulo VI ao meio ambiente: "todos têm direito ao meio ambiente ecologicamente equilibrado, e deve ao Poder Público e a Coletividade o dever de defendê-lo e preservá-lo para as presentes e futuras gerações”.

Neste contexto, inúmeras Leis, Decretos, Resoluções, foram criados com intuito de disciplinar o trato das relações que afetam o meio ambiente.

Criado na década de 1980, antes da promulgação da Constituição, o CONAMA - Conselho Nacional do Meio Ambiente, órgão consultivo e deliberativo, do IBAMA é responsável por mais de 350 resoluções referentes ao meio ambiente. Dentre as quais, destacam-se as Resoluções CONAMA N 357/2005 e a CONAMA 430/2011.

Os efluentes só poderão ser descartados se estiverem dentro dos parâmetros estabelecidos pela Resolução CONAMA N³57, de 17 de março de 2005 (CONAMA) e pela Resolução CONAMA N430/2011, que dispõe sobre as condições e padrões de lançamento de efluentes, complementando a Resolução N³57. O objetivo destas Resoluções é garantir um meio ambiente sustentado, e em particular, a manutenção da integridade das águas receptoras que se destinam aos diversos usos pretendidos (CAVALCANTI, 2012).

A reutilização da água pode ser direta ou indireta, decorrente de ações planejadas ou não (LAVRADOR FILHO, 1987).

$\checkmark \quad$ Reuso indireto não planejado da água: ocorre quando a água, utilizada em alguma atividade humana, é descarregada no meio ambiente e novamente utilizada a jusante, em sua forma diluída, de maneira não intencional e não controlada. 
Caminhando até o ponto de captação para o novo usuário, a mesma está sujeita às ações naturais do ciclo hidrológico (diluição, autodepuração).

$\checkmark \quad$ Reuso indireto planejado da água: ocorre quando os efluentes, depois de tratados, são descarregados de forma planejada nos corpos de águas superficiais ou subterrâneas que serão utilizadas a jusante, de maneira controlada, no atendimento de algum uso benéfico.

$\checkmark \quad$ Reuso direto planejado das águas: ocorre quando os efluentes, após serem tratados, são encaminhados diretamente de seu ponto de descarga até o local do reuso, não sendo descarregados no meio ambiente. É o caso com maior ocorrência, destinando-se a uso em indústria ou irrigação.

A Figura 1.1 - apresenta o fluxograma explicando as etapas do reuso desde a fonte geradora até o destino final.

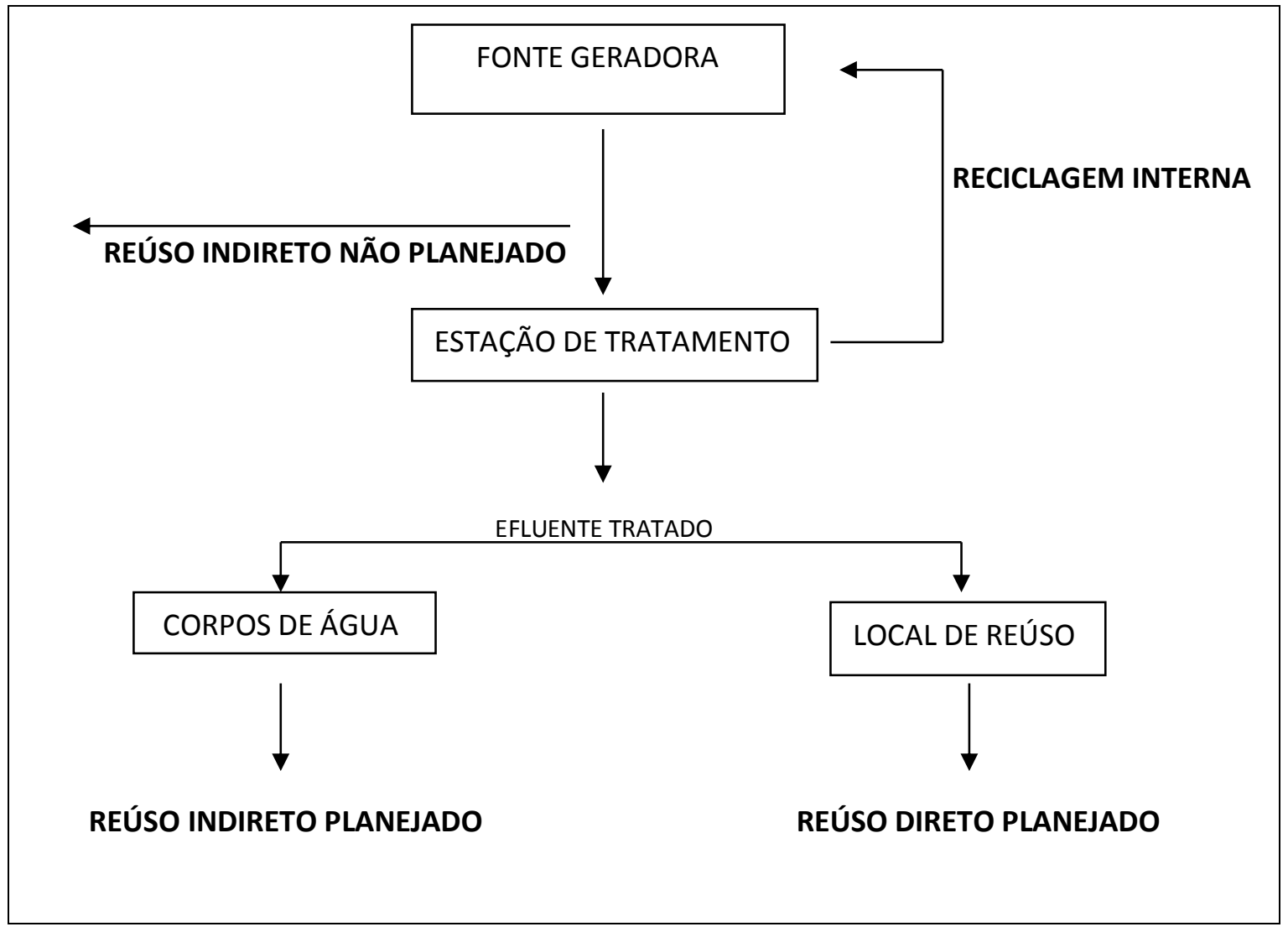

FIGURA 1.1 - Fluxograma das etapas do reuso desde a fonte geradora até o destino final. 
O reuso da água é um tema atual e de grande importância para a sociedade preocupada em preservar os recursos naturais, e tem sido objeto de diversos estudos (SINGH, 2001).

Entre as principais aplicações da água reciclada tem-se (CIRRA, 2002): irrigação paisagística, irrigação de campos para cultivos, usos industriais, recarga de aquíferos, usos urbanos não potáveis, finalidades ambientais e usos diversos.

Segundo GUIDOLIN (2000), é imprescindível destacar o conteúdo dos elementos minerais presentes em efluentes urbanos brutos, quando estes serão utilizados para reuso em agricultura, visto que alguns elementos atuam como macronutrientes $(\mathrm{N}$, $\mathrm{P}, \mathrm{K}, \mathrm{Ca}, \mathrm{Mg}$ e S) ou micronutrientes ( $\mathrm{Zn}, \mathrm{Cu}, \mathrm{Fe}, \mathrm{Mn} \mathrm{Mo}$, Se e Ni) enquanto que outros são indesejáveis $(\mathrm{Cd}, \mathrm{Hg}$ e $\mathrm{Pb})$, sendo alguns deles necessários ao desenvolvimento vegetal e enquanto que outros são fitotóxicos.

Diversos métodos são aplicados para a remoção de íons metálicos de soluções aquosas, tais como, troca iônica, extração com solvente, flotação, coagulação, eletrodeposição, precipitação química, separação por membranas e adsorção.

A adsorção é um processo físico-químico que vem sendo muito utilizado em tratamentos de efluentes, ganhando destaque como um meio de tratá-los com qualidade, desde que estes efluentes contenham baixas concentrações de contaminantes químicos dissolvidos (BASCETIN et al., 2003).

$\mathrm{Na}$ adsorção, diferentes forças de interação estão envolvidas, e são estas forças que distinguem a adsorção física (fisissorção) da química (quimissorção). As moléculas que estão sendo adsorvidas são denominadas de adsorvato, enquanto o material sólido no qual ocorre a adsorção é chamado de adsorvente.

A adsorção física é caracterizada como um processo reversível, pouco específico, rápido e, geralmente, limitado pelo fenômeno da difusão. Neste caso, as moléculas do adsorvato são retidas mediante interações fracas $\left(10-50 \mathrm{~kJ}^{\mathrm{mol}}{ }^{-1}\right)$ de Van der Waals ou polarização (SOMASUNDARAN, 1996).

A adsorção química é caracterizada pela tendência de uma interação mais forte, envolvendo o compartilhamento de elétrons entre os compostos adsorvidos e a superfície do adsorvente, resultando na modificação da distribuição das cargas 
eletrônicas das moléculas adsorvidas, cujas forças de ligação são da mesma ordem das ligações químicas. A energia de adsorção está compreendida entre 50 e $2000 \mathrm{~kJ}^{\mathrm{mol}}{ }^{-1}$, tornando o processo irreversível e lento, evidencia-se que esse tipo de adsorção é muito específico, sendo acompanhado por uma forte variação da energia de ativação (ATKINS, 2008).

Existem basicamente dois modelos físico-químicos de adsorção: os modelos semi-empíricos que fornecem maior compreensão e descrição dos mecanismos fundamentais de adsorção, cuja forma matemática é selecionada à priori para atender reações de equilíbrio ligadas ao balanço de massa e de carga (GOLDBERG, 1995) e os modelos empíricos que descrevem dados experimentais de adsorção sem base teórica e apontam para descrição simplificada dos resultados experimentais de adsorção (SOARES, 2004). Os modelos baseiam-se na relação entre a concentração do metal na fase líquida e na fase sólida, em uma situação de equilíbrio definida pela equivalência dos potenciais químicos de ambas as fases, a esta relação dá-se o nome de isoterma (BRADL, 2004).

As isotermas de adsorção permitem a determinação dos parâmetros relacionados ao equilíbrio do processo, tais como a constante de adsorção e a quantidade máxima de adsorvato que o material pode agregar à sua superfície (FERREIRA, 2009; OKIEL et. al., 2011). Dependem de uma série de fatores, incluindo sua concentração, a carga de superfície do adsorvente, a força iônica e o pH da solução.

Os modelos de Freundlich, Langmuir e Dubinin-Radushkevich (D-R) são utilizados com maior frequência, a fim de melhorar o ajuste da curva obtida experimentalmente, pois as isotermas de adsorção podem desviar-se da linearidade, devido a possível presença de contaminantes suficientes para afetar a saturação dos sítios.

O modelo de Langmuir é o mais simplificado para descrever isotermas de adsorção com formação de monocamada. De acordo com esse modelo, os sítios ativos da superfície do adsorvente são energeticamente equivalentes e a adsorção independe da presença ou ausência de espécies adsorvidas na sua vizinhança, ou seja, os sítios possuem a mesma entalpia de adsorção que independe do grau de cobertura (SANTOS, 2013). A isoterma de Langmuir é representada pela Equação 01: 


$$
\mathrm{q}_{\mathrm{e}}=\frac{\mathrm{q}_{\mathrm{m}} \mathrm{K}_{\mathrm{L}} \mathrm{C}_{\mathrm{e}}}{1+\mathrm{K}_{\mathrm{L}} \mathrm{C}_{\mathrm{e}}}
$$

equação 01

sendo,

$\mathrm{q}_{\mathrm{e}}$ : massa de soluto por unidade de massa do adsorvente (mg. $\mathrm{g}^{-1}$ );

$\mathrm{q}_{\mathrm{m}}$ : massa de soluto necessária para saturar completamente a monocamada do adsorvente $(\mathrm{mg} / \mathrm{g})$;

$\mathrm{C}_{\mathrm{e}}$ : concentração do soluto em solução no equilíbrio $\left(\mathrm{mg} . \mathrm{L}^{-1}\right)$;

$\mathrm{K}_{\mathrm{L}}$ : constante de Langmuir ( $\mathrm{L} \cdot \mathrm{mg}^{-1}$ ), relacionada a energia de adsorção.

A equação 02 expressa a isoterma de Langmuir na forma linear:

$\frac{C_{e}}{q_{e}}=\frac{C_{e}}{Q_{0}}+\frac{1}{K_{L} Q_{0}}$ equação 02

sendo,

$\mathrm{Q}_{0}$ capacidade máxima de adsorção na monocada $\left(\mathrm{mg} \cdot \mathrm{g}^{-1}\right)$.

O modelo de Freundlich descreve uma adsorção reversível heterogênea, uma vez que, não restringe a uma monocamada de cobertura do adsorvente. À medida que o grau de ocupação aumenta, as forças das ligações entre adsorvente e adsorvato decrescem. Esse modelo considera a adsorção em multisítios e tem sido utilizada para descrever a adsorção de metais em solução aquosa (GU, et. al., 1994).

A isoterma de Freundlich é representada segundo a equação 03:

$q_{e}=K_{F} C_{e}^{\frac{1}{n}}$

equação 03

sendo,

$\mathrm{q}_{\mathrm{e}}$ : massa do adsorbato adsorvido por grama de adsorvente $\left(\mathrm{mg} \cdot \mathrm{g}^{-1}\right)$;

$\mathrm{C}_{\mathrm{e}}$ : concentração do adsorbato em equilíbrio com o adsorvente $\left(\right.$ mol. $\left.\mathrm{L}^{-1}\right)$;

1/n: indica a heterogeneidade energética dos sítios de adsorção;

$\mathrm{K}_{\mathrm{F}}$ : constante de Freundlich. 
Os valores de $\mathrm{K}_{\mathrm{F}}$ e 1/n são úteis para comparar diversos sistemas que envolvam processos de adsorção, desde que estudados nas mesmas condições experimentais. $\mathrm{O}$ expoente $1 / \mathrm{n}$ indica se a isoterma é favorável ou desfavorável, sendo que valores de $n$ no intervalo de 1 a 10 apontam para condições de adsorção favoráveis.

A equação 04 expressa isoterma de Freundlich na forma linear:

$\log q_{e}=\log K_{F}+\frac{1}{n} C_{e}$

equação 04

Outro modelo importante é o Dubinin-Radushkevich (D-R), com este modelo pode-se estimar a porosidade característica do adsorvente e a energia livre de adsorção. Com a aplicação dos dados experimentais, pode-se distinguir entre a adsorção física e a química. A Isoterma de (D-R) é mais geral que a de Langmuir uma vez que ela não assume uma superfície homogênea ou um potencial de adsorção constante e é representada segundo a equação 05:

$$
\mathrm{q}_{\mathrm{e}}=\mathrm{q}_{\text {máx }} \cdot \mathrm{e}^{\left(-\beta \varepsilon^{2}\right)} \quad \text { equação } 05
$$

$\mathrm{q}_{\mathrm{e}}$ : concentração de adsorbato adsorvida por grama de adsorvente (mol.L ${ }^{-}$ $\left.1 / \mathrm{g}_{\text {adsorvente }}\right)$;

qmáx: constante de Dubinin-Radushkevich, relativa a massa máxima adsorvida de adsorbato por grama de adsorvente.

$\varepsilon:$ potencial de Polanyi;

$\beta$ : constante energética, relativa à energia de transferência do adsorbato para adsorvente.

Aplicando o logaritmo, obtêm-se a sua forma linear mostrada na equação 06:

$$
\ln q_{\mathrm{e}}=\ln q_{\text {máx }}-\beta \varepsilon^{2} \quad \text { equação } 06
$$

O potencial de Polanyi é um potencial de sorção, entre o sítio ativo do adsorvente e o adsorvato é dado segundo a equação 07 :

$$
\varepsilon=\mathrm{RT} \ln \left(1+\frac{1}{\mathrm{Ce}}\right) \quad \text { equação } 07
$$




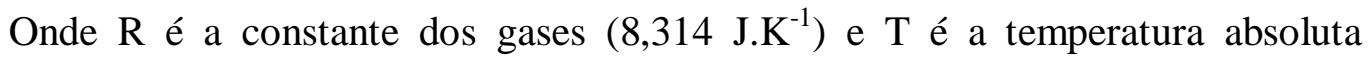
(Kelvin). O valor da energia de adsorção média E (J/mol), pode ser calculado a partir da equação 08: (OUADJENIA-MAROUF et. al. 2010).

$$
\mathrm{E}=\frac{1}{\sqrt{-2 \beta}}
$$

equação 08

$\mathrm{O}$ valor de $\mathrm{E}$, indicará se a interação adsorvente/adsorbato é química ou física. Valores de E entre 8 e $16 \mathrm{~kJ} / \mathrm{mol}$ correspondem a processos químicos, valores de $\mathrm{E}<8$ $\mathrm{kJ} / \mathrm{mol}$, indicam que o mecanismo de adsorção é físico (DUBININ et. al., 1947; SALTALI et. al., 2007; ZHENG et. al., 2008b; ERDEM et. al., 2009; OZCAN et. al., 2006).

Dentre os diversos métodos físico-químicos, a adsorção em argilas se destaca por ser um método considerado efetivo e barato, de fácil operação, aplicabilidade em baixas concentrações, e ainda apresentar a possibilidade de modificações químicas como a intercalação, pilarização (ativação térmica), ativação ácida ou básica e de fácil obtenção quando comparado aos demais (AL-JLIL, 2009).

A argila é um material natural, terroso, de granulação fina, que geralmente adquire plasticidade quando umedecido. Pode ser classificada em termos de sua estrutura cristalina em dois grupos: silicatos cristalinos lamelares e silicatos cristalinos fibrosos.

As argilas são constituídas essencialmente por partículas cristalinas extremamente pequenas (diâmetro abaixo de $2 \mu \mathrm{m}$ ) de um número restrito de minerais conhecidos como "argilominerais", orientados ao acaso. Uma argila pode ser composta por partículas de um argilomineral ou por uma mistura de diversos argilominerais. Estes são compostos por silicatos hidratados de alumínio e ferro, podendo conter, ainda, teores de elementos alcalinos e alcalino-terrosos. Outros materiais e minerais, tais como “matéria orgânica”, sais solúveis e partículas de quartzo, pirita, mica, calcita, dolomita, são encontrados, além desses podem ser encontrados minerais não cristalinos ou amorfos.

Os argilominerais possuem estruturas com camadas constituídas por folhas contínuas formadas por tetraedros de silício (ou alumínio) e oxigênio, e folhas formadas por octaedros de alumínio (magnésio ou ferro), oxigênio e hidroxilas. Na Figura 1.2.a, 
são apresentadas as estruturas do grupo tetraédrico e na 1.2.b da lâmina tetraédrica; nas Figuras 1.2.c e 1.2.d, são apresentadas as estruturas do grupo octaédrico e da lâmina octaédrica, respectivamente.
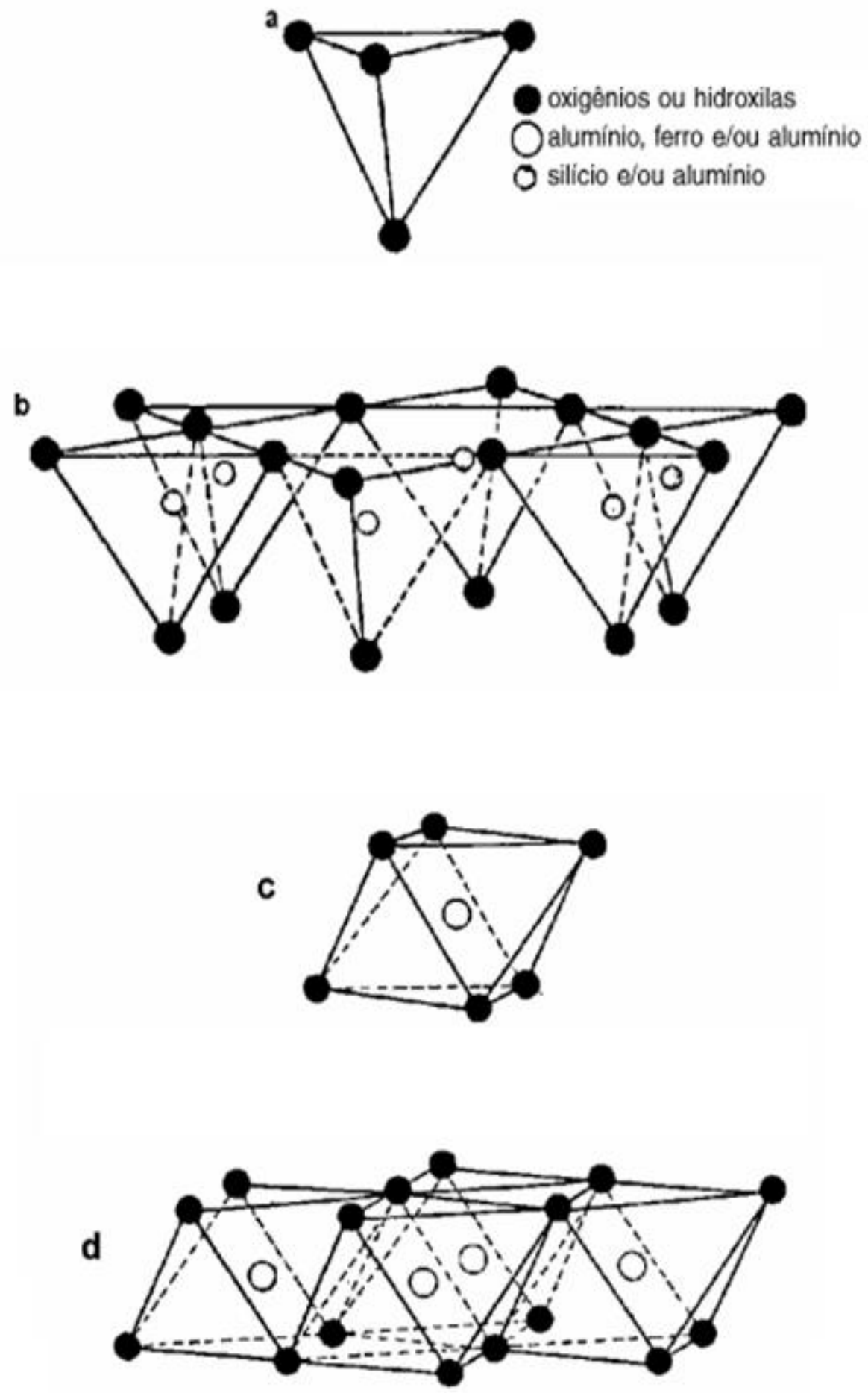

FIGURA 1.2 a - Grupo tetraédrico, b - Lâmina tetraédrica, c - Grupo octaédrico, d - Lâmina octaédrica (GOMES, 1986). 
As lâminas tetraédricas e octaédricas podem se encaixar para formar camadas (compostas por duas ou mais lâminas) de várias maneiras, originando as estruturas dos argilominerais (SANTOS, 1989).

A nomenclatura para os tipos de camadas é uma simples expressão da razão entre os sítios tetraédricos e octaédricos. Assim, um argilomineral do tipo 1:1 apresenta uma camada tetraédrica e outra octaédrica, enquanto que em um argilomineral que apresentar uma camada octaédrica e duas tetraédricas será do tipo 2:1. As Figuras 1.3.a e 1.3.b, apresentam uma estrutura de um argilomineral do tipo 1:1 e 2:1, respectivamente.
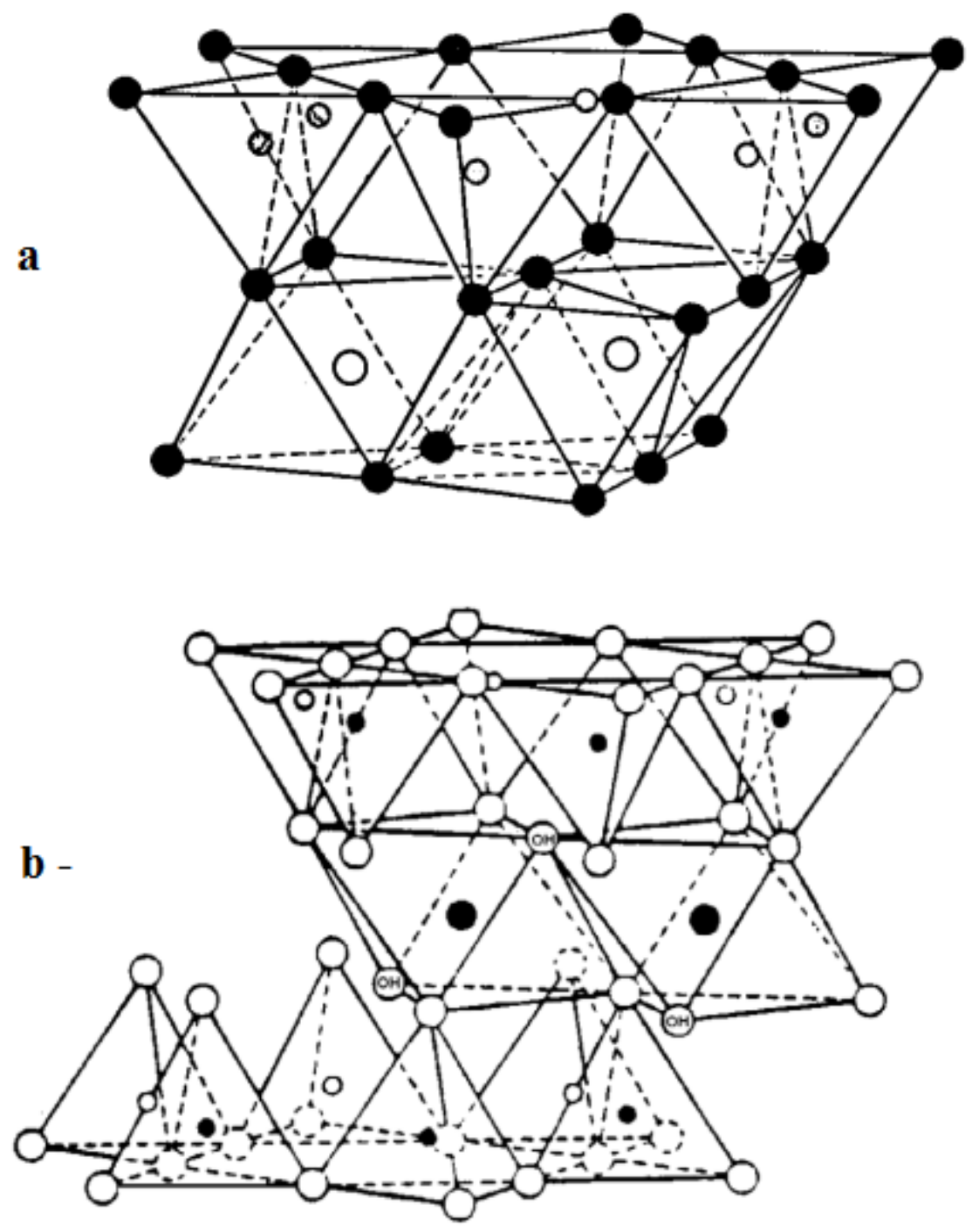

FIGURA 1.3 a - Estrutura de um argilomineral do Tipo 1:1, b - Estrutura de um argilomineral do Tipo 2:1 (GOMES, 1986). 
A caulinita é um grupo de argilominerais do tipo 1:1, nesse grupo encontram-se os seguintes minerais:

- Dickita $\left(\mathrm{Al}_{2} \mathrm{Si}_{2} \mathrm{O}_{5}(\mathrm{OH})_{4}\right)$;

- Haloisita diidratada $\left(2 \mathrm{H}_{2} \mathrm{O} . \mathrm{Al}_{2} \mathrm{Si}_{2} \mathrm{O}_{5}(\mathrm{OH})_{4}\right)$;

- Haloisita tetraidratada $\left(4 \mathrm{H}_{2} 0 . \mathrm{Al}_{2} \mathrm{Si}_{2} \mathrm{O}_{5}(\mathrm{OH})_{4}\right)$;

- Endelita $\left(\mathrm{Al}_{2} \mathrm{Si}_{2} \mathrm{O}_{5}(\mathrm{OH})_{4} .2\left(\mathrm{H}_{2} \mathrm{O}\right)\right)$

- Caulinita $\left(\mathrm{Al}_{2} \mathrm{Si}_{2} \mathrm{O}_{5}(\mathrm{OH})_{4}\right)$;

- Nacrita $\left(\mathrm{Al}_{2} \mathrm{Si}_{2} \mathrm{O}_{5}(\mathrm{OH})_{4}\right)$;

- Odinita $\left.\left(\mathrm{Fe}^{3+}, \mathrm{Mg}, \mathrm{Al}, \mathrm{Fe}^{2+}, \mathrm{Ti}, \mathrm{Mn}\right)_{25}(\mathrm{Si}, \mathrm{Al})_{2}(\mathrm{OH})_{4}\right)$

As variações no arranjo empilhado possivelmente pelos locais desocupados na camada dioctaédrica, são responsáveis pela diferença entre a caulinita, nacrita e dickita (BATTEY, 1981).

Substituições isomórficas de átomos de $\mathrm{Si}^{4+}$ das camadas tetraédricas por átomos de $\mathrm{Al}^{3+}$ ou de átomos de $\mathrm{Al}^{3+}$ por $\mathrm{Mg}^{2+}$ nas camadas octaédricas, são frequentes. Essas substituições não são capazes de causar distorção na estrutura das lamelas, por serem estes átomos de tamanhos similares (SANTOS, 1989 e NEUMANN et. al., 2000), porém, geram um excesso de carga negativa responsável por algumas das propriedades interessantes das argilas. Este excesso de carga negativa é compensado pela adsorção de cátions nas superfícies externas das camadas, sendo que a quantidade de cátions adsorvidos necessária para neutralizar as cargas negativas nas camadas do material é medida pela capacidade de troca catiônica (CTC) (SODRE, 2001).

As argilas são empregadas numa série de produtos acabados, por possuírem propriedades adequadas, pela abundância e por ser de fácil manuseio. Apresentam poder adsorvente, podem ser empregadas como peneiras moleculares, como agentes descorantes e clarificantes de óleos vegetais e minerais, como suportes catalíticos, como agentes de filtração, como adsorventes de óleos em água, etc.

A capacidade de troca catiônica das argilas pode ser modificada por meio de processos físicos (ativação térmica) ou químicos (ativação ácida). A ativação térmica consiste em aquecer a argila a uma determinada temperatura enquanto que na ativação ácida faz-se um tratamento químico que consiste na lixiviação de metais em posições octaédricas da estrutura dos argilominerais como o alumínio, ferro, magnésio, entre 
outros. Esses processos promovem a destruição das lamelas, eliminação de impurezas e alterações da composição química e estrutural da argila. O resultado é um aumento da área superficial, porosidade e no número de sítios ácidos, dependendo da intensidade do tratamento (LENARDA, 2007).

Deve-se considerar ainda que a capacidade de adsorção das argilas pode variar de acordo com os parâmetros tais como: tempo de contato, $\mathrm{pH}$ e concentração dos íons metálicos em solução.

Dentre os diversos tipos de argilas, a caulinita é um argilomineral que desponta como candidato a agente adsorvente de íons metálicos em solução por apresentar baixo custo, pela sua facilidade de obtenção e pela possibilidade de aumentar sua eficiência quando modificada (TARASEVICH, 2001).

Diante do exposto é importante avaliar a capacidade de adsorção dos íons metálicos $\mathrm{Cr}^{3+}, \mathrm{Zn}^{2+}, \mathrm{Cd}^{2+}, \mathrm{Pb}^{2+}, \mathrm{Cu}^{2+} \mathrm{e} \mathrm{Ni}^{2+}$ em caulinita comercial com a finalidade de remoção destes íons de soluções aquosas para reuso e/ou descarte, obedecendo aos parâmetros estabelecidos pelas Resoluções CONAMA N³57 e 430. 


\section{2 - OBJETIVOS}

\section{1 - Objetivo Geral}

Avaliar a Capacidade de adsorção dos íons metálicos $\mathrm{Cr}^{3+}, \mathrm{Zn}^{2+}, \mathrm{Cd}^{2+}, \mathrm{Pb}^{2+}$, $\mathrm{Cu}^{2+}$ e $\mathrm{Ni}^{2+}$ em caulinita com a finalidade de remoção destes íons de soluções aquosas para reuso e/ou descarte.

\section{2 - Objetivos Específicos}

Determinar a capacidade de troca catiônica de argilas comerciais não modificadas e modificadas por ativação térmica e ativação ácida com $\mathrm{HCl}$ e $\mathrm{H}_{2} \mathrm{SO}_{4}$.

Estabelecer os parâmetros otimizados para o uso de caulinita comercial como adsorvente pelo estudo dos efeitos da proporção adsorvente/adsorvato, concentração inicial do íon em solução, pH e tempo de contato.

Determinar a constante de adsorção e a quantidade máxima de adsorção nas condições de trabalho por meio das isotermas de Freundlich, Langmouir e DubininRadushkevich (D-R). 


\section{1 - AMOSTRAGEM}

Para os ensaios, foram adquiridos três materiais denominados "caulinita" de diferentes fornecedores, que neste trabalho foram denominadas por $\mathrm{A}, \mathrm{B}$ e $\mathrm{C}$, ilustrados na FIGURA 3.1.

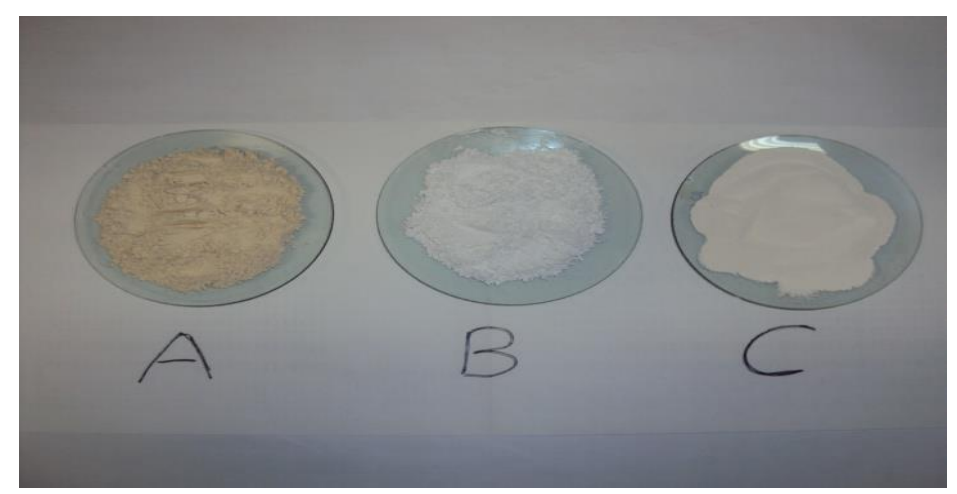

FIGURA 3.1 - Ilustração dos três materiais adquiridos e utilizados neste trabalho.

Antes de iniciar os testes, todas as três amostras foram secas a $90^{\circ} \mathrm{C}$ por 3 horas e em seguida foram pulverizadas com almofariz e pistilo e passadas em peneira de 75 $\mu \mathrm{m}(200 \mathrm{ABNT})$.

\section{2 - METODOLOGIA}

\subsection{1 - FLUORESCÊNCIA DE RAIOS-X (FRX)}

Devido a sua simplicidade, rapidez e precisão, a técnica de fluorescência de raios $\mathrm{X}$ está sendo cada vez mais utilizada para análise química de argilas e minerais argilosos. Destaca-se por ser uma técnica instrumental, não destrutiva e por permitir a determinação simultânea de vários elementos com uma ampla faixa de números atômicos, de modo rápido e com baixo custo. A FRX permite identificar os elementos presentes na amostra e determinar suas concentrações pelas intensidades dos raios $\mathrm{X}$ característicos emitidos por esses elementos após serem bombardeados por raios X com energia suficiente.

Existem duas variantes para a técnica, por dispersão de comprimento de onda e por dispersão de energia: a segunda apresenta menor sensibilidade analítica e maior 
interferência espectral, mas tem sido muito usada devido ao custo reduzido em relação à primeira. Em espectrômetros de comprimento de onda dispersiva, o feixe de raios policromáticos de comprimentos de ondas característicos provenientes da amostra é disperso por um cristal com espaçamento interplanar conhecido. No espectrômetro por energia dispersiva, os comprimentos de onda da radiação emitida pela amostra são separados com base em suas energias (MARTINS, 2010). Neste trabalho foi utilizada a técnica de fluorescência de raios-x por dispersão de comprimento de onda (WDXRF) pelo método semi-quantitativo.

\subsection{2 - DIFRAÇÃO DE RAIOS-X (DRX)}

A técnica de difração de raios $X$ é de grande importância mineralógica, pois é o método mais indicado na determinação das fases cristalinas presentes nas argilas que podem ser definidas como um conjunto de pequenos cristais orientados ao acaso, ou materiais cerâmicos. Isto é possível porque nos sólidos cristalinos ou semi-cristalinos, os átomos ou molécula arranjam-se em formas periódicas tridimensionais que estão separados entre si por planos na mesma ordem de grandeza dos comprimentos de onda dos raios X. Desta forma, é possível identificar os principais grupos de argilominerais com base nas distâncias interplanares basais, isto é, a distância entre as camadas que definem a estrutura cristalina lamelar do argilomineral (SANTOS, 1975).

A DRX fornece informações mais amplas, precisas e detalhadas quanto à qualificação, caracterização e quantificação dos constituintes presentes numa argila, além disso, é uma técnica de análise não destrutiva, rápida e muito versátil, na qual feixes de raios $\mathrm{X}$ incidem em uma família de planos da amostra em um ângulo $\theta$, ocorrendo a difração, tendo apenas o obstáculo de não se poder aplicar a minerais não cristalinos ou com cristalinidade incipiente (PEREIRA, 2008; MARTINS, 2010).

Para análise de argilas por DRX, geralmente utiliza-se o método do pó, em que o comprimento de onda é mantido constante e se varia o ângulo de difração. Como resultado se obtém uma representação gráfica do arranjo atômico no retículo cristalino. A intensidade dos picos de difração fornece uma base para a estimativa da concentração dos minerais presentes na amostra (MARTINS, 2010).

O padrão de difração é tipicamente apresentado como um gráfico com os ângulos de difração ou distância interplanar, pela intensidade de linhas difratadas dos 
planos cristalinos. Se existirem várias fases, o resultado será de difratogramas superpostos, um para cada fase, as quais podem ser identificadas utilizando técnicas de reconhecimento de padrões com base em um arquivo de padrões monofásicos.

Há vários fatores em relação à natureza física e química da amostra, como a descontinuidade nos cristais, variação na composição química e presença de substâncias amorfas que podem influenciar muito na intensidade de difração e, portanto, na validade da estimativa quantitativa dos minerais (WHITTIG, 1965; HILL e MADSEN, 2006).

\subsection{3 - ANÁLISE POR ATIVAÇÃO NEUTRÔNICA INSTRUMENTAL}

Nas últimas décadas a INAA tem sido amplamente utilizada na determinação de elementos em níveis menores e traço em vários tipos de matrizes, sendo um método de análise multielementar não destrutivo, podendo-se determinar até 40 elementos em uma mesma amostra. Esta técnica apresenta alta sensibilidade para níveis de concentração da ordem de $\mu \mathrm{g} \cdot \mathrm{g}^{-1}$ e ng. $\mathrm{g}^{-1}$, alta especificidade e alta seletividade. Dentre suas aplicações, estão análises ambientais, estudos nutricionais, estudos relacionados à saúde, materiais geológicos e ciência dos materiais (IAEA, 2001; SILVA, 2004; MOREIRA et al, 2007; FEI et al, 2010).

A INAA consiste no bombardeamento de um dado material, por nêutrons, seguido da medida da radioatividade induzida. O método baseia-se em uma reação nuclear resultante da interação de um nêutron com um núcleo alvo produzindo um núcleo composto, em estado excitado, que irá decair de acordo com a meia vida do nuclídeo formado, através de uma variedade de formas (Figura 3.2). A reação (n, $\gamma$ ) é a mais comumente empregada devido a sua maior probabilidade de ocorrência, tanto com nêutrons térmicos como com nêutrons epitérmicos. As atividades induzidas são determinadas por meio de detectores semicondutores que possuem grande capacidade para medir e discriminar as energias dos raios gama emitidos pelos núcleos excitados (MEYERS, 2000).

A intensidade da radiação emitida é proporcional à concentração do elemento na amostra e, uma vez que, cada radioisótopo, produzido no processo de ativação, possui características próprias de emissão (meia vida e energia das partículas ou radiação gama), é possível efetuar determinações por meio de comparação com a atividade 
medida em materiais de referência certificados e padrões sintéticos pipetados (FEI et al., 2010; MOREIRA et al., 2007).

1 - Feixe de nêutrons

2 - Núcleo alvo

3 - Raio gama pronto

4 - Núcleo atômico excitado

5 - Núcleo atômico radioativo

6 - raio gama atrazado

7 - partícula beta

8 - Núcleo estável
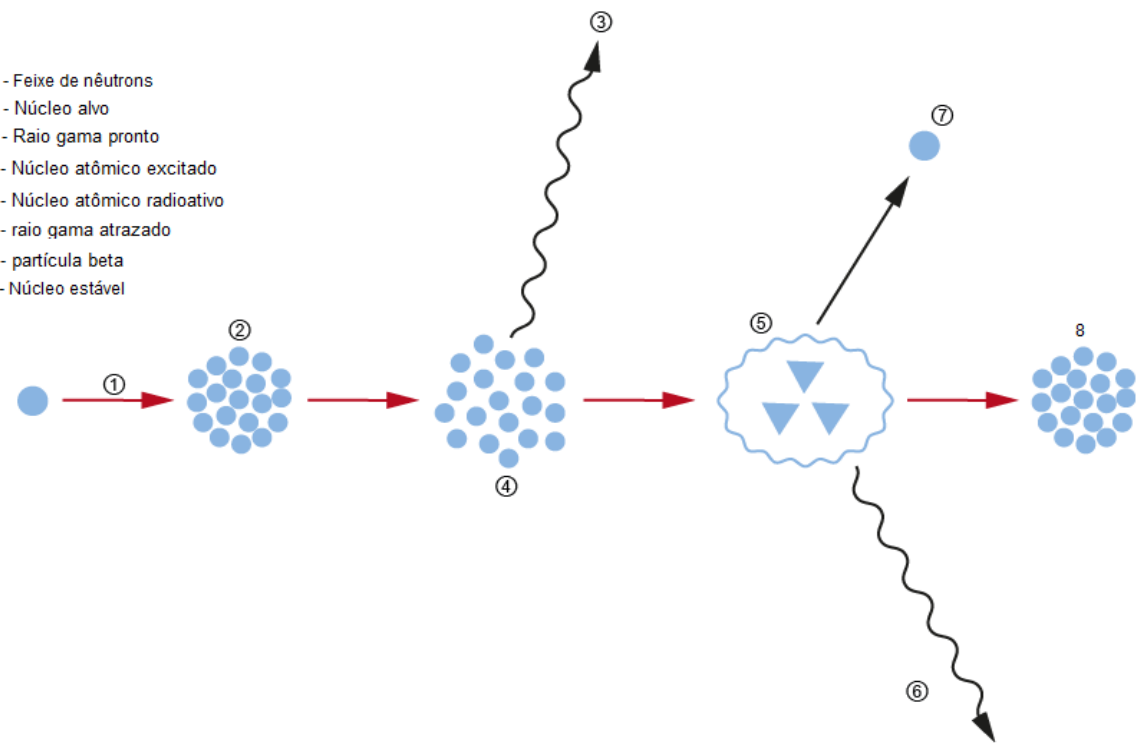

FIGURA 3.2: Processo esquemático da formação de um radionuclídeo artificial empregado na técnica de INAA.

Entre as principais características da técnica de INAA, podemos destacar:

Capacidade de determinação multielementar simultânea;

Alta sensibilidade, determinação em níveis de $\mu \mathrm{g} \cdot \mathrm{kg}^{-1}$ até concentrações da ordem de \%;

Boa exatidão e precisão;

Baixo limite de detecção para 30 a 40 elementos;

Técnica não destrutiva;

Pequena quantidade de amostra utilizada para a análise;

Entre as desvantagens da utilização desta técnica, podemos destacar:

Tempo longo de análise, comparado com as demais técnicas;

Manipulação de amostras irradiadas; 
Geração de lixo radioativo;

Necessidade de um reator nuclear;

Os procedimentos utilizados em INAA são geralmente classificados de acordo com o tempo de irradiação. Na irradiação curta as amostras são enviadas para o reator por meio de um tubo pneumático e são expostas ao fluxo de nêutrons por períodos que variam de alguns segundos a alguns minutos. Na irradiação longa, as amostras são levadas ao reator e expostas ao fluxo de nêutrons por períodos que variam de horas a dias. $\mathrm{Na}$ irradiação curta as amostras são inseridas em cápsulas de polietileno ou polipropileno e em cápsulas de alumínio para irradiação longa. Cápsulas de PVC ou frascos de vidro não são geralmente utilizados uma vez que se tornam muito radioativas devido à formação de ${ }^{38} \mathrm{Cl}$ ou ${ }^{24} \mathrm{Na}$, respectivamente. Os espectros de raios gama emitidos pelas amostras, depois de serem irradiadas, são obtidos em detectores de germânio hiper puro após um tempo de resfriamento (decaimento) necessário para diminuir a sua atividade a níveis que permitam sua manipulação e contagem (MEYERS, 2000).

No método comparativo (BOSTELMANN, 2006; MOREIRA, 2010) que foi utilizado neste trabalho a concentração é determinada pela comparação das áreas dos picos, obtidos no espectro gama da amostra irradiada com as áreas dos picos dos mesmos elementos nos espectros dos materiais de referência que foram irradiados juntamente com as amostras, utilizando-se para o cálculo a seguinte expressão:

$$
C a^{i}=\frac{\left(A a^{i} a \cdot m p \cdot C p^{i}\right) e^{\lambda(t a-t p)}}{A p^{i} \cdot m a}
$$

Onde:

$\mathrm{Ca}^{\mathrm{i}}$ : concentração do elemento i na amostra $\left(\mu \mathrm{g} \cdot \mathrm{g}^{-1}\right.$ ou \%)

$\mathrm{Cp} \mathrm{p}^{\mathrm{i}}$ : concentração do elemento i no padrão $\left(\mu \mathrm{g} \cdot \mathrm{g}^{-1}\right.$ ou \%)

$\mathrm{Aa}^{\mathrm{i}}$ : Atividade do elemento i na amostra (cps)

Ap: Atividade do elemento i na amostra (cps)

ma e mp: massa da amostra e do padrão, respectivamente

$\lambda$ : Constante de decaimento do radioisótopo $\left(\mathrm{t}^{-1}\right)$ 
ta - tp: diferença de tempo entre as contagens da amostra e padrão, respectivamente (min)

Na Tabela 3.1 são mostrados os elementos determinados, o radioisótopo formado na ativação e a energia da radiação gama por ele emitida, os seus tempos de meia vida e o tempo de decaimento antes da realização das medidas.

TABELA 3.1 - Elementos determinados por ativação neutrônica, radioisótopo formado na ativação, energia dos raios gama utilizados na espectrometria gama, meias-vidas e tempo de decaimento.

\begin{tabular}{ccccc}
\hline Elemento & Radioisótopo & E $(\mathbf{k e V})$ & Meia-Vida & Tempo de \\
\hline $\mathrm{As}$ & ${ }^{76} \mathrm{As}$ & 559 & 26,32 horas & 7 dias \\
$\mathrm{Ba}$ & ${ }^{131} \mathrm{Ba}$ & 496 & 11,8 dias & 15 dias \\
$\mathrm{Br}$ & ${ }^{82} \mathrm{Br}$ & 554 e 776 & 35,3 horas & 7 dias \\
$\mathrm{Ca}$ & ${ }^{47} \mathrm{sc}$ & 158 & 3,35 dias & 15 dias \\
$\mathrm{Ce}$ & ${ }^{141} \mathrm{Ce}$ & 145 & 32,5 dias & 15 dias \\
$\mathrm{Co}$ & ${ }^{60} \mathrm{Co}$ & 1173 e 1332 & 5,72 anos & 15 dias \\
$\mathrm{Cr}$ & ${ }^{57} \mathrm{Cr}$ & 320 & 27,7 dias & 15 dias \\
$\mathrm{Cs}$ & ${ }^{134} \mathrm{Cs}$ & 795,85 & 2,06 anos & 15 dias \\
$\mathrm{Eu}$ & ${ }^{152} \mathrm{Eu}$ & 121 e 1408 & 13,33 anos & 15 dias \\
$\mathrm{Fe}$ & ${ }^{59} \mathrm{Fe}$ & 1009 e 1291,6 & 44,5 dias & 15 dias \\
$\mathrm{Hf}$ & ${ }^{181} \mathrm{Hf}$ & 482,18 & 742,39 dias & 15 dias \\
$\mathrm{K}$ & ${ }^{42} \mathrm{~K}$ & 1524,58 & 12,36 horas & 7 dias \\
$\mathrm{La}$ & ${ }^{140} \mathrm{La}$ & 328 e 1596,21 & 40,27 horas & 7 dias \\
$\mathrm{Lu}$ & ${ }^{177} \mathrm{Lu}$ & 208,26 & 6,71 dias & 15 dias \\
$\mathrm{Na}$ & ${ }^{24} \mathrm{Na}$ & 1368,68 & 14,96 horas & 7 dias \\
$\mathrm{Nd}$ & ${ }^{174} \mathrm{Nd}$ & 91,1 e 531,01 & 10,98 dias & 15 dias \\
$\mathrm{Rb}$ & ${ }^{86} \mathrm{Rb}$ & 1076 & 18,66 dias & 15 dias \\
$\mathrm{Sb}$ & ${ }^{122} \mathrm{Sb}$ & 564 & 2,7 dias & 7 dias \\
$\mathrm{Sc}$ & ${ }^{45} \mathrm{Sc}$ & 889 & 83,81 dias & 15 dias \\
$\mathrm{Se}$ & ${ }^{75} \mathrm{Se}$ & 264 & 119,77 dias & 15 dias \\
$\mathrm{Sm}$ & ${ }^{153} \mathrm{Sm}$ & 103,18 & 46,27 horas & 7 dias \\
$\mathrm{Ta}$ & ${ }^{182} \mathrm{Ta}$ & 1221 e 1231 & 114,5 dias & 15 dias \\
$\mathrm{Tb}$ & ${ }^{160} \mathrm{~Tb}$ & 879,38 & 72,3 dias & 7 dias \\
$\mathrm{Th}$ & ${ }^{233} \mathrm{~Pa}$ & 312,01 & 27 dias & 15 dias \\
$\mathrm{U}$ & ${ }^{239} \mathrm{~Np}$ & $228,18 \mathrm{e} 277,6$ & 2,36 dias & 7 dias \\
$\mathrm{Yb}$ & ${ }^{169} \mathrm{Yb}$ & 177,21 e 197,98 & 32,02 dias & 7 dias \\
$\mathrm{Zn}$ & 1115,6 & 243,9 dias & 15 dias \\
$\mathrm{Zr}$ & 724,2 e 756,7 & 64,02 & 15 dias \\
\hline $65 \mathrm{Zn}$ & & &
\end{tabular}




\subsection{4 - ABSORÇÃO ATÔMICA COM FORNO DE GRAFITE}

A técnica de espectrofotometria de absorção atômica com forno de grafite foi empregada para a determinação das concentrações de chumbo e cádmio tanto para caracterização das argilas quanto para o estudo de adsorção. A determinação das concentrações é feita através de uma curva de calibração construída a partir de padrões analíticos dos elementos a serem analisados.

A técnica consiste em atomizar o analito através de um forno de grafite aquecido eletricamente, um feixe de luz proveniente de uma lâmpada construída a partir do elemento que se pretende analisar, é dirigido através da nuvem do elemento atomizado, passando por um monocromador até atingir o detector. As concentrações dos átomos são determinadas pela medida da absorção de radiação em determinados comprimentos de onda característicos dos elementos. A grande vantagem está na sensibilidade, que vai da ordem de partes por milhão $(\mu \mathrm{g} / \mathrm{g})$ até partes por trilhão $(\mathrm{pg} / \mathrm{g})$, devido à capacidade de gerar átomos rapidamente e mantê-los no caminho óptico por tempo suficiente para que se obtenha boa reprodutibilidade de exatidão das determinações. As temperaturas no forno de grafite por indução atingem de 2000 a $3000^{\circ} \mathrm{C}$, proporcionando a atomização da amostra (SKOOG et al., 1998). Porém, apesar de oferecer limites de detecção muito baixos, essa técnica sofre interferência de matriz, que é geralmente minimizada com o ajuste das temperaturas e uso de modificadores químicos (BEATY e KERBER, 1993).

Para a análise um discreto volume da solução da amostra é introduzido diretamente no interior do tubo de grafite por meio de um amostrador automático. As etapas de aquecimento da amostra ocorrem dentro do tubo aquecido eletricamente através da conexão deste com dois contatos elétricos. O aquecimento ocorre em três estágios: dessolvatação, pirólise e atomização.

$\mathrm{Na}$ dessolvatação, ocorre a secagem da amostra a uma temperatura entre $90 \mathrm{e}$ $120{ }^{\circ} \mathrm{C}$. Em seguida, na pirólise, a amostra é calcinada e ocorre a decomposição da matéria orgânica e de moléculas inorgânicas com temperaturas superiores a $500{ }^{\circ} \mathrm{C}$. Após a calcinação da amostra, com um súbito aumento da corrente, a temperatura do 
tubo eleva-se para 2000 a $3000^{\circ} \mathrm{C}$, proporcionando a atomização (SKOOG et al, 1998; BEATY e KERBER, 1993; HARRIS, 2005).

O vapor atômico resultante da atomização absorve a radiação monocromática, fornecida por uma lâmpada do metal e o detector fotoelétrico mede a intensidade da radiação transmitida. O inverso da transmitância é convertido logaritmicamente para absorbância, que é diretamente proporcional à densidade numérica de átomos no vapor, até uma concentração limite. A quantificação do metal se dá com a comparação do sinal analítico obtido na leitura da amostra com uma curva analítica (BEATY e KERBER, 1993).

Para o gás de purga geralmente é utilizado argônio, que além de servir como gás de arraste, mantém a atmosfera interna inerte, evitando a oxidação do forno (BEATY e KERBER, 1993). O tubo possui dois fluxos de argônio: um externo, que previne o contato com o ar do meio externo, que poderia causar a incineração do tubo e um fluxo interno, que passa através das duas extremidades e previne não apenas o contato do tubo com o ar do meio externo, mas também promove o arraste dos vapores formados nas etapas de aquecimento para limpeza do tubo (SKOOG et al, 1998).

\subsection{5 - ESPECTROMETRIA DE EMISSÃO ÓPTICA COM PLASMA INDUTIVAMENTE ACOPLADO (ICP-OES)}

A técnica de espectrometria de emissão óptica com plasma indutivamente acoplado foi empregada para a determinação dos elementos $\mathrm{Cu}, \mathrm{Cr}, \mathrm{Zn}$ e $\mathrm{Ni}$, tanto para caracterização das amostras de argila quanto nas soluções para o estudo de adsorção. É uma técnica bem estabelecida para análise simultânea de vários elementos. A técnica utiliza-se de argônio para a formação do plasma.

O plasma é um gás parcialmente ionizado onde co-existem elétrons livres e íons positivos em movimento, sua temperatura mais elevada, a estabilidade e o ambiente quimicamente inerte da atmosfera de Ar eliminam a maioria das interferências encontradas nas análises que utilizam chama para atomização do analito (MEIRELLES, 2012).

$\mathrm{Na}$ espectrometria de emissão óptica com plasma de argônio, a amostra é introduzida no plasma, onde ocorre à evaporação do solvente, formação de partículas sólidas, em seguida, ocorre fusão, dissociação para formação de átomos e íons livres. 
Uma energia adicional é fornecida para excitar esses átomos e íons livres a um estado de energia mais elevado. Estes átomos excitados (instáveis) emitem fótons de luz para retornarem ao estado fundamental (estável). A intensidade de emissão é proporcional à concentração do elemento presente na amostra. Na Figura 3.3, está representado as partes básicas de um ICP OES.

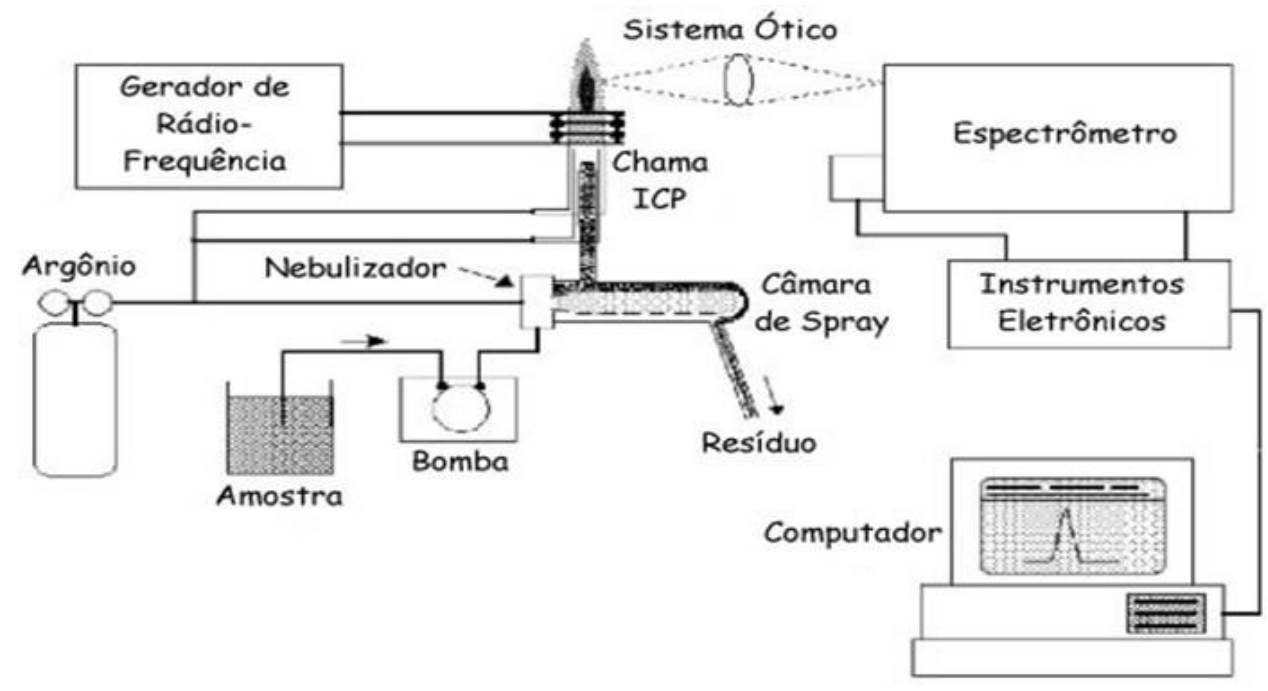

FIGURA 3.3 - Partes básicas de um ICP OES

(http://www.pa.ingv.it/laboratori/tracce/elementi.html acessado em 01/02/2015).

As etapas básicas da análise por ICP OES consistem em:

- Preparar as amostras - algumas amostras requerem etapas especiais de preparação, incluindo tratamento com ácidos, aquecimento e digestão por micro-ondas;

- Nebulização - Nesta etapa a solução contendo a amostra é convertida em aerossol (névoa fina de gotículas) que são então levadas ao centro do plasma, pelo fluxo de argônio;

- Dessolvatação/Volatilização - Nesta etapa o solvente é evaporado e as porções remanescentes de líquidos e sólidos são convertidas em gases;

- Atomização - A fase gasosa é quebrada e ficam disponíveis apenas os átomos, a temperatura do plasma e o ambiente quimicamente inerte são fundamentais neste estágio; 
- Excitação/Emissão - Os átomos ganham energia devido à colisões e emitem luz com comprimentos de onda característicos para cada elemento químico;

- Separação/Detecção - A luz separada pela grade de difração é quantitativamente mensurada (MANNING et. al., 1997).

A precisão e exatidão das análises ICP OES são consideradas suficientes para análises elementares em níveis traço. Mesmo na presença de interferências, modernas técnicas de compensação de sinal são utilizadas para realizar análises com notável precisão (geralmente menor de 1\%).

\subsection{CARACTERIZAÇÃO DAS ARGILAS}

\subsection{1 - MINERALÓGICA}

\subsubsection{1 - DIFRAÇÃO DE RAIOS-X}

Para análise mineralógica as amostras foram pulverizadas e passadas em peneira de $75 \mu \mathrm{m}$ (200 ABNT), em seguida foram encaminhadas para o laboratório de química do Instituto de Geociências (IGc) da Universidade de São Paulo (USP). As amostras foram analisadas em um difratômetro de pó Siemens modelo D5000 com detector de cintilação ótica fixa, equipado com difratômetro e monocromador de grafite, foi utilizada a radiação $\mathrm{Cu} \mathrm{K \alpha}$ em $40 \mathrm{kV}$ e $40 \mathrm{~mA}$. 


\subsection{2 - QUÍMICA}

\subsubsection{1 - FLUORESCÊNCIA DE RAIOS-X}

Para a caracterização química por fluorescência de raios-X as amostras foram pulverizadas e passadas em peneira de $75 \mu \mathrm{m}$ (200 ABNT), e encaminhadas para o Centro de Química e Meio Ambiente (CQMA), localizado no Instituto de Pesquisas Energéticas e Nucleares (IPEN). A caracterização química das amostras por difração de raios X foi realizada utilizando-se um espectrômetro WDXRF marca RIGAKU, modelo RIX 3000 com anodo de Rh no tudo de raios X, voltagem de aceleração máxima a 60 $\mathrm{kV}$, detector cintilador de $\mathrm{NaI}(\mathrm{Tl})$ e contador de fluxo proporcional.

\subsubsection{2 - ANÁLISE POR ATIVAÇÃO NEUTRÔNICA INSTRUMENTAL}

Para a determinação da composição elementar dos elementos traço presentes nas argilas estudadas, aproximadamente $100 \mathrm{mg}$ de amostra e dos materiais de referência STM-2 proveniente do United State Geological Survey e HISS-1 proveniente do National Research Council Canada foram precisamente pesados, selados em sacos de polietileno previamente descontaminados e encaminhados para irradiação por um período de 8 horas sob um fluxo de nêutrons de $10^{12} \mathrm{~cm}^{-2} \mathrm{~s}^{-1}$ no reator IEA-R1 do IPEN.

Duas séries de medidas foram feitas, a primeira após uma semana de decaimento e a segunda entre 15 e 20 dias após a irradiação. O tempo de contagem foi de 1,5 horas para as amostras e 1 hora para os materiais de referência e padrões pipetados.

A espectrometria gama para determinação das concentrações foi feita em um detector de germânio Hiper Puro da EG \& G Ortec com resolução de 1,90 e 2,04 keV para o ${ }^{57} \mathrm{Co} \mathrm{e}{ }^{60} \mathrm{Co}$, respectivamente.

\subsubsection{3 - DISSOLUÇÃO DAS AMOSTRAS DE CAULINITA}

As amostras foram secas a $90^{\circ} \mathrm{C}$ por 3 horas e em seguida foram pulverizadas com almofariz e pistilo e passadas em peneira de $75 \mu \mathrm{m}$ (200 ABNT). Desse material peneirado foram retirados $0,250 \mathrm{~g}$ de cada amostra de argila, e as três amostras foram dissolvidas com Água Régia. 
Para execução do método da Água Régia $\left(\mathrm{HCl}+\mathrm{HNO}_{3}\right.$, numa proporção 3:1); em béquer de teflon e chapa aquecedora. Após a evaporação da água régia foram adicionados $5 \mathrm{~mL}$ de ácido fluorídrico (HF) em cada amostra, que também foram evaporados à secura e posteriormente o resíduo foi tratado com $\mathrm{HNO}_{3}$ até que não se observasse mais a liberação dos fumos brancos característicos da presença de HF.

Após o resfriamento das amostras, estas foram filtradas e avolumadas a $50 \mathrm{~mL}$ com água ultra pura Milli Q. Duas alíquotas de cada amostra foram dissolvidas e reservadas para análise (Absorção Atômica - Pb e Cd; Espectrometria de emissão óptica com plasma indutivamente acoplado - $\mathrm{Ni}, \mathrm{Zn}, \mathrm{Cu}$ e $\mathrm{Cr}$ ) em duplicata das mesmas.

\subsection{3 - TEOR DE UMIDADE, MATÉRIA ORGÂNICA E PERDA AO FOGO}

Teor de umidade é a relação expressa na forma percentual, entre o peso da água contida num certo volume de argila e o peso da parte sólida existente neste mesmo

volume. É uma medida importante para estabelecer a relação entre o comportamento de uma argila e suas propriedades.

Para este ensaio foram utilizados $1,0 \mathrm{~g}$ de argila, medidos em balança com resolução $0,001 \mathrm{~g}$, colocadas em cápsulas de porcelana, e submetida à temperatura de $100^{\circ} \mathrm{C}$ em estufa por um período de 48 horas, após este período as amostras foram colocadas em dessecador, após 1 hora, a massa foi medida.

Após a medida do teor de umidade, os mesmos recipientes contendo as amostras foram levados à mufla a uma temperatura constante de $550^{\circ} \mathrm{C}$ por 4 horas para determinação do teor de matéria orgânica. Para obtenção do teor de perda ao fogo, as amostras foram colocadas novamente na mufla a uma temperatura de $1000^{\circ} \mathrm{C}$ por 4 horas. O procedimento de armazenamento em dessecador foi repetido antes das determinações de suas massas.

Após os ensaios, calculou-se o teor de umidade, matéria orgânica e perda ao fogo, expressas em porcentagem, utilizando as equações 10, 11 e 12, respectivamente.

$$
\% U=\frac{P 2}{P 1} \times 100
$$

equação 10

Em que \%U é o teor de umidade, P1 é a massa da amostra natural mais a massa recipiente, e P2 é a massa da amostra seca mais a massa do recipiente. 


$$
\% M O=\frac{P 3}{P 2} \times 100 \quad \text { equação } 11
$$

Em que \%MO é o teor de matéria orgânica, P2 é a massa da amostra seca, e P3 é a massa da amostra submetida à temperatura de $550^{\circ} \mathrm{C}$.

$$
\% P F=\frac{P 4}{P 2} \times 100 \quad \text { equação } 12
$$

Em que \%PF é o teor de perda ao fogo, P2 é a massa da amostra seca, e P4 é a massa da amostra submetida à temperatura de $1000^{\circ} \mathrm{C}$.

\subsection{4 - ATIVAÇÃO DE ARGILAS}

A capacidade de adsorção das argilas pode variar de acordo com diversos parâmetros; tais como: tempo de contato, $\mathrm{pH}$, concentração dos íons metálicos, etc. Porém, esta capacidade de adsorção pode ser elevada se a argila passar por um processo de ativação, que consiste na aplicação de tratamentos químicos e físicos com a finalidade de alterar suas propriedades.

O tratamento ácido, consiste na lixiviação das argilas em ácidos inorgânicos, geralmente ácido clorídrico $(\mathrm{HCl})$ ou ácido sulfúrico $\left(\mathrm{H}_{2} \mathrm{SO}_{4}\right)$. A função dos ácidos é promover a desagregação das partículas da argila, eliminar impurezas e aumentar a acidez da superfície pela substituição de cátions trocáveis por íons de hidrogênio ou pelo surgimento de sítios do tipo ácido de Lewis, nos átomos de alumínio. (DIAS, SANTOS, 2001) O tratamento térmico, assim como as lixiviações ácidas, podem aumentar a área específica e o volume de poros dos argilominerais (MORONTA, et. al. 2002).

\subsubsection{1 - ATIVAÇÃO TÉRMICA}

O tratamento térmico foi realizado em estufa. As amostras das três caulinitas foram aquecidas a diferentes temperaturas de $150,200,250$ e $300^{\circ} \mathrm{C}$, por períodos de 1 , 2 e 3 horas.

\subsubsection{2 - ATIVAÇÃo ÁCIDA}

No tratamento ácido, as amostras foram tratadas com solução de ácido clorídrico nas concentrações $1,2,3,4$ e 6 mol.L $\mathrm{L}^{-1}$, por 1 hora, a $90{ }^{\circ} \mathrm{C}$ sob agitação constante. 
Outro tratamento, porém utilizando-se uma solução de ácido sulfúrico, foi realizado nas mesmas condições que as usadas para o tratamento com ácido clorídrico.

Após o tratamento ácido as amostras foram filtradas a vácuo e lavadas com água Milli Q ultra pura até $\mathrm{pH}$ neutro e secas em estufa com temperatura de $100^{\circ} \mathrm{C}$ por um período de 24 horas. Em seguida, as amostras foram pulverizadas e passadas em peneira de $75 \mu \mathrm{m}$ (200 ABNT) e, novamente, levadas em estufa com temperatura de $200^{\circ} \mathrm{C}$ por um período de 1 hora.

\subsection{5 - CAPACIDADE DE TROCA CATIÔNICA}

CASANOVA (1986) Sugeriu o método de adsorção de azul de metileno (AAM) para determinação da capacidade de troca catiônica (CTC) de solos e argilas, por sua rapidez, simplicidade e boa reprodutibilidade, além de permitir a medição concomitante da superfície específica. Assim este método foi escolhido para ser utilizado neste estudo. O método de adsorção de azul de metileno, que consiste na titulação de uma suspensão de $0,5 \mathrm{~g}$ de argila (passada na peneira $0,074 \mathrm{~mm}$ ) em $300 \mathrm{~mL}$ de água com uma solução de Azul de Metileno 0,01N, sob agitação constante. Após a adição de 1 $\mathrm{mL}$ da solução do corante e 5 minutos de agitação retira-se 1 gota da suspensão (água + argila + corante) com auxilio de uma pipeta de Pasteur, que é pingada sobre o papel de filtro (Whatman, número 41). O ponto de viragem dá-se quando a mancha formada pela difusão da gota no papel apresentar uma aura azul clara, significando que há excesso do corante na solução. Uma ilustração da identificação do ponto de viragem desta titulação está representada na Figura 3.4, na Figura 3.5 é mostrado o arranjo utilizado e na Figura 3.6, o resultado obtido experimentalmente em laboratório.

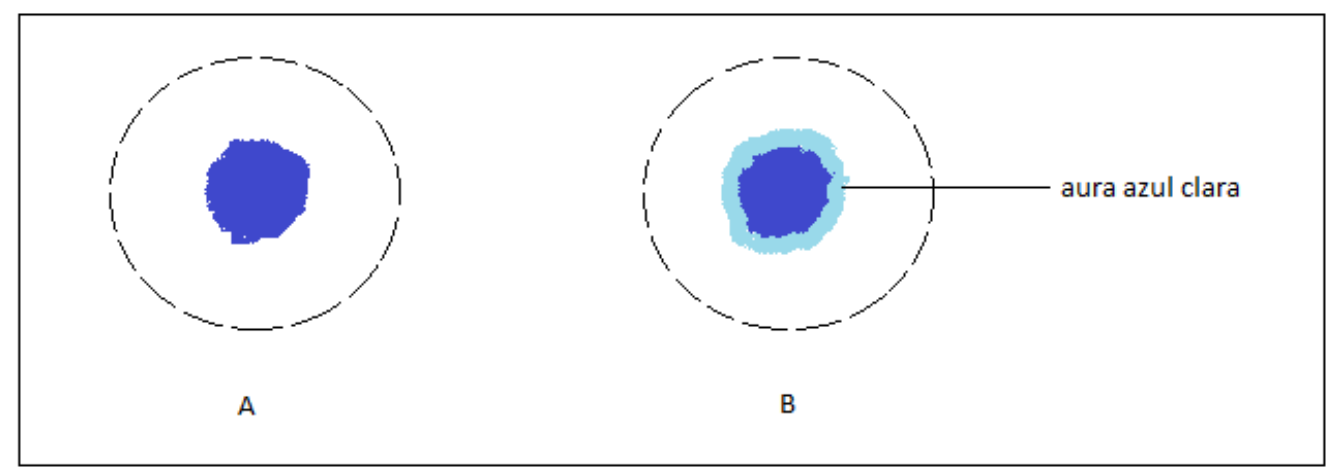

FIGURA 3.4 - Identificação do ponto de viragem da titulação com azul de metileno pelo aparecimento da aura azul clara em torno da argila difundida no papel. 


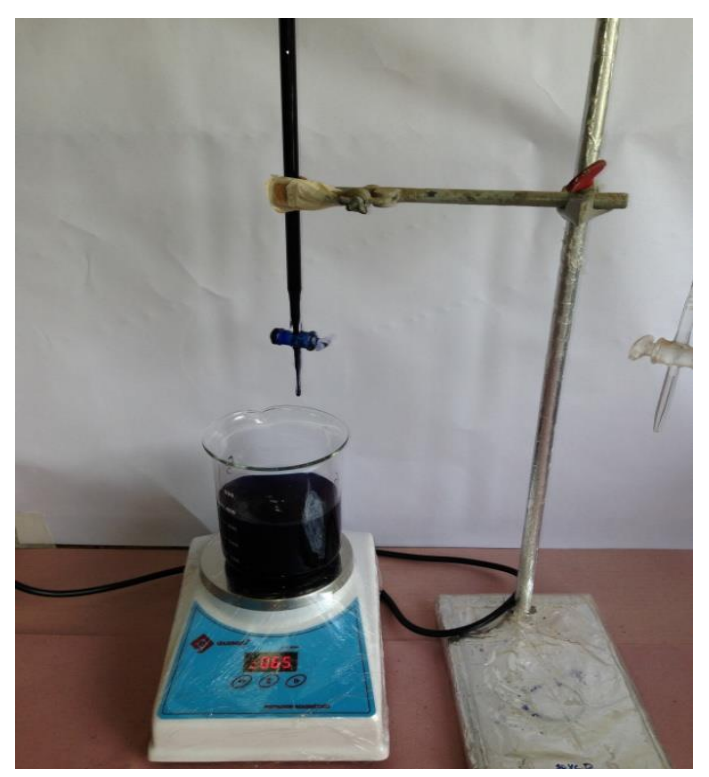

FIGURA 3.5 - Montagem do arranjo experimental utilizado para a determinação da capacidade de troca catiônica pelo método do Azul de Metileno.

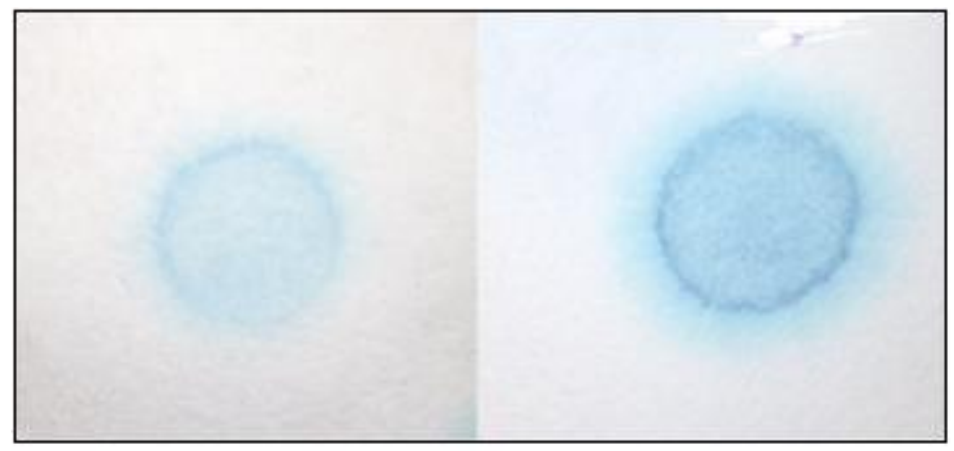

FIGURA 3.6 - Indicação experimental do ponto de viragem para a determinação da CTC pelo método de titulação com azul de metileno.

Para calcular o valor da CTC, utilizou-se a seguinte equação:

$$
\mathbf{C T C}=\frac{V \times C \times \mathbf{1 0 0}}{m}
$$

Sendo:

CTC: Capacidade de Troca Catiônica, em meq/100g;

V: Volume utilizado de solução de azul de metileno na titulação;

C: Concentração de Azul de Metileno;

m: Massa da amostra 


\section{4 - ESTUDO DA ADSORÇÃO}

O estudo da cinética de adsorção é importante para esclarecer a interação existente entre o material adsorvido e adsorvente no tempo que são colocados em contato. Isto explica o potencial de adsorção do adsorvente e o tempo necessário para a remoção do adsorvido.

A capacidade de retenção de elementos metálicos é uma medida útil na definição da aplicabilidade da argila como geoacumulador, pois define a quantidade máxima de constituinte que poderá ser removido de uma solução. A capacidade de retenção de elementos metálicos $(\mathrm{R})$ pode ser obtida através da seguinte expressão (AKAR et al., 2009):

$$
\mathrm{R}=[(\mathrm{Ci}-\mathrm{Cx}) \cdot \mathrm{V}] \cdot \mathrm{m}^{-1} \quad \text { equação } 14
$$

Sendo: $\mathrm{Ci}=$ concentração inicial do elemento metálico na solução;

$\mathrm{Cx}=$ concentração de elemento metálico na solução em determinado intervalo amostral; $\mathrm{V}=$ volume de solução;

$\mathrm{m}=$ massa de amostra de argila.

\subsection{1 - EFEITO DA PROPORÇÃO}

O estudo do efeito da proporção adsorvente/adsorvato foi realizado pela mistura de diferentes quantidades de caulinita com as soluções dos íons metálicos. Na Tabela 3.2, encontram-se as concentrações das soluções que foram utilizadas nos testes deste estudo. As concentrações foram escolhidas com base no valor estabelecido pela norma CONAMA 357/05, sua complementação CONAMA 430/2011 e Decreto Estadual 8468/76 que estabelece os limites máximos permitidos para utilização de efluentes em culturas (menor valor apresentado na tabela) variando até 50 vezes. 
TABELA 3.2 - Concentrações das soluções que foram utilizadas nos testes de adsorção em caulinita.

\begin{tabular}{c|ccccc}
\hline Elementos & \multicolumn{4}{|c}{ Concentração em mg. $\mathrm{L}^{-1}$} \\
\hline $\mathrm{Cd}$ & $* 0,2$ & 1,0 & 5,0 & 8,0 & 10 \\
$\mathrm{~Pb}$ & $* 0,5$ & 6,0 & 12 & 18 & 25 \\
$\mathrm{Cu}$ & $* 1,0$ & 12 & 25 & 37 & 50 \\
$\mathrm{Cr}$ & $* 0,1$ & 1,0 & 2,5 & 3,5 & 5,0 \\
$\mathrm{Ni}$ & $* 2,0$ & 25 & 50 & 75 & 100 \\
$\mathrm{Zn}$ & $* 5,0$ & 65 & 125 & 180 & 250 \\
\hline
\end{tabular}

*Limites estabelecidos pela Norma CONAMA 357/05 e 430/2011.

Cada uma destas soluções dos íons estudados foi tratada com argila nas proporções de 1:50, 5:50 e 10:50 (argila:solução), por um período de 2 horas sob agitação constante em pH 6,0 e temperatura ambiente. Após os testes, as amostras foram centrifugadas e o sobrenadante foi separado e reservado para análise. (Absorção Atômica - $\mathrm{Pb}$ e $\mathrm{Cd}$; Espectrometria de emissão óptica com plasma indutivamente acoplado - Ni, $\mathrm{Zn}, \mathrm{Cu}$ e $\mathrm{Cr}$ ).

\subsection{2 - EFEITO DO pH}

A mistura que apresentou a maior capacidade de adsorção, foi testada em relação à variação do pH. Uma solução, escolhida a partir dos resultados do estudo da cinética de adsorção, de cada um dos íons estudados foi tratada com caulinita nas condições especificada variando-se o $\mathrm{pH}$ no intervalo de 1 a 8 .

$\mathrm{O}$ efeito do $\mathrm{pH}$ sobre a adsorção foi investigado usando $5 \mathrm{~mL}$ da solução dos íons metálicos e $0,5 \mathrm{~g}$ ou $1,0 \mathrm{~g}$ do adsorvente, dependendo da melhor condição determinado no estudo da cinética de adsorção, mantido em agitação constante de 80 rpm por um período de 120 minutos e temperatura ambiente de $25^{\circ} \mathrm{C}$.

$\mathrm{O}$ pH das soluções foram ajustados com soluções de $\mathrm{NH}_{4} \mathrm{OH} 0,1$ mol.L $\mathrm{L}^{-1}$ ou $\mathrm{HCl}$ 0,1 mol. $\mathrm{L}^{-1}$. Após o tempo de contato, as soluções foram centrifugadas por um período de 25 minutos a $3000 \mathrm{rpm}$, e o sobrenadante foi separado e reservado para análise (Absorção Atômica - $\mathrm{Pb}$ e $\mathrm{Cd}$; Espectrometria de emissão óptica com plasma indutivamente acoplado - $\mathrm{Ni}, \mathrm{Zn}, \mathrm{Cu}$ e $\mathrm{Cr}$ ), brancos, sem adição das argilas, foram utilizados para controle da concentração inicial dos metais. 


\subsection{3 - EFEITO DO TEMPO DE CONTATO}

A mesma mistura utilizada para estudo do $\mathrm{pH}$ também foi utilizada para verificação da influência do tempo de contato. Duas soluções, escolhidas a partir dos resultados do estudo da cinética de adsorção e de efeito do $\mathrm{pH}$ de cada um dos íons estudados foram tratadas com caulinita por diferentes intervalos de tempo, variando de $5,10,20,30,60$ e 120 minutos.

Após o tempo de contato, as soluções foram centrifugadas por um período de 25 minutos a $3000 \mathrm{rpm}$, e o sobrenadante foi separado e reservado para análise (Absorção Atômica - $\mathrm{Pb}$ e $\mathrm{Cd}$; Espectrometria de emissão óptica com plasma indutivamente acoplado - Ni, Zn, Cu e Cr), brancos, sem adição das argilas, foram utilizados para controle da concentração inicial dos metais.

\section{5 - MEDIDAS DAS CONCENTRAÇÕES NAS SOLUÇÕES}

\subsection{1 - ABSORÇÃO ATÔMICA COM FORNO DE GRAFITE}

As medidas foram realizadas em espectrofotômetro de absorção atômica com forno de grafite (GFAAS) modelo AAnalyst 800 da Perkin Elmer do Laboratório de Absorção Atômica do LAN/IPEN (Figura 3.7).

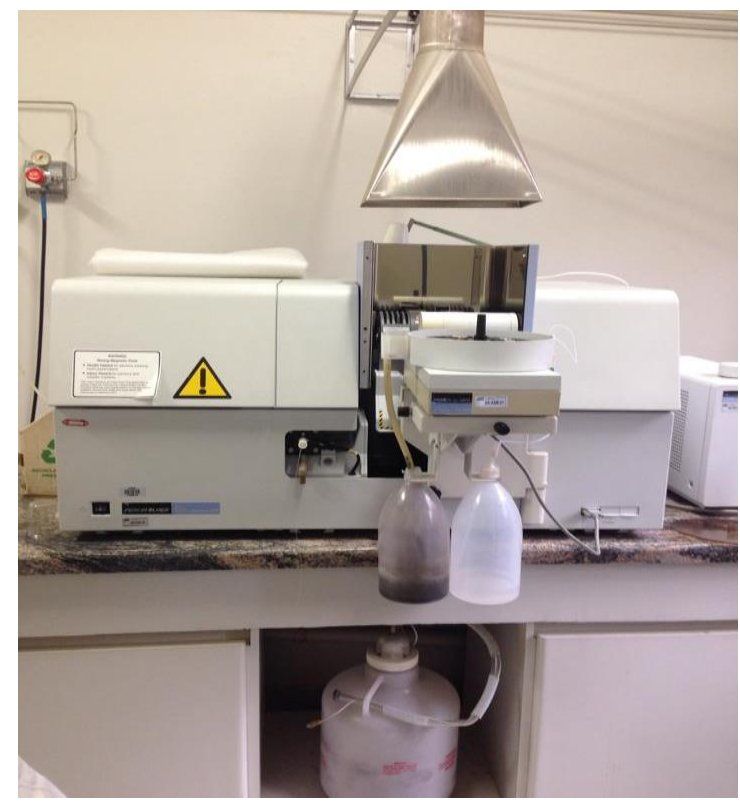

FIGURA 3.7: Equipamento de GFAAS modelo AAnalyst 800 da Perkin Elmer para determinação de $\mathrm{Cd}$ e $\mathrm{Pb}$. 
Antes da determinação das concentrações de $\mathrm{Cd}$ e $\mathrm{Pb}$ nas amostras, foram preparadas soluções destes elementos a partir de soluções estoque diluídas em $\mathrm{HNO}_{3}$ 0,2\% (v/v) (Merck), usado também como diluente, para construção da curva de calibração do equipamento. As concentrações das soluções utilizadas na curva de calibração são apresentadas na Tabela 3.3 e as curvas de calibração para $\mathrm{Cd}$ e $\mathrm{Pb}$ são apresentadas nas Figuras 3.8 e 3.9.

TABELA 3.3 - Concentrações das soluções utilizadas na construção da curva de calibração para determinação de $\mathrm{Cd}$ e $\mathrm{Pb}$ pela técnica de GFAAS.

\begin{tabular}{ccc}
\hline Soluções de calibração & \multicolumn{2}{c}{ Concentração calculada $\mu \mathrm{g} \mathrm{L}^{-1}$} \\
\cline { 2 - 3 } & $\mathrm{Cd}$ & $\mathrm{Pb}$ \\
\hline Branco & 0 & 0 \\
SE-1 & 1,398 & 23,75 \\
SE-2 & 2,796 & 47,5 \\
SE-3 & 4,194 & 71,251 \\
SE-4 & 5,592 & 95,002 \\
SE-5 & 6,99 & 118,725 \\
\hline
\end{tabular}

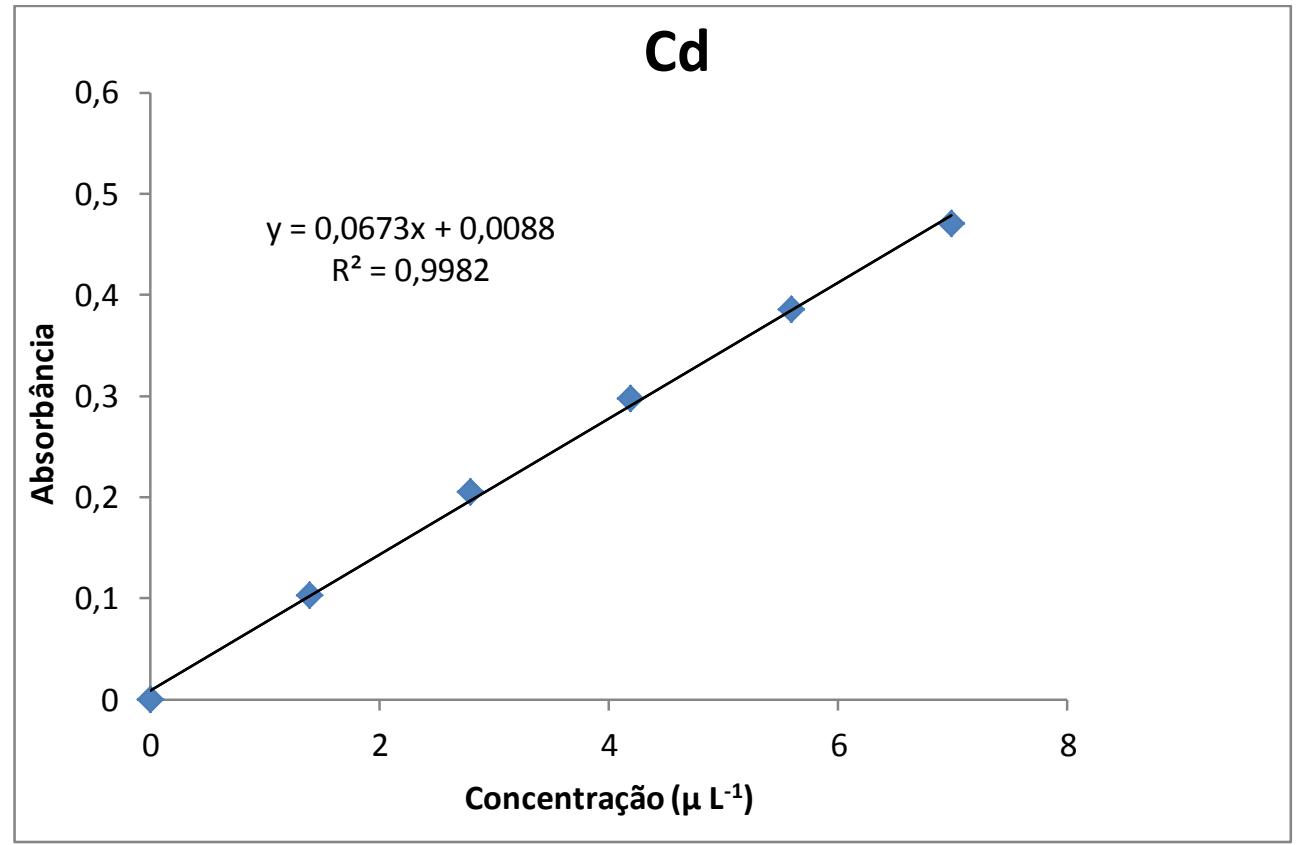

FIGURA 3.8 - Curva de calibração para Cd obtida por GFAAS. 


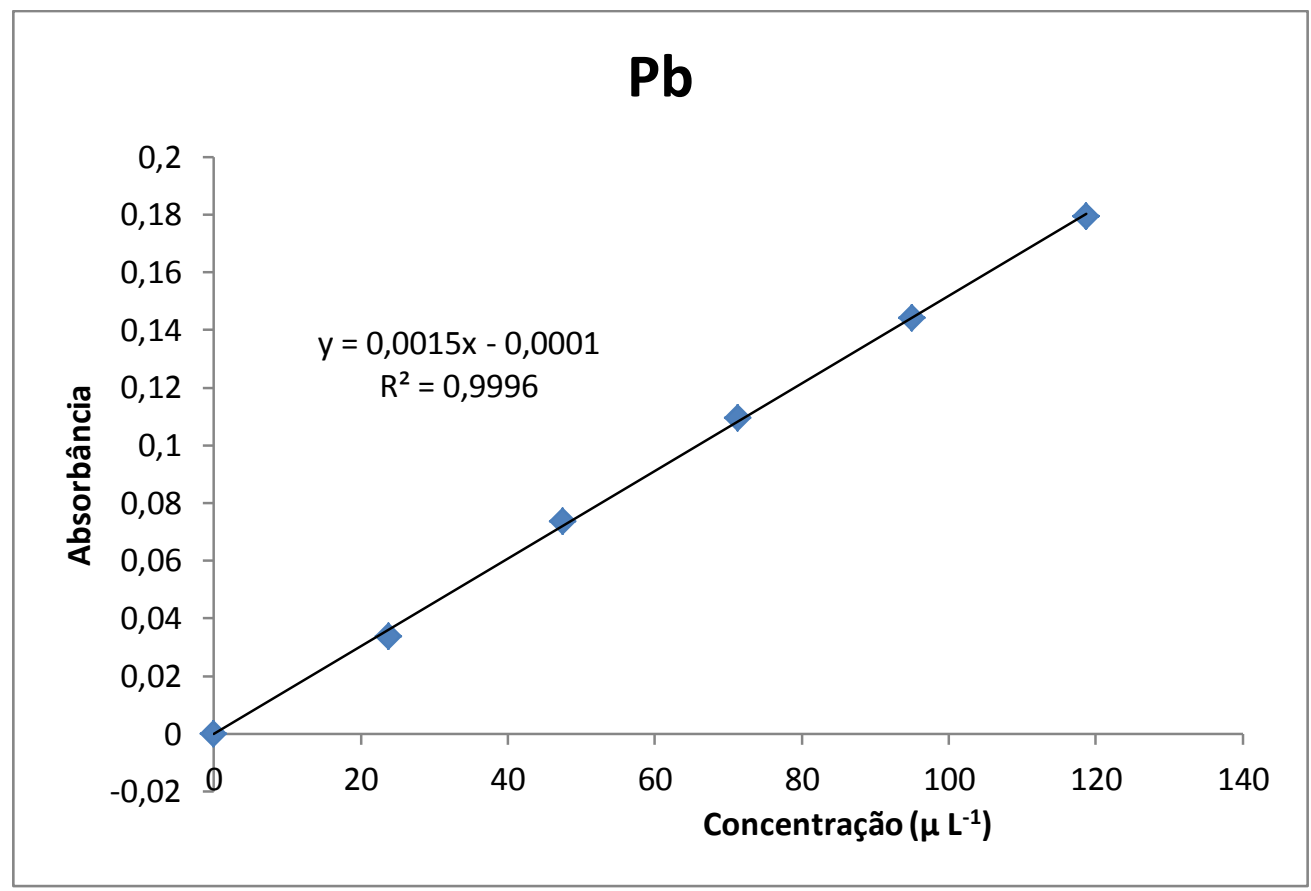

FIGURA 3.9 - Curva de calibração para Pb obtida por GFAAS.

Utilizou-se o programa Winlab 32 for AAS versão 6.2.0.0079 (Perkin Elmer) para a construção da curva analítica e leitura das amostras. O sinal analítico foi determinado a partir da área do pico de absorção e utilizou-se o modo de regressão linear para o ajuste da curva.

A linearidade das curvas de calibração foi checada tanto de forma visual no momento das medidas, como também pelo coeficiente de correlação linear das curvas (r). Obteve-se um valor do coeficiente de correlação linear $r>0,99$. Dessa forma a reta foi considerada um modelo matemático adequado para esse estudo, em que o sinal do equipamento é diretamente proporcional à concentração dos analitos quantificados.

Na Tabela 3.4 são apresentados os parâmetros de determinação de $\mathrm{Cd}$ e $\mathrm{Pb}$ ajustados para o equipamento de GFAAS. 
TABELA 3.4 - Parâmetros de determinação de $\mathrm{Cd}$ e $\mathrm{Pb}$ ajustados para análise.

\begin{tabular}{ccc}
\hline Parâmetros de determinação & Cd & Pb \\
\hline Lâmpada & EDL & EDL \\
Comprimento de onda & $228,8 \mathrm{~nm}$ & 283,3 \\
Fenda & $0,7 \mathrm{~nm}$ & $0,7 \mathrm{~nm}$ \\
Corrente da lâmpada & $230 \mathrm{Ma}$ & $440 \mathrm{Ma}$ \\
Volume de injeção da amostra & $20 \mu \mathrm{L}$ & $20 \mu \mathrm{L}$ \\
Volume de injeção de modificador químico & $10 \mu \mathrm{L}$ & $10 \mu \mathrm{L}$ \\
\hline
\end{tabular}

\subsection{2 - ESPECTROMETRIA DE EMISSÃO ÓPTICA COM PLASMA INDUTIVAMENTE ACOPLADO (ICP-OES)}

Após os diversos tratamentos das soluções com argila, as amostras foram encaminhadas para análise em um Espectrômetro de Emissão Óptica com Plasma Indutivamente Acoplado (ICP- OES), do Laboratório de Análises Química e Ambiental - LAQA, localizado no CQMA/IPEN. 


\section{4 - RESULTADOS}

Os dados obtidos e utilizados nos estudos da proporção, efeito do $\mathrm{pH}$, tempo de contato e isotermas de adsorção, são apresentados nos anexos A, B, C e D, respectivamente.

\section{1 - CARACTERIZAÇÃO MINERALÓGICA DAS ARGILAS}

\subsection{1 - DIFRAÇÃO DE RAIOS-X}

Os difratogramas de raios $\mathrm{X}$ das amostras $\mathrm{CA}, \mathrm{CB}$ e CC estão representados nas Figuras 4.1, 4.2 e 4.3, respectivamente. O difratograma 1, referente à amostra CA mostrou predominância de quartzo e uma pequena quantidade de caulinita, o difratograma 2, aponta que a amostra $\mathrm{CB}$ é composta por pirofilita, com quantidades consideráveis de ilita, moscovita e diásporo, enquanto que o difratograma 3 (amostra CC) resultou em caulinita com um grau de cristalinidade maior que as demais.

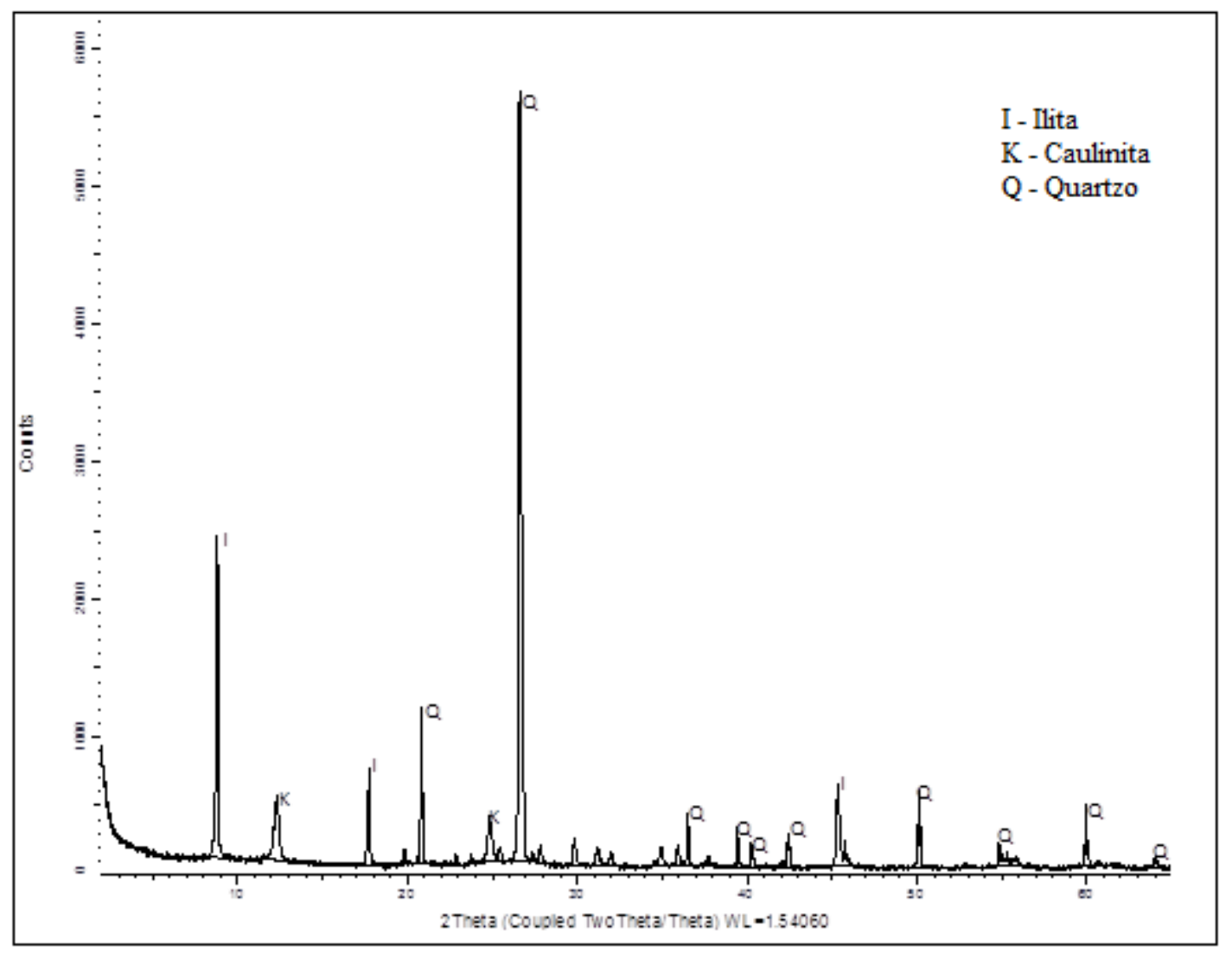

FIGURA 4.1 - Difratograma 1, referente à amostra de Caulinita A. 
Resultados encontrados por ARAÚJO e SILVA (2003), mostram que, no tratamento térmico realizado à temperatura de $600^{\circ} \mathrm{C}$, os picos referentes à caulinita praticamente desaparecem, porém, o tratamento a $800^{\circ} \mathrm{C}$ não produz alterações, quando comparado com o tratamento a $600^{\circ} \mathrm{C}$.

MORAES ET AL. (2003), verificaram que os tratamentos térmicos a $600^{\circ} \mathrm{C}$ e $800^{\circ} \mathrm{C}$ foram capazes de contribuir para o desaparecimento dos picos referentes à caulinita.

O difratograma 1 apresenta picos de 7,31A (pouco intenso) e $3,59 \AA$, que é

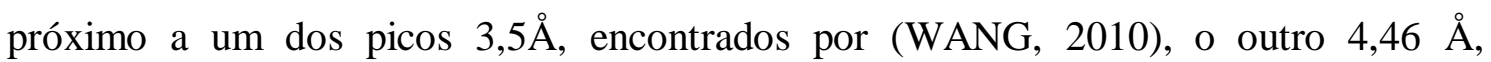
correspondentes aos espaçamentos das reflexões da caulinita, apontam uma estrutura desordenada, ou seja, que sofreu algum tratamento ácido ou térmico.

De acordo com o resultado obtido pelo difratograma 1, pode-se concluir que a amostra A sofreu uma transformação em sua estrutura, tornando-a uma estrutura mais desorganizada, denominada metacaulinita.

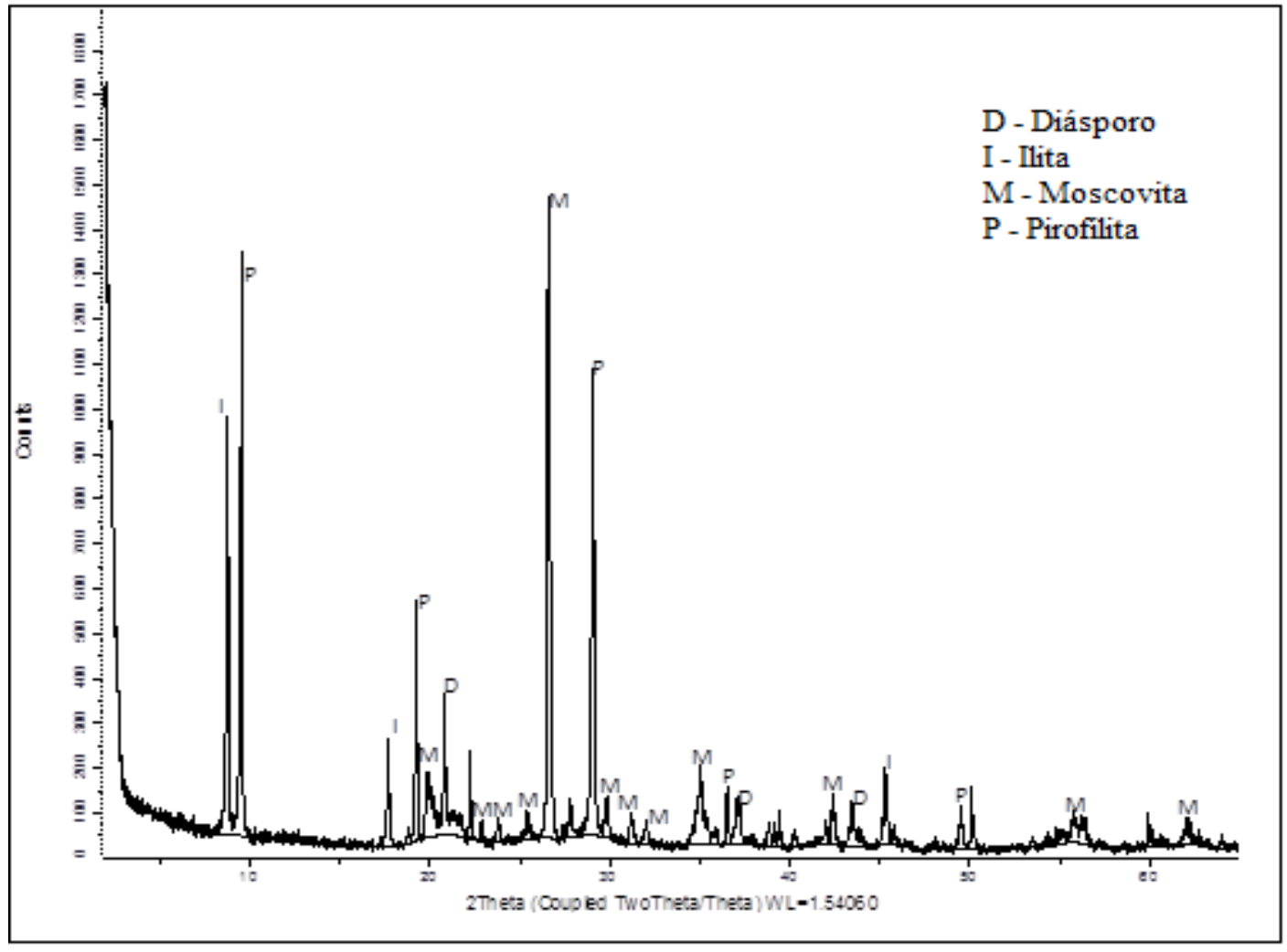

FIGURA 4.2 - Difratograma 2, referente à amostra de Caulinita B. 
De acordo com o difratograma 2, observa-e que a amostra $\mathrm{CB}$ contém alto teor de impurezas.

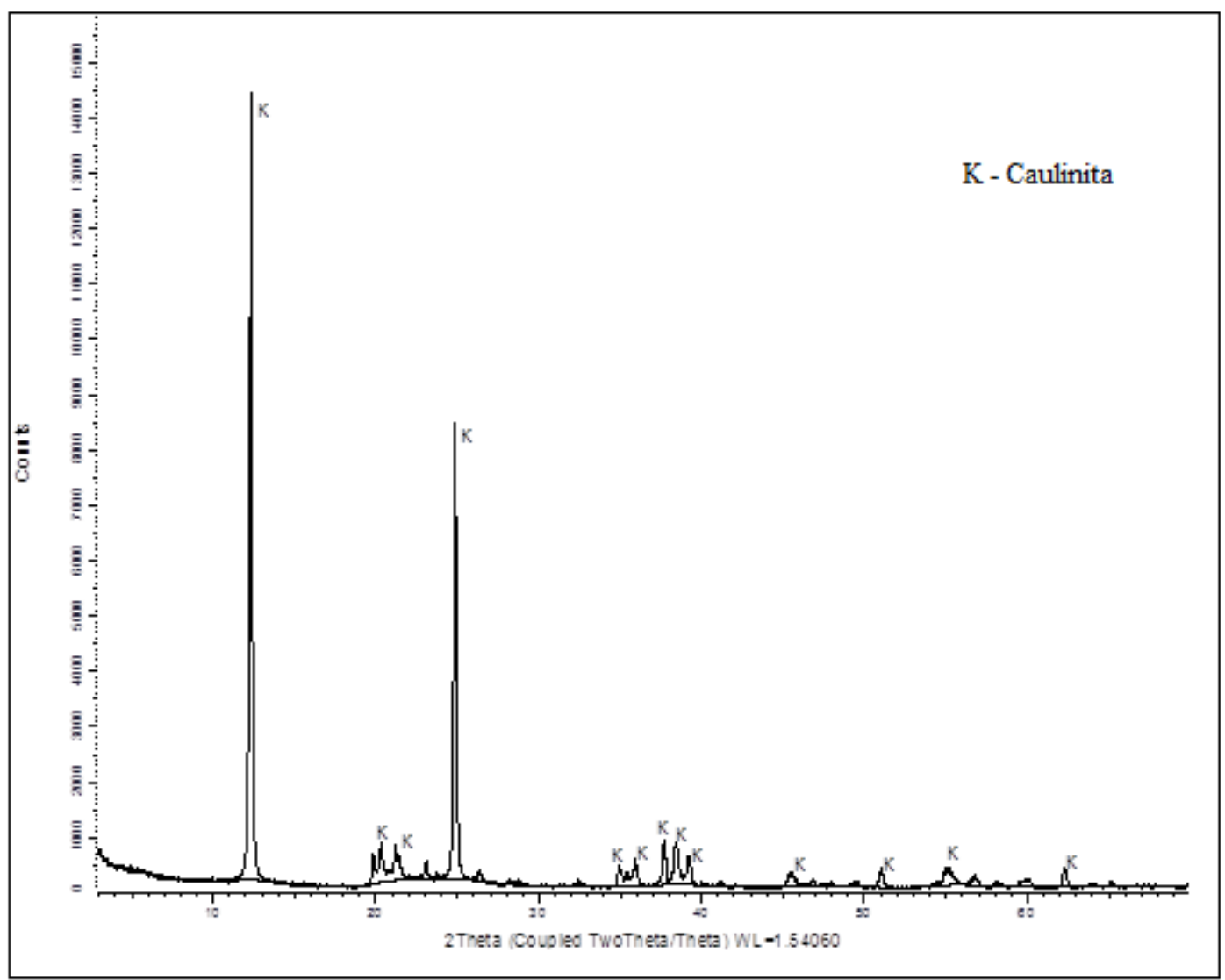

FIGURA 4.3 - Difratograma 3, referente à amostra de Caulinita C.

A cristalinidade de uma caulinita pode ser observada no difratograma de raios- $\mathrm{X}$ por meio de reflexões que ocorrem no intervalo de $19-22^{\circ}(2 \theta)$, como sugerem os autores TARI et. al. (1999) e KAKAL, et. al. (2001). Numa caulinita bem ordenada, observam-se reflexões bem definidas com intensidades proporcionais. Nota-se que apenas a amostra CC apresenta alto grau de cristalinidade, devido à presença de reflexões bem definidas e proporcionais, no intervalo citado.

A identificação do mineral caulinita realizada através da difração de raios $\mathrm{X}$ é

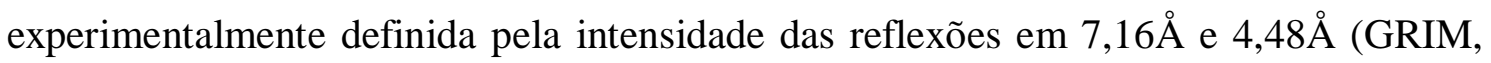
1968). O difratograma 3 , referente à caulinita $C$, apresentou os picos de $7,25 \AA$ e $4,43 \AA$, com valores relativamente próximos ao encontrado na referência citada acima, além disso, a confirmação de que a Argila $\mathrm{C}$ é constituída exclusivamente por caulinita foi confirmada na análise pela utilização de um padrão deste mineral. 


\section{2 - CARCACTERIZAÇÃO QUÍMICA DAS ARGILAS}

\subsection{1 - FLUORESCÊNCIA DE RAIOS-X}

Na Tabela 4.1 estão apresentados os resultados das três amostras de argilas CA, CB e CC, obtidos através da análise de fluorescência de raios-x por dispersão de comprimento de onda e resultados de outros trabalhos encontrados em literatura para fins comparativos.

TABELA 4.1 - Comparação das características químicas de argila, teores dos óxidos em $\%$.

\begin{tabular}{|c|c|c|c|c|c|c|}
\hline & $\begin{array}{c}\text { CAULINITA } \\
\text { CA }\end{array}$ & $\begin{array}{c}\text { CAULINITA } \\
\text { CB }\end{array}$ & $\begin{array}{c}\text { CAULINITA } \\
\text { CC }\end{array}$ & $\begin{array}{c}\text { ARAGÃO } \\
(2013)\end{array}$ & $\begin{array}{c}\text { SALLES } \\
(2011)\end{array}$ & $\begin{array}{c}\text { ZATTA } \\
(2010)\end{array}$ \\
\hline $\mathrm{SiO}_{2}$ & 65,00 & 61 & 53 & 74,30 & 52,75 & 50,30 \\
\hline $\mathrm{Al}_{2} \mathrm{O}_{3}$ & 19,90 & 34 & 46 & 19,70 & 43,13 & 25,50 \\
\hline $\mathrm{Fe}_{2} \mathrm{O}_{3}$ & 2,40 & 0,3 & 0,40 & 1,02 & 3,05 & 5,00 \\
\hline $\mathrm{K}_{2} \mathrm{O}$ & 6,90 & 3,4 & 0,025 & 2,01 & 0,52 & - \\
\hline $\mathrm{TiO}_{2}$ & 1,00 & 0,3 & 0,40 & 0,096 & - & - \\
\hline $\mathrm{Na}_{2} \mathrm{O}$ & 0,18 & 0,35 & 0,34 & 0,18 & 0,09 & - \\
\hline $\mathrm{MnO}_{2}$ & $<0,01$ & $<0,01$ & - & - & - & - \\
\hline $\mathrm{MgO}$ & 0,17 & 0,07 & - & 0,59 & 0,46 & - \\
\hline $\mathrm{H}_{2} \mathrm{O}$ & - & - & - & - & - & - \\
\hline $\mathrm{CaO}$ & 0,01 & 0,07 & 0,006 & 0,05 & 0,00 & - \\
\hline $\mathrm{TiO}_{2} / \mathrm{CaO}$ & 100 & - & - & - & - & - \\
\hline $\mathrm{P}_{2} \mathrm{O}_{5}$ & - & - & 0,067 & - & - & 1,3 \\
\hline
\end{tabular}

Ao avaliar os resultados apresentados na tabela, constata-se que há uma variação considerável entre os mesmos, uma vez que, a composição química da caulinita é peculiar de cada região e também as argilas comerciais adquiridas não são constituídas por caulinita pura, exceto para a amostra CC. Nota-se que a caulinita é um argilomineral constituído principalmente de óxidos de silício e alumínio.

A alumina ou óxido de alumínio revela a quantidade de argilomineral presente, quanto mais alumina, maior será a quantidade de caulinita. A sílica ou óxido de silício está relacionada com os argilominerais, micas, feldspatos e quartzo. Uma argila que apresenta um alto teor de $\mathrm{SiO}_{2}$ e teor apreciável de $\mathrm{MgO}$ e $\mathrm{CaO}$ provavelmente indica a 
presença do argilomineral montmorillonita (SANTOS, 1975; GRUN, 2007; MOTTA et. al., 2008).

Como esperado, apenas a amostra CC $(1,15)$ apresenta a relação molar $\mathrm{SiO}_{2} / \mathrm{Al}_{2} \mathrm{O}_{3}$ semelhante à caulinita teórica $(1,09)$. A amostra CA, apresenta a maior relação, 3,26, que indica alta quantidade de sílica livre e as quantidades relativamente altas de Fe, K e Ti indicam a presença de impurezas de Fe e Ti óxidos e mica (VEADO et. al, 1976; MIRANDA-TREVINO e COLES, 2003). De acordo com (BRINDLEY et. al, 1986) elevadas quantidades de cátions trocáveis estão relacionadas com a estrutura desordenada, indicando que a composição da amostra CC possui maior quantidade de caulinita que as CA e CB.

Os principais constituintes químicos foram sílica, alumínio e o potássio. A técnica de fluorescência de raios $X$ apresenta-se como uma ótima ferramenta para a determinação da composição química, no entanto não é suficiente para a identificação de caulinita.

\subsection{2 - ATIVAÇÃO NEUTRÔNICA INSTRUMENTAL}

Elementos menores (elementos cuja concentração está compreendida entre 1,0 e $0,1 \%$ ) e elementos traços (toda espécie química natural que está presente no meio ambiente em baixas concentrações, $<0,1 \%$ ) foram analisados para as três amostras de caulinita, obtidos por meio de análise por ativação com nêutrons, (Tabela 4.2) mostram uma grande variação, como demonstram os resultados de fluorescência de raios $-X$. A amostra CA apresentou as maiores concentrações para os elementos $\mathrm{Ca}, \mathrm{Cr}, \mathrm{Cs}, \mathrm{Fe}, \mathrm{K}$, $\mathrm{Rb}$, Sb e Sc; a amostra $\mathrm{CC}$ apresentou concentrações elevadas apenas para os elementos de terras raras leves, $\mathrm{Ce}$, $\mathrm{La}$ e $\mathrm{Nd}$, e para o elemento $\mathrm{Br}$. Todos os outros elementos estavam presentes em concentrações mais elevadas na amostra CB. Enriquecimento de terras raras em fase de caulinita foi documentada por AJA (1998) e MARQUES et. al. (2011), uma vez que os processos causa remobilização diagenética dos elementos terras raras que são absorvidos por argilominerais, principalmente aqueles que se formam sob condições de baixa temperatura, como a caulinita. As concentrações mais elevadas de $\mathrm{K}, \mathrm{Rb}$ e $\mathrm{Cs}$ em amostras de $\mathrm{CA}$ e $\mathrm{CB}$ podem ser explicadas pela presença de minerais ricos em potássio, mica, Ilite moscovita, bem como a quantidade relativamente mais elevada de outros elementos vestigiais pode ser explicada pela presença destes mesmos minerais, visto que eles são bem conhecidos por apresentarem muitos sítios disponíveis 
para substituição devido à sua estrutura em camadas (LYONS e HOSTERMAN, 1989; PALMER e LYONS, 1996). Apenas a amostra CA mostrou uma quantidade de ferro de cerca de $1 \%$ e, como mostrado nos difratogramas, não foi identificado mineral contendo ferro, que pode também explicar relativamente a baixa concentração de Co, outro elemento siderófilo.

TABELA 4.2 - Concentrações obtidas por Análise de Ativação Nêutronica, em mg kg-1, exceto quando indicado \% e suas respectivas incertezas associadas, determinadas por propagação de erros.

\begin{tabular}{|c|c|c|c|c|c|c|c|c|}
\hline \multicolumn{2}{|c|}{ Amostra As } & \multicolumn{3}{|c|}{$\mathrm{Ba}$} & \multirow[t]{2}{*}{$\mathrm{Br}$} & \multicolumn{3}{|c|}{$\mathrm{Ca} \%$} \\
\hline $\mathrm{CA}$ & 1,1 & $\pm 0,2$ & 561 & \pm 82 & & & 0,75 & $\pm 0,09$ \\
\hline $\mathrm{CB}$ & 2,4 & $\pm 0,3$ & 623 & \pm 83 & 0,5 & $\pm 0,2$ & 0,34 & $\pm 0,06$ \\
\hline $\mathrm{CC}$ & 0,4 & $\pm 0,1$ & & & 0,7 & $\pm 0,2$ & 0,28 & $\pm 0,07$ \\
\hline \multicolumn{2}{|c|}{ Amostra $\mathrm{Ce}$} & \multicolumn{3}{|c|}{$\mathrm{Co}$} & $\mathrm{Cr}$ & \multicolumn{3}{|c|}{$\mathrm{Cs}$} \\
\hline $\mathrm{CA}$ & 102 & \pm 7 & 1,3 & $\pm 0,1$ & 98 & \pm 14 & 8,0 & $\pm 0,8$ \\
\hline $\mathrm{CB}$ & 139 & \pm 10 & 0,73 & $\pm 0,09$ & 16 & \pm 3 & 4,3 & $\pm 0,4$ \\
\hline $\mathrm{CC}$ & 202 & \pm 14 & 0,6 & $\pm 0,1$ & 25 & \pm 4 & 0,20 & $\pm 0,06$ \\
\hline \multicolumn{2}{|c|}{ Amostra $\mathrm{Eu}$} & \multicolumn{3}{|c|}{$\mathrm{Fe}(\%)$} & Hf & \multicolumn{3}{|c|}{$\mathrm{K}(\%)$} \\
\hline $\mathrm{CA}$ & 1,13 & $\pm 0,05$ & 1,36 & $\pm 0,04$ & 7,5 & $\pm 0,2$ & 6 & \pm 2 \\
\hline $\mathrm{CB}$ & 1,70 & $\pm 0,08$ & 0,28 & $\pm 0,01$ & 12,5 & $\pm 0,2$ & 3,8 & $\pm 0,9$ \\
\hline $\mathrm{CC}$ & 1,22 & $\pm 0,06$ & 0,38 & $\pm 0,02$ & 4,3 & $\pm 0,1$ & & \\
\hline \multicolumn{2}{|c|}{ Amostra La } & \multicolumn{3}{|c|}{$\mathrm{Lu}$} & $\mathrm{Na} \%$ & \multicolumn{3}{|c|}{$\mathrm{Nd}$} \\
\hline $\mathrm{CA}$ & 70 & \pm 21 & 0,68 & $\pm 0,04$ & 0,18 & $\pm 0,01$ & 51 & \pm 17 \\
\hline $\mathrm{CB}$ & 110 & \pm 5 & 1,58 & $\pm 0,07$ & 0,19 & $\pm 0,01$ & 87 & \pm 7 \\
\hline $\mathrm{CC}$ & 200 & \pm 8 & 0,20 & $\pm 0,03$ & 0,16 & $\pm 0,01$ & 173 & \pm 20 \\
\hline \multicolumn{2}{|c|}{ Amostra Rb } & & \multicolumn{2}{|l|}{$\mathrm{Sb}$} & \multicolumn{2}{|l|}{$\mathrm{Sc}$} & \multicolumn{2}{|l|}{$\mathrm{Se}$} \\
\hline $\mathrm{CA}$ & 252 & \pm 16 & 3,7 & $\pm 0,6$ & 21,8 & $\pm 0,2$ & & \\
\hline $\mathrm{CB}$ & 125 & \pm 8 & 0,8 & $\pm 0,1$ & 10,6 & $\pm 0,1$ & 8 & \pm 1 \\
\hline $\mathrm{CC}$ & & & 0,6 & $\pm 0,1$ & 5,73 & $\pm 0,06$ & 3,3 & $\pm 0,9$ \\
\hline \multicolumn{2}{|c|}{ Amostra Sm } & & \multicolumn{2}{|l|}{$\mathrm{Ta}$} & \multicolumn{2}{|l|}{$\mathrm{Tb}$} & \multicolumn{2}{|l|}{ Th } \\
\hline $\mathrm{CA}$ & 8,8 & $\pm 0,5$ & 1,3 & $\pm 0,1$ & 4,1 & $\pm 0,4$ & 24 & \pm 2 \\
\hline $\mathrm{CB}$ & 20 & \pm 1 & 5,3 & $\pm 0,2$ & 7,8 & $\pm 0,4$ & 91 & \pm 9 \\
\hline $\mathrm{CC}$ & 8,2 & $\pm 0,5$ & 1,0 & $\pm 0,1$ & 1,4 & $\pm 0,3$ & 44 & \pm 4 \\
\hline
\end{tabular}




\begin{tabular}{lllllllll}
\hline Amostra & $\mathrm{U}$ & & $\mathrm{Yb}$ & & $\mathrm{Zn}$ & \multicolumn{3}{c}{$\mathrm{Zr}$} \\
\hline $\mathrm{CA}$ & 3,8 & $\pm 0,5$ & 2,8 & $\pm 0,3$ & 84 & \pm 5 & 314 & \pm 53 \\
$\mathrm{CB}$ & 10,5 & $\pm 0,9$ & 8,1 & $\pm 0,7$ & 99 & \pm 6 & 510 & \pm 52 \\
$\mathrm{CC}$ & 1,3 & $\pm 0,3$ & 1,0 & $\pm 0,1$ & 73 & \pm 5 & 178 & \pm 35 \\
\hline
\end{tabular}

Espaços em branco referem-se a valores não determinados.

\subsection{3 - TEOR DE UMIDADE, MATÉRIA ORGÂNICA E PERDA AO FOGO}

Os resultados de teor de umidade $\% \mathrm{U}$, matéria orgânica $\% \mathrm{MO}$ e perda ao fogo \%PF das amostras CA, CB e CC estão apresentados na Tabela 4.3. Também são apresentados os termogramas das amostras CA, CB e CC, nas Figuras 4.4, 4.5 e 4.6, respectivamente.

TABELA 4.3 - Resultados de teor de umidade, matéria orgânica e perda ao fogo.

\begin{tabular}{cccc}
\hline Amostra & $\% \mathrm{U}\left(100^{\circ} \mathrm{C}\right)$ & $\% \mathrm{MO}\left(550^{\circ} \mathrm{C}\right)$ & $\% \mathrm{PF}\left(1000^{\circ} \mathrm{C}\right)$ \\
\hline $\mathrm{CA}$ & 0,20 & 3,40 & 4,00 \\
$\mathrm{CB}$ & 0,30 & 4,16 & 5,27 \\
$\mathrm{CC}$ & 0,62 & 12,71 & 14,32 \\
\hline
\end{tabular}

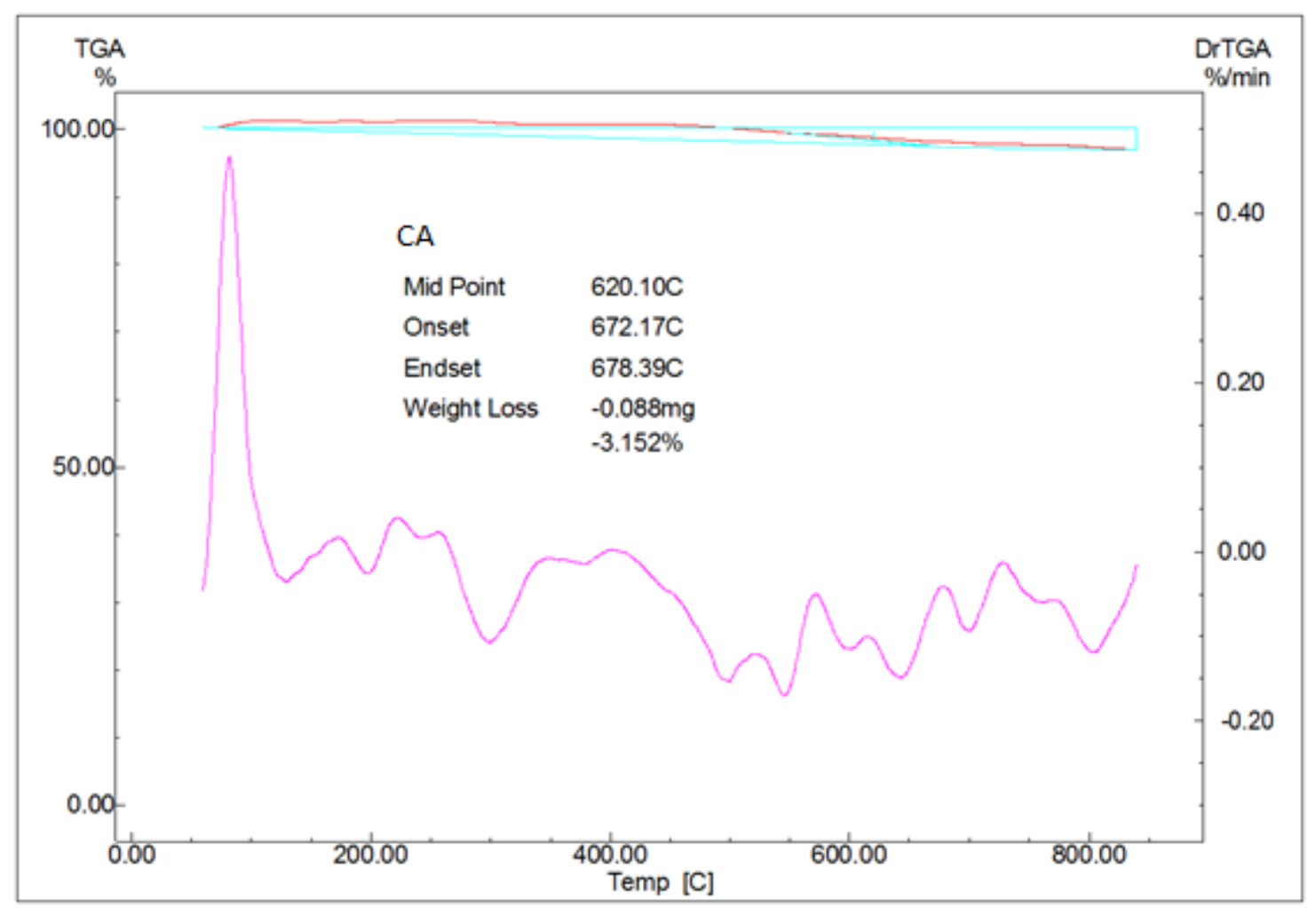

FIGURA 4.4 - Termograma 1, referente à amostra CA. 


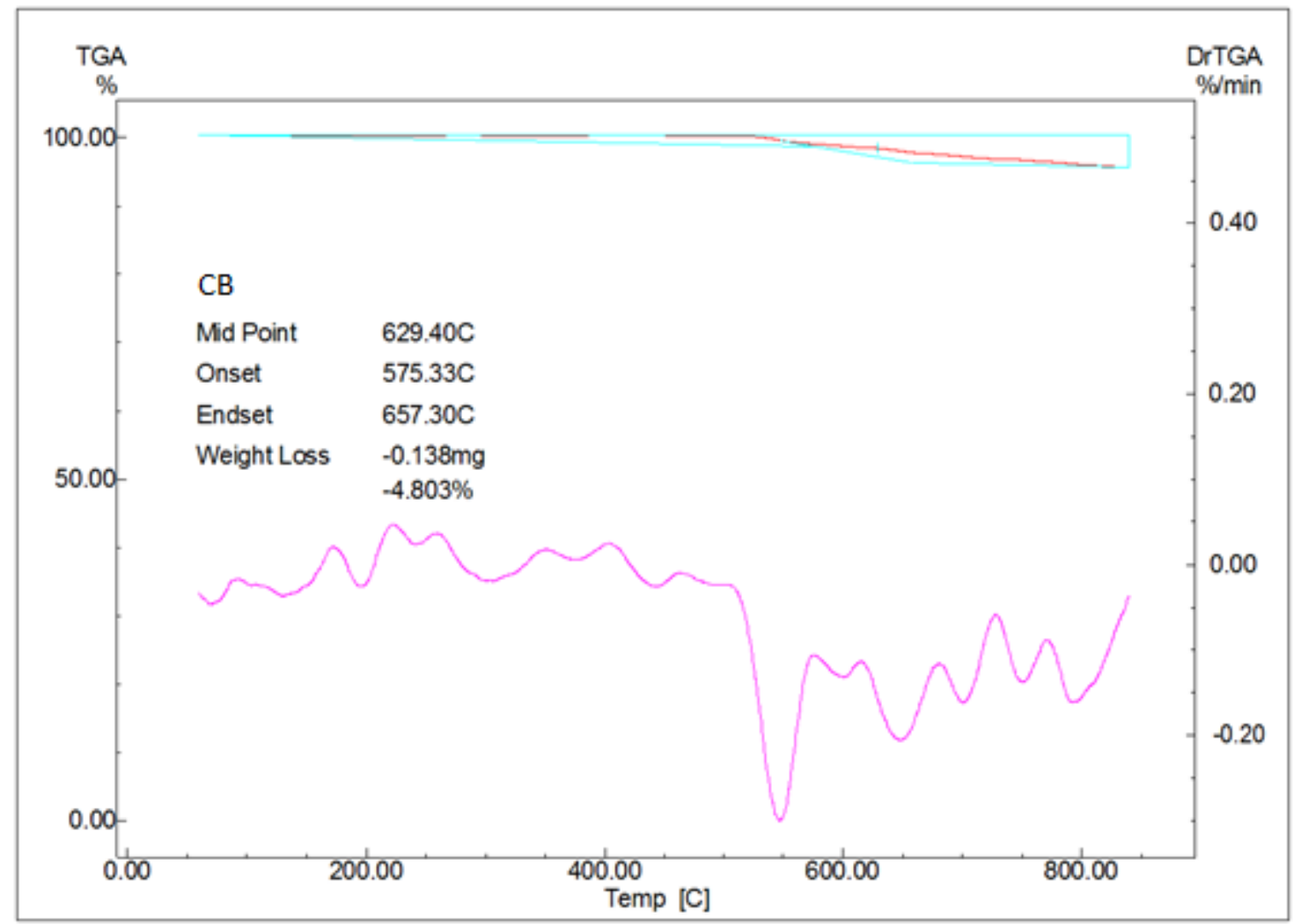

FIGURA 4.5 - Termograma 2, referente à amostra CB .

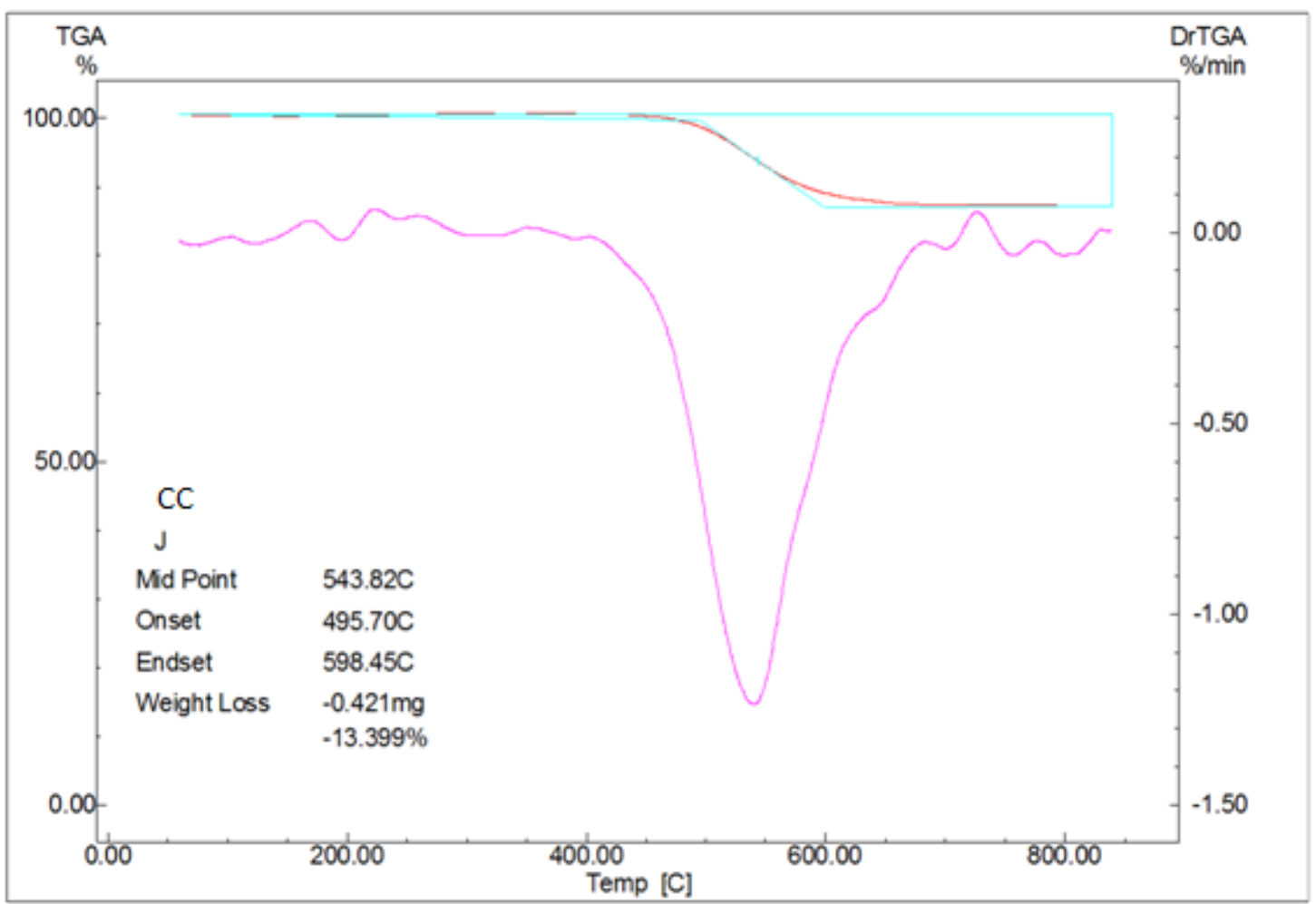

FIGURA 4.6 - Termograma 3, referente à amostra CC. 
De uma forma geral os argilominerais apresentam características de comportamento térmico semelhantes, como perda de água e transição de fases. Existem dois tipos de água: a água da umidade, que evapora por volta de $100^{\circ} \mathrm{C}$ e a água interna do cristal, que é eliminada entre $550^{\circ} \mathrm{C}$ e $600^{\circ} \mathrm{C}$, somente acima desta temperatura pode ser identificado o início efetivo da sinterização.

Entre $850^{\circ} \mathrm{C}$ e $1000^{\circ} \mathrm{C}$ ocorre à decomposição dos carbonatos, eles se transformam em óxidos de cálcio e não reagem com os silicatos. Acima de $900^{\circ} \mathrm{C}$ os fundentes (óxidos de potássio, sódio e ferro, entre outros) formam fase líquida. A partir de $1000^{\circ} \mathrm{C}$ os argilominerais se reorganizam em novas estruturas cristalinas.

De acordo com os resultados apresentados na tabela 4.3, nota-se perda de água da umidade, para as três amostras, que pode ser representada pela equação 7 .

$\mathrm{Al}_{2} \mathrm{Si}_{2} \mathrm{O}_{5}(\mathrm{OH})_{4} \cdot\left(\mathrm{H}_{2} \mathrm{O}\right)_{\mathrm{X}} \rightarrow \mathrm{Al}_{2} \mathrm{Si}_{2} \mathrm{O}_{5}(\mathrm{OH})_{4}+\mathrm{X} \mathrm{H}_{2} \mathrm{O}$

Nos termogramas das amostras CA, CB e CC são verificados a desidroxilação das estruturas (equação 8) associado a um pico endotérmico encontrado em $545^{\circ} \mathrm{C}$ a $550^{\circ} \mathrm{C}$. No termograma da amostra $\mathrm{CA}$, é encontrado um pico exotérmico por volta de $100^{\circ} \mathrm{C}$, que pode ser causado por uma cristalização, cura, oxidação ou adsorção, que supõe que a argila CA pode ter sofrido algum beneficiamento.

$\mathrm{Al}_{2} \mathrm{Si}_{2} \mathrm{O}_{5}(\mathrm{OH})_{4} \rightarrow \mathrm{Al}_{2} \mathrm{O}_{3}+2 \mathrm{SiO}_{2}+2 \mathrm{H}_{2} \mathrm{O} \quad$ equação 8

A perda de massa teórica neste processo foi de 3,15\%, 4,80\% e 13,39\% (método termogravimétrico), respectivamente para as amostras CA, CB e CC; e 3,40\%, 4,16\% e 12,71\% ("método da estufa"), respectivamente para as amostras CA, CB e CC,

ZATTA (2010) encontrou 13,96\% de perda de massa teórica, valor próximo quando comparado com os resultados da amostra CC encontrados pelos dois métodos.

A $1000^{\circ} \mathrm{C}$ é atribuído, o evento da cristalização da mulita, ou seja, a uma transição de fase dos óxidos constituintes da caulinita (GARDOLINSKI, 2003). 


\subsection{4 - CAPACIDADE DE TROCA CATIÔNICA}

Os resultados obtidos apontaram que os tratamentos, ácidos e térmicos, não causaram alterações substanciais na capacidade de troca catiônica das amostras. Desta forma, a argila $\mathrm{C}$ foi escolhida, para continuidade do trabalho, pois foi à única que se verificou ser verdadeiramente constituída por caulinita conforme demonstrado pelos resultados de DRX. Além disso, ela também apresentou os maiores valores de CTC e menor granulometria. Os resultados obtidos da CTC, com seus respectivos tratamentos encontram-se nas Tabelas 4.4 e 4.5 .

As argilas têm a propriedade de reagir química e reversivelmente com cátions devido ao fato de apresentarem uma carga negativa em sua superfície externa por causa das substituições isomórficas dentro do cristal dos argilominerais de $\mathrm{Mg}^{2+}$ e de $\mathrm{Si}^{4+}$ por $\mathrm{Al}^{3+}$ e também devido a ligações partidas (broken bonds) dos íons superficiais do cristal, além da substituição do hidrogênio das hidroxilas (SANTOS, 1975).

TABELA 4.4 - Resultados da capacidade de troca catiônica das três amostras, após o tratamento térmico (média de 3 medidas).

\section{CTC (meq/100g)}

\begin{tabular}{c|c|ccccc}
\hline \multirow{2}{*}{$\begin{array}{c}\text { Tempo } \\
\text { (hora) }\end{array}$} & \multirow{2}{*}{ ARGILA } & \multicolumn{5}{|c}{ Temperatura ${ }^{\circ} \mathrm{C}$} \\
\cline { 3 - 7 } 1 & & Sem Tratamento & 150 & 200 & 250 & 300 \\
\hline \multirow{3}{*}{1} & B & 7,94 & 6,62 & 7,94 & 5,96 & 7,94 \\
& C & 5,95 & 5,94 & 6,57 & 5,96 & 5,98 \\
& A & 9,00 & 7,92 & 3,98 & 5,96 & 7,96 \\
\hline \multirow{3}{*}{2} & B & & 5,98 & 5,9 & 5,91 & 5,98 \\
& C & & 5,98 & 5,9 & 5,94 & 6,63 \\
& A & & 5,97 & 3,97 & 5,97 & 5,95 \\
\hline \multirow{3}{*}{3} & B & & 5,32 & 4,59 & 5,99 & 5,98 \\
& C & & 5,32 & 6,58 & 5,99 & 5,98 \\
& A & & 6,96 & 3,98 & 5,96 & 6,96 \\
\hline
\end{tabular}


TABELA 4.5 - Resultados da capacidade de troca catiônica das três amostras, após o tratamento ácido (média de 3 medidas).

\begin{tabular}{c|c|ccccc}
\hline \multicolumn{8}{c}{ CTC (meq/100g) } \\
\hline \multirow{2}{*}{ ÁCIDO } & \multirow{2}{*}{ ARGILA } & \multicolumn{7}{|c}{ Concentração mol/L } \\
\cline { 3 - 7 } & & 1,0 & 2,0 & 3,0 & 4,0 & 6,0 \\
\hline \multirow{3}{*}{$\mathrm{H}_{2} \mathrm{SO}_{4}$} & A & 5,92 & 6,95 & 5,94 & 5,91 & 6,95 \\
& B & 6,93 & 6,61 & 6,62 & 6,61 & 5,98 \\
& C & 7,95 & 5,97 & & 5,97 & \\
\hline \multirow{3}{*}{$\mathrm{HCl}$} & A & 5,96 & 6,94 & 7,27 & 5,98 & 6,62 \\
& B & 5,30 & 5,97 & 5,97 & 6,92 & 5,94 \\
& C & 5,96 & 6,96 & & 6,00 & \\
\hline
\end{tabular}

Do ponto de vista industrial, o termo "argilas ativadas com ácidos" foi inicialmente reservado para o tratamento de bentonitas e, nos dias atuais, o termo tem sido amplamente empregado como um método de tratamento químico voltado para a melhoria da superfície e das propriedades catalíticas das argilas (BERTELLA, 2010). Os ácidos utilizados têm a tarefa de promover a desagregação das partículas de argila, eliminar impurezas e aumentar a acidez de superfície pela substituição de cátions trocáveis por íons hidrogênio ou pelo surgimento de sítios do tipo ácidos de Lewis, nos átomos de alumínio (GOMES, 1986).

Um provável motivo pelo qual não houve aumento da Capacidade de Troca Catiônica, ao realizar as ativações, pode estar relacionado ao fato que as argilas não foram adquiridas na forma in natura, mas, argilas comerciais, ou seja, possivelmente podem já ter sofrido algum tipo de tratamento.

\section{3 - RESULTADOS ESTUDO DA ADSORÇÃO}

\subsection{1 - EFEITO DA PROPORÇÃO}

Nos gráficos das Figuras 4.7, 4.8, 4.9, 4.10, 4.11 e 4.12 são apresentados os resultados do estudo de adsorção realizado pela mistura de diferentes quantidades de 
caulinita com as soluções dos íons metálicos. Os valores das concentrações das soluções antes e após o tratamento com a caulinita foram obtidos através das técnicas de absorção atômica com forno de grafite e espectrometria de emissão óptica com plasma indutivamente acoplado.

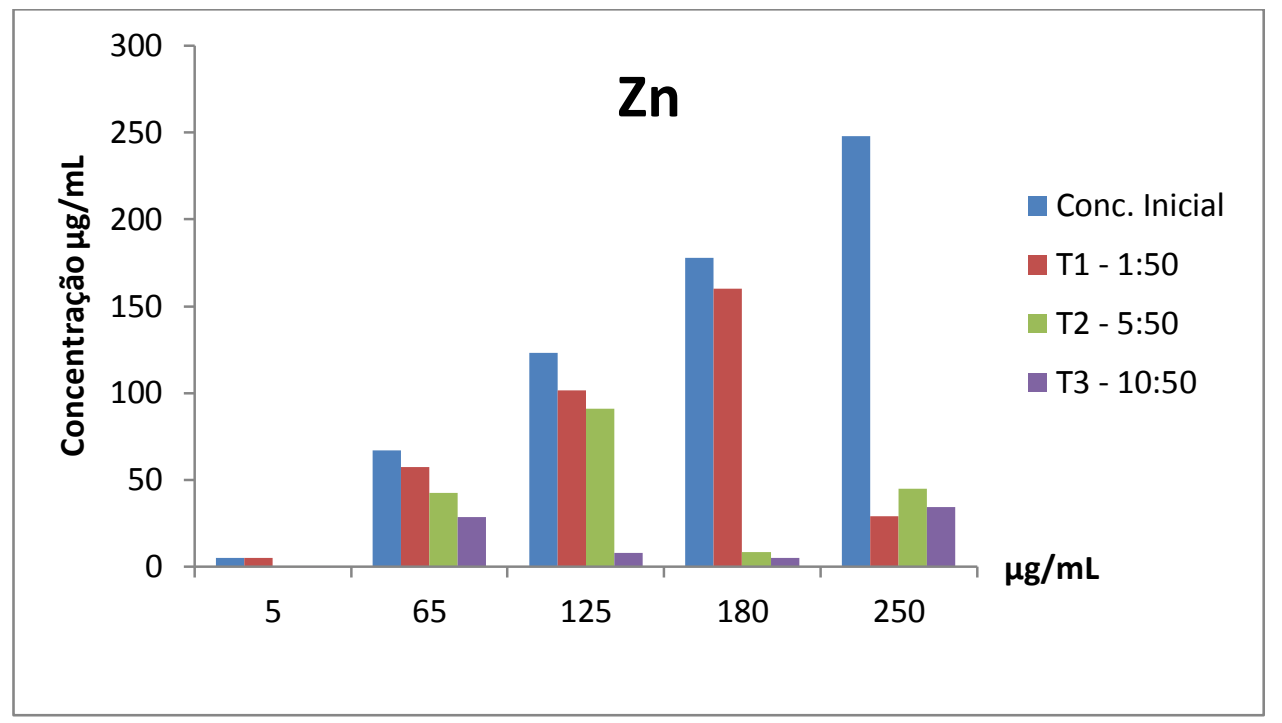

FIGURA 4.7 - Gráfico da concentração de íons de zinco na solução após tratamento a $25^{\circ} \mathrm{C}$ e 2 horas de agitação, sendo: $\mathrm{Ci}$ a concentração inicial, T1 proporção 1:50, T2 proporção 5:50 e T3 proporção 10:50.

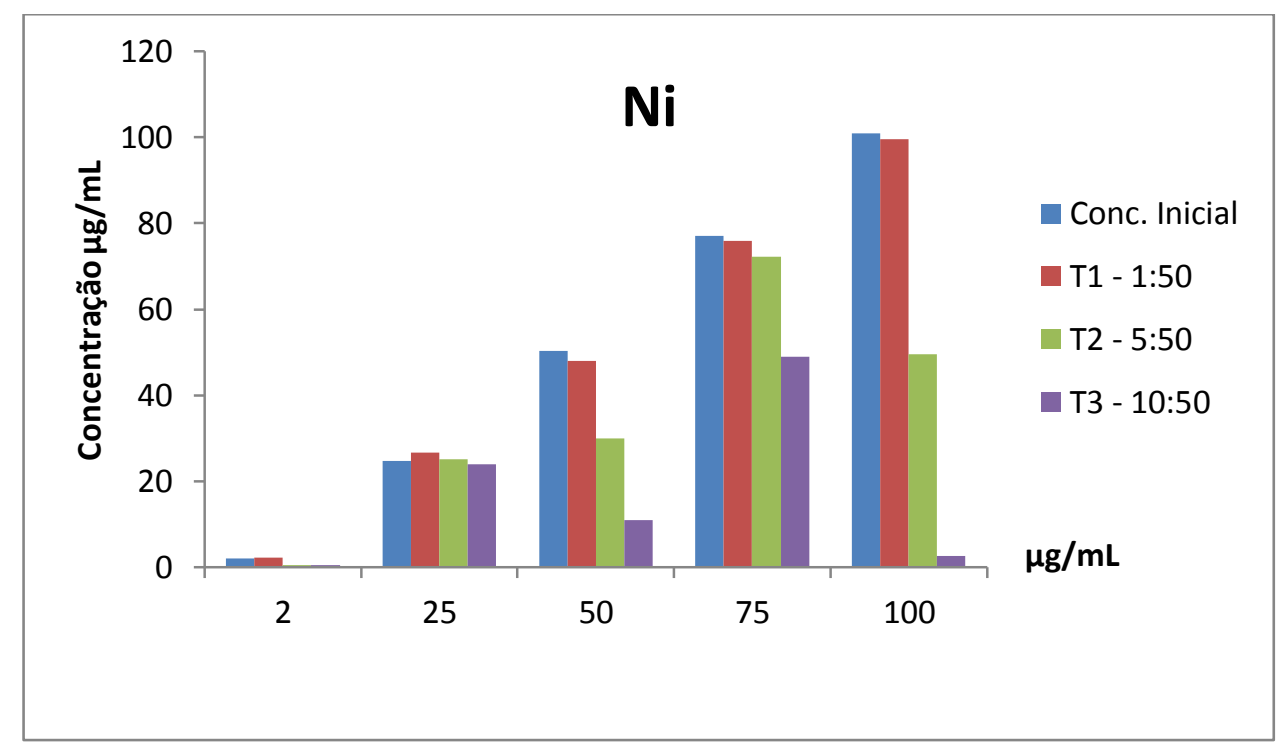

FIGURA 4.8 - Gráfico da concentração de íons de níquel na solução após tratamento a $25^{\circ} \mathrm{C}$ e 2 horas de agitação, sendo: Ci a concentração inicial, T1 proporção 1:50, T2 proporção 5:50 e T3 proporção 10:50. 


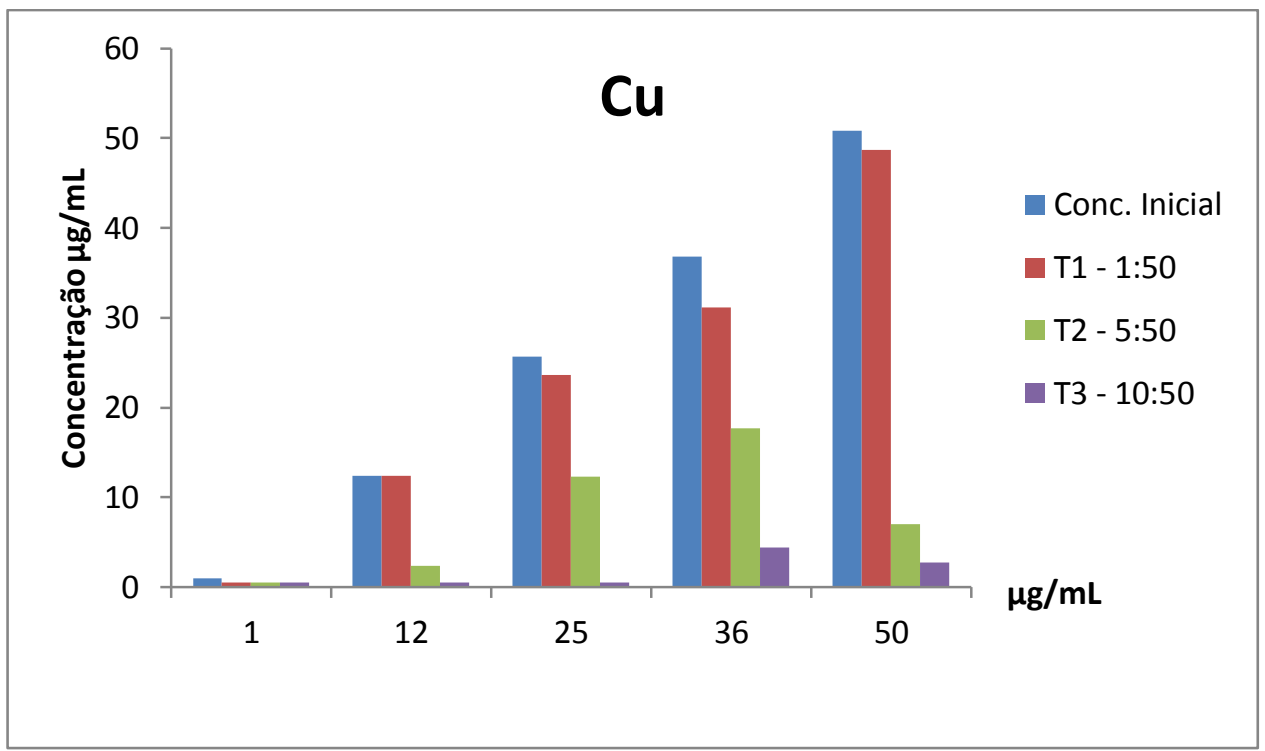

FIGURA 4.9 - Gráfico da concentração de íons de cobre na solução após tratamento a $25^{\circ} \mathrm{C}$ e 2 horas de agitação, sendo: Ci a concentração inicial, T1 proporção 1:50, T2 proporção 5:50 e T3 proporção 10:50.

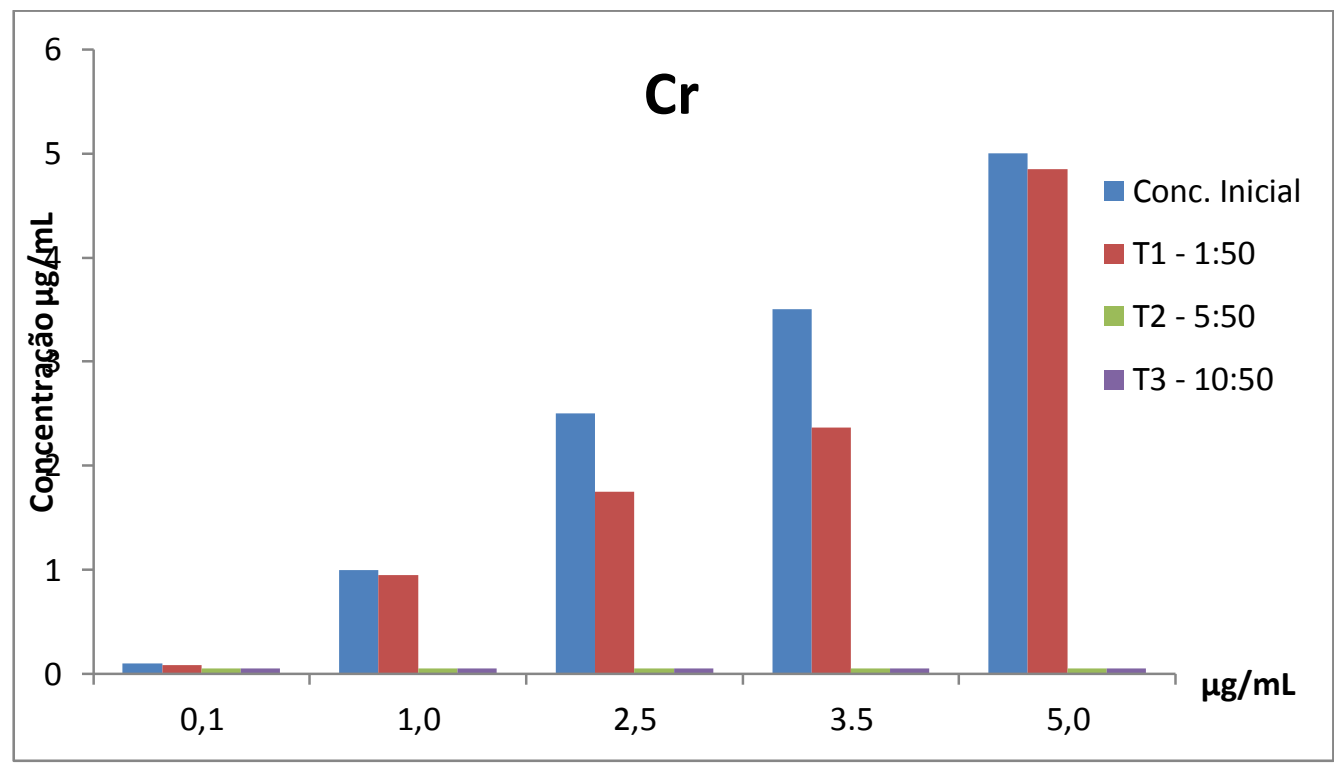

FIGURA 4.10 - Gráfico da concentração de íons de cromo na solução após tratamento a $25^{\circ} \mathrm{C}$ e 2 horas de agitação, sendo: $\mathrm{Ci}$ a concentração inicial, T1 proporção 1:50, T2 proporção 5:50 e T3 proporção 10:50. 


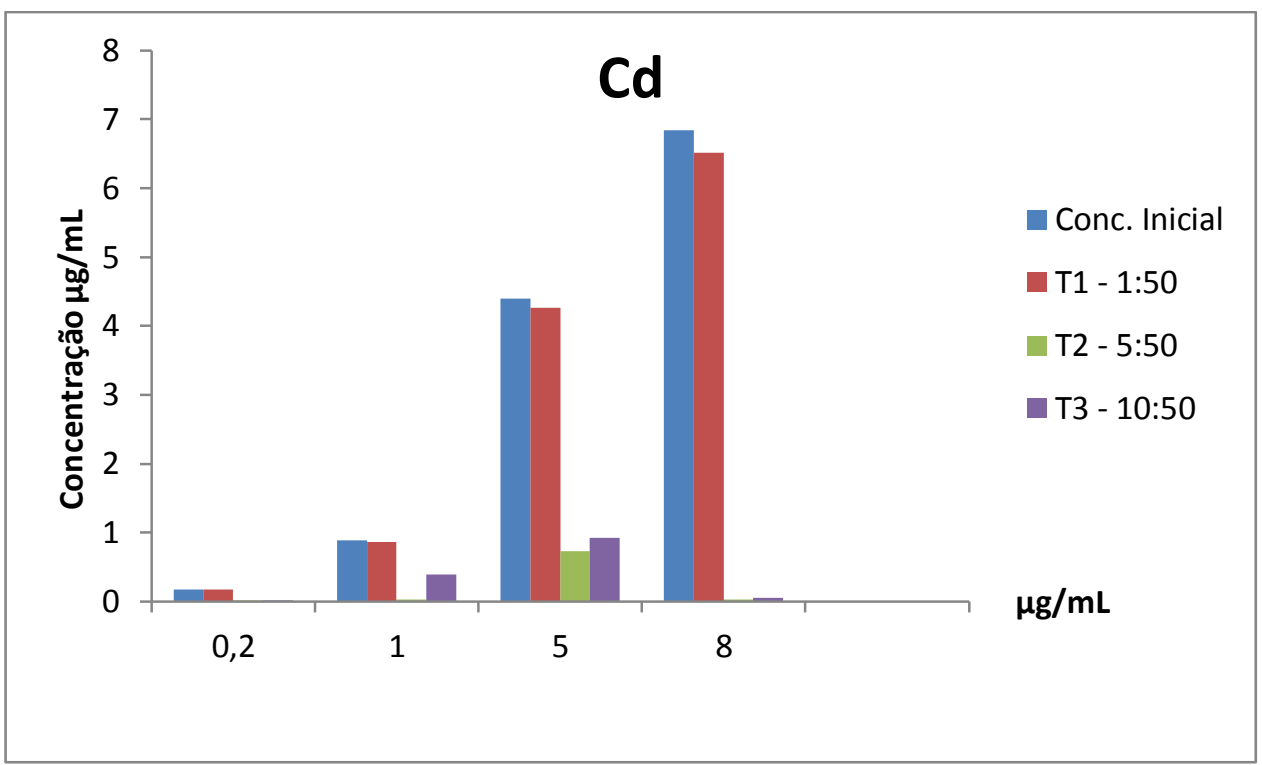

FIGURA 4.11 - Gráfico da concentração de íons de cádmio na solução após tratamento a $25^{\circ} \mathrm{C}$ e 2 horas de agitação, sendo: $\mathrm{Ci}$ a concentração inicial, T1 proporção 1:50, T2 proporção 5:50 e T3 proporção 10:50.

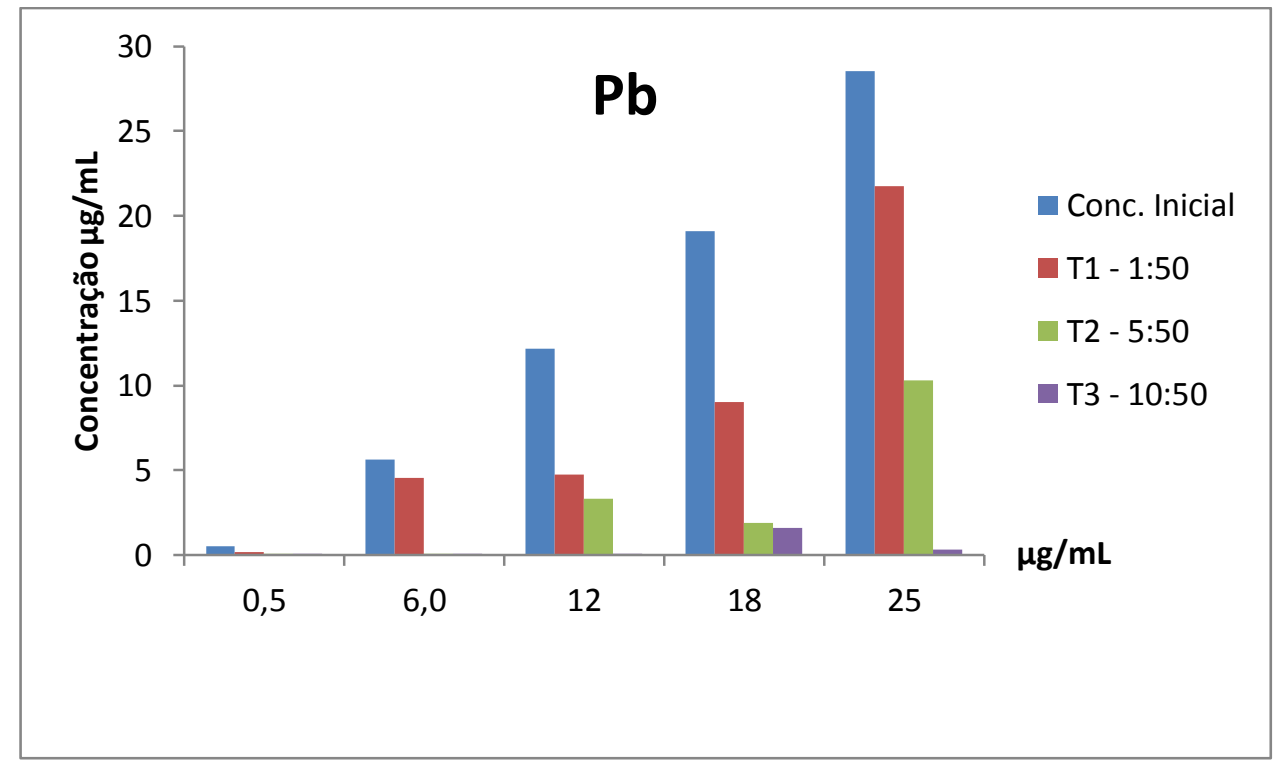

FIGURA 4.12 - Gráfico da concentração de íons de chumbo na solução após tratamento a $25^{\circ} \mathrm{C}$ e 2 horas de agitação, sendo: Ci a concentração inicial, T1 proporção 1:50, T2 proporção 5:50 e T3 proporção 10:50.

Comparando-se os resultados obtidos mostrados nos gráficos, pode-se avaliar que a adsorção é um processo que depende relativamente da proporção argila:solução, a melhor capacidade de adsorção observada para os íons $\mathrm{Cd}$ (II) e $\mathrm{Cr}$ (III) foi para a proporção de 5:50. O íon Cd (II) apresentou uma variação de $0,4 \%\left(8,0\right.$ mg. $\left.\mathrm{L}^{-1}\right)$ a $16,5 \%$ 
(5,0 mg. $\left.\mathrm{L}^{-1}\right)$ da concentração de íons, inicialmente presente na solução, após o tratamento (T2) e o Cr (III) uma variação de $1 \%\left(5,0 \mathrm{mg} . \mathrm{L}^{-1}\right)$ a $50 \%\left(0,1 \mathrm{mg} . \mathrm{L}^{-1}\right)(\mathrm{T} 2)$.

Para os íons Cu (II), Ni (II), Pb (II) e Zn (II), a melhor proporção foi de 10:50. Nesta condição o íon $\mathrm{Cu}(\mathrm{II})$ apresentou uma variação de 1,9\% (25 mg. $\left.\mathrm{L}^{-1}\right)$ a 52,5\% (1,0 $\left.\mathrm{mg} . \mathrm{L}^{-1}\right)$ da concentração de íons, inicialmente presente na solução, após o tratamento (T3), o Ni (II) entre 2,5\% (100 mg. $\left.\mathrm{L}^{-1}\right)$ a 97\% (25 mg.L $\left.\mathrm{L}^{-1}\right)$, o Pb (II) uma variação de $0,2 \%\left(6,0 \mathrm{mg} . \mathrm{L}^{-1}\right)$ a $8,3 \%\left(18 \mathrm{mg} . \mathrm{L}^{-1}\right)$ e o $\mathrm{Zn}(\mathrm{II})$ variou de $2,7 \%\left(180 \mathrm{mg} . \mathrm{L}^{-1}\right)$ a $42,5 \%$ (65 mg. $\left.\mathrm{L}^{-1}\right)$.

\subsection{2 - EFEITO DO pH}

Para a análise do efeito do pH na capacidade de remoção dos íons metálicos, foi considerada a melhor condição no estudo da proporção de cada elemento, estabelecida no item anterior. As soluções tiveram os valores de $\mathrm{pH}$ ajustados para 1, 2, 4, 5 e 8.

Os resultados obtidos para os íons Cd (II), $\mathrm{Pb}$ (II), $\mathrm{Cr}$ (III), Cu (II), Ni (II) e Zn (II) estão apresentados nos gráficos das Figuras 4.13, 4.14, 4.15, 4.16, 4.17, 4.18, 4.19, 4.20, 4.21, 4.22, 4.23, 4.24, respectivamente, para duas concentrações distintas.

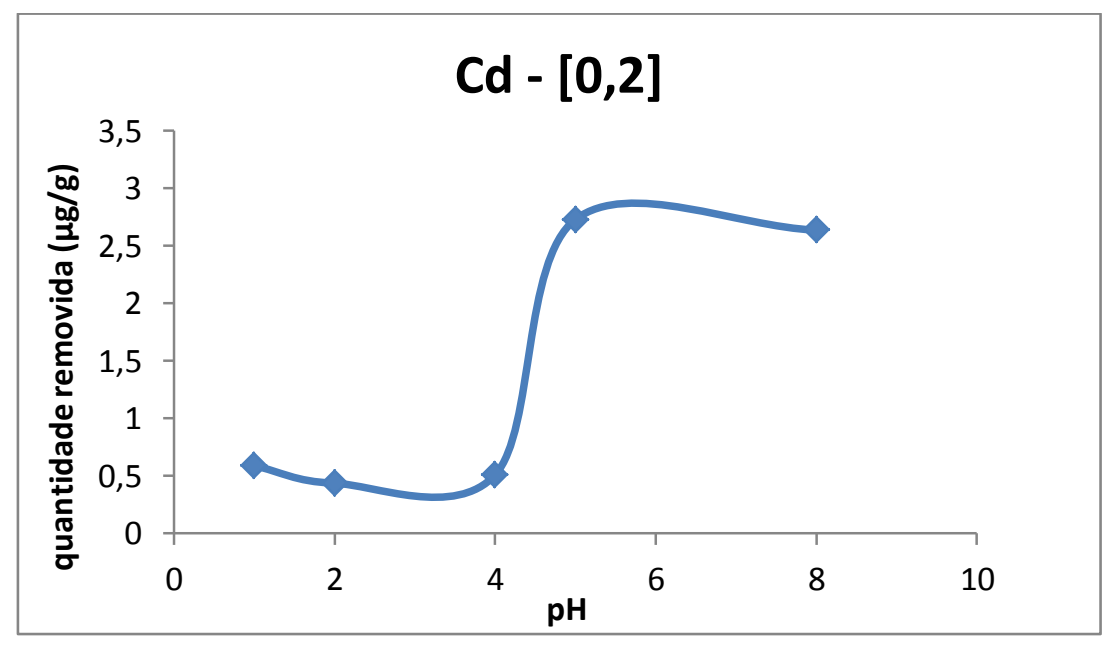

FIGURA 4.13 - Efeito do pH na adsorção do íon de cádmio $0,2 \mathrm{mg} \cdot \mathrm{L}^{-1}$. 


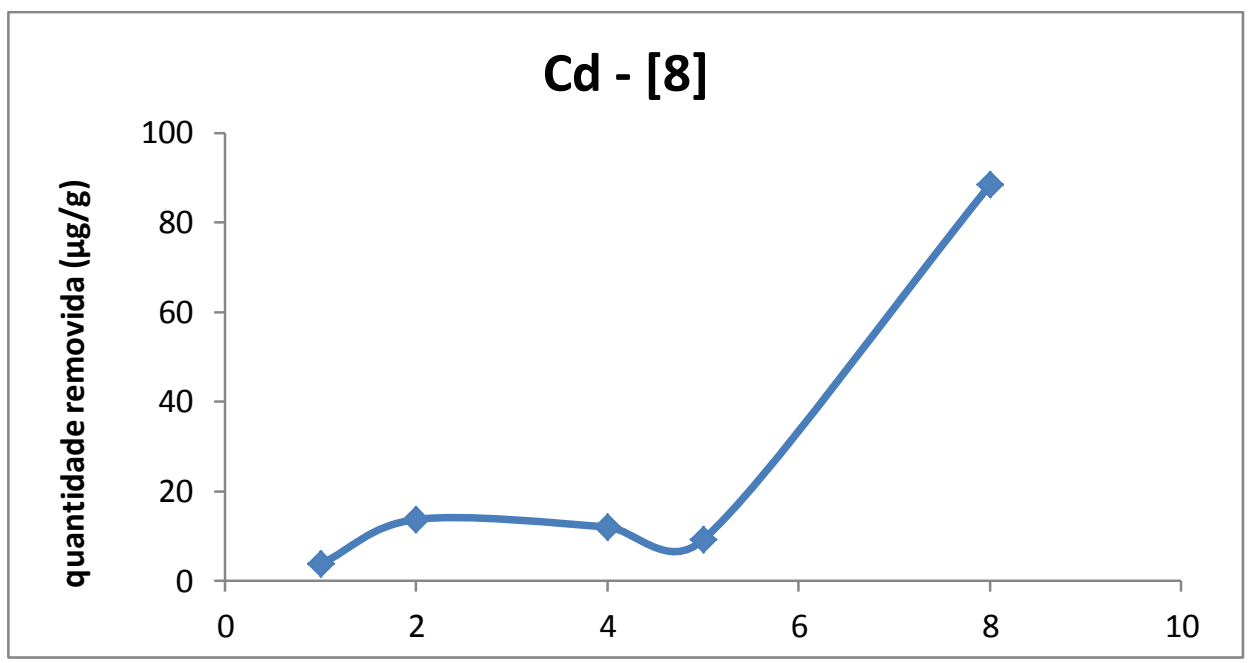

FIGURA 4.14 - Efeito do pH na adsorção do íon de cádmio $8 \mathrm{mg} \cdot \mathrm{L}^{-1}$.

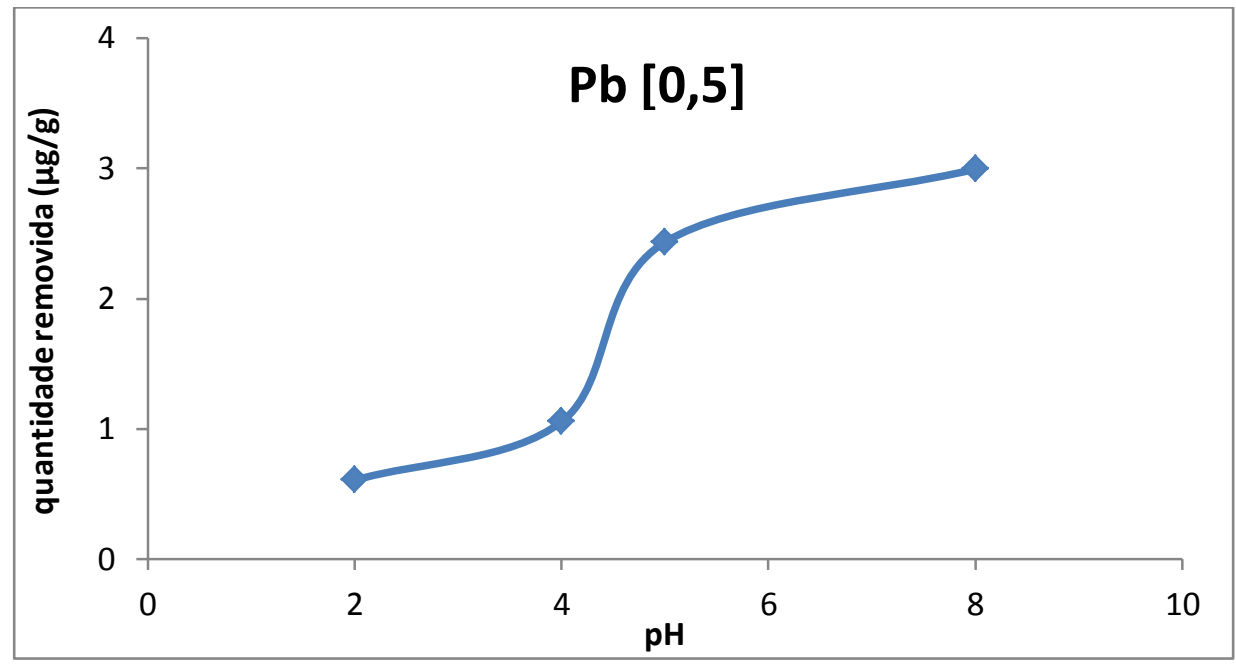

FIGURA 4.15 - Efeito do pH na adsorção do íon de chumbo $0,5 \mathrm{mg} \cdot \mathrm{L}^{-1}$.

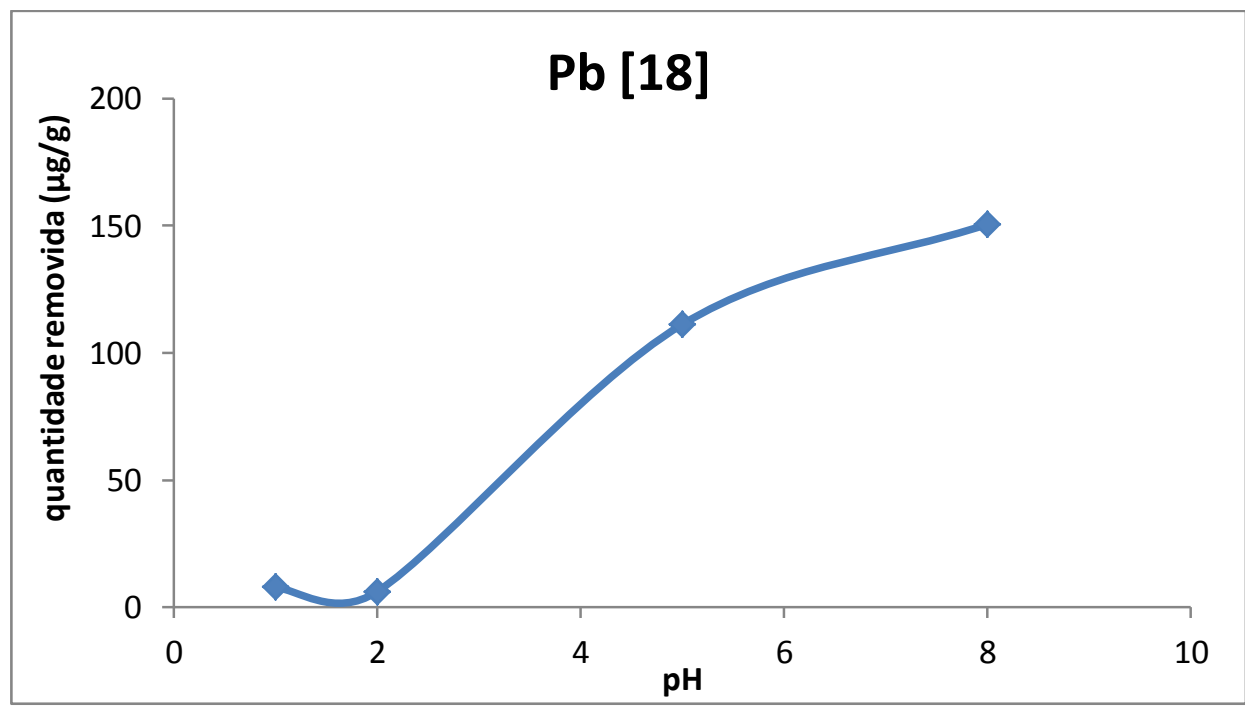

FIGURA 4.16 - Efeito do pH na adsorção do íon de chumbo $18 \mathrm{mg} . \mathrm{L}^{-1}$. 


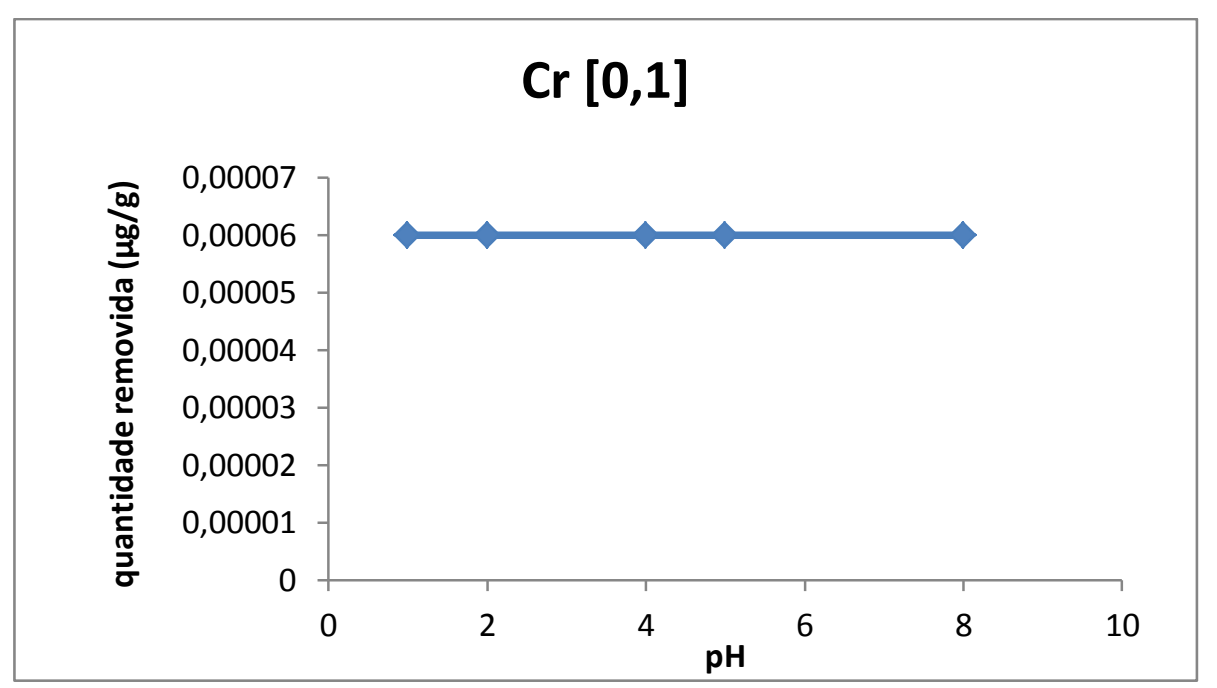

FIGURA 4.17 - Efeito do pH na adsorção do íon de cromo $0,1 \mathrm{mg} \cdot \mathrm{L}^{-1}$.

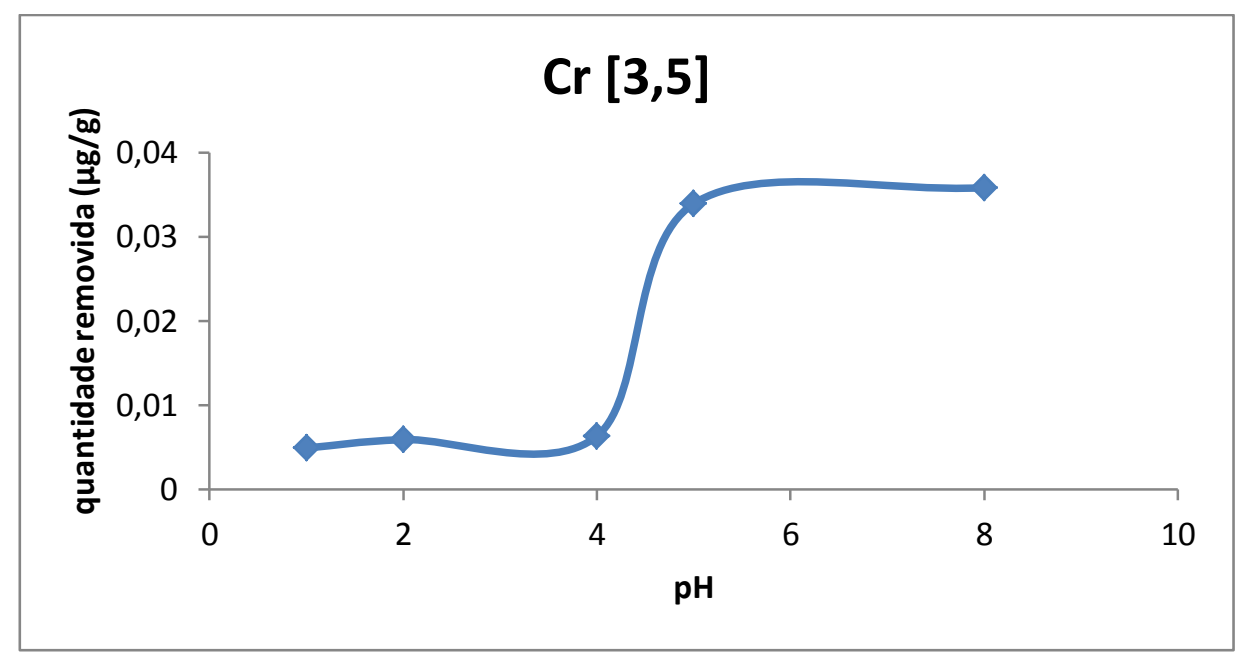

FIGURA 4.18 - Efeito do pH na adsorção do íon de cromo 3,5 mg. $\mathrm{L}^{-1}$.

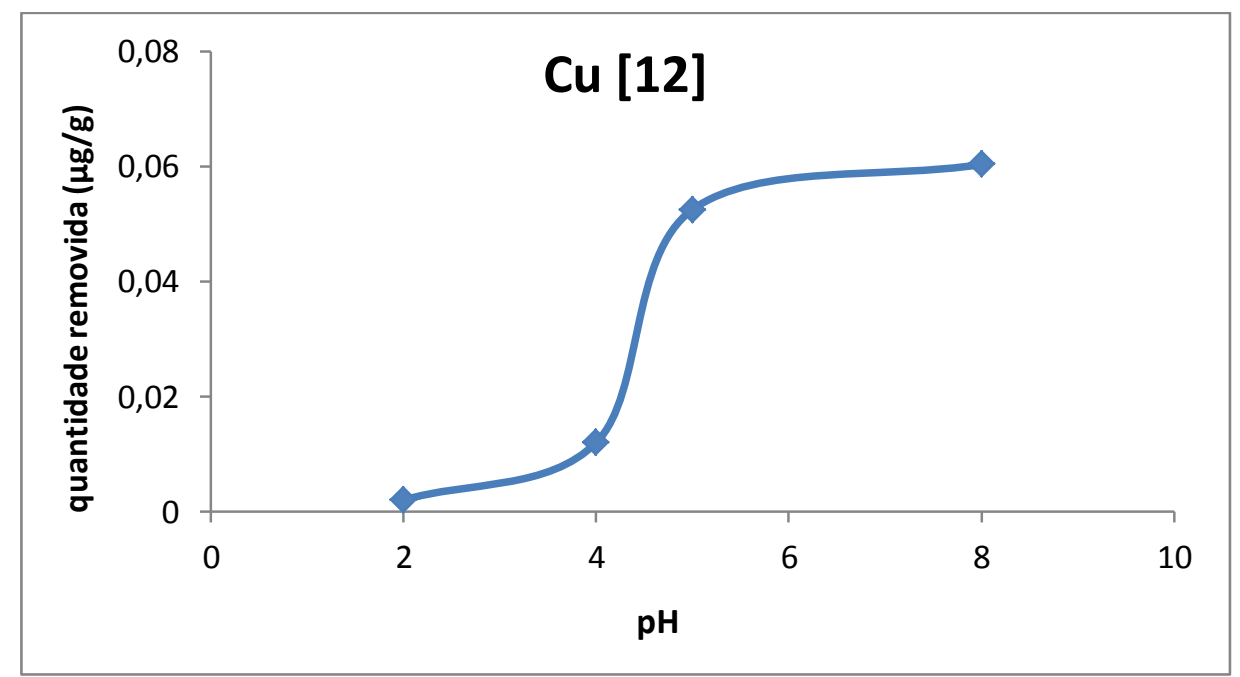

FIGURA 4.19 - Efeito do pH na adsorção do íon de cobre $12 \mathrm{mg} . \mathrm{L}^{-1}$. 


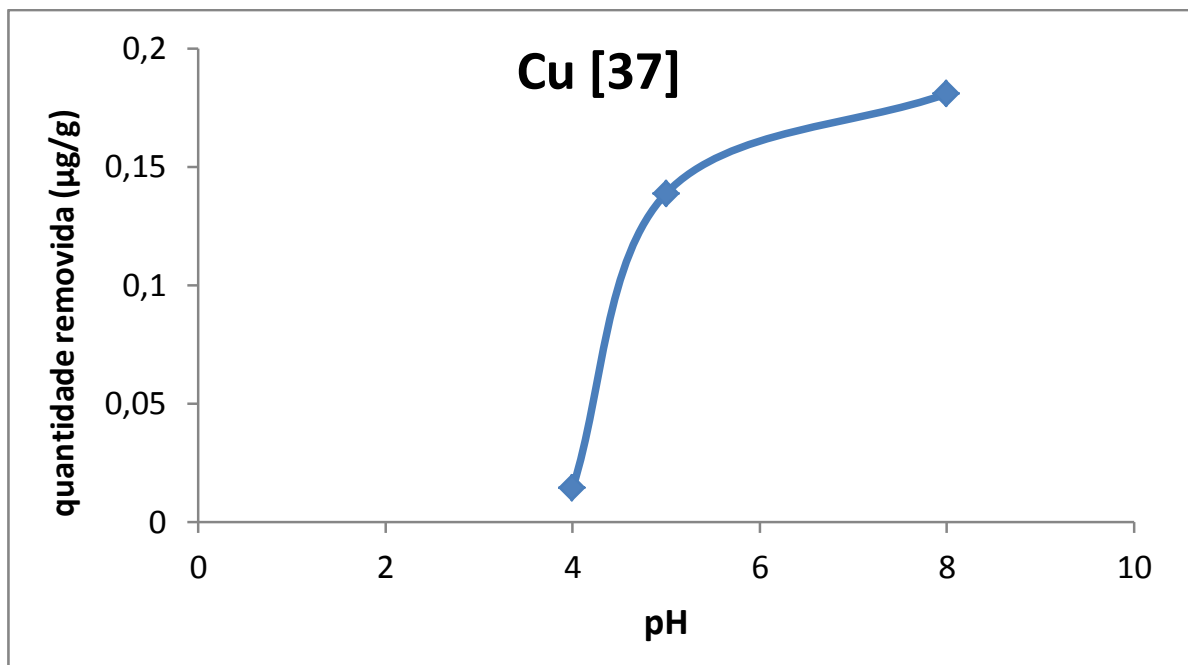

FIGURA 4.20 - Efeito do pH na adsorção do íon de cromo $37 \mathrm{mg} \cdot \mathrm{L}^{-1}$.

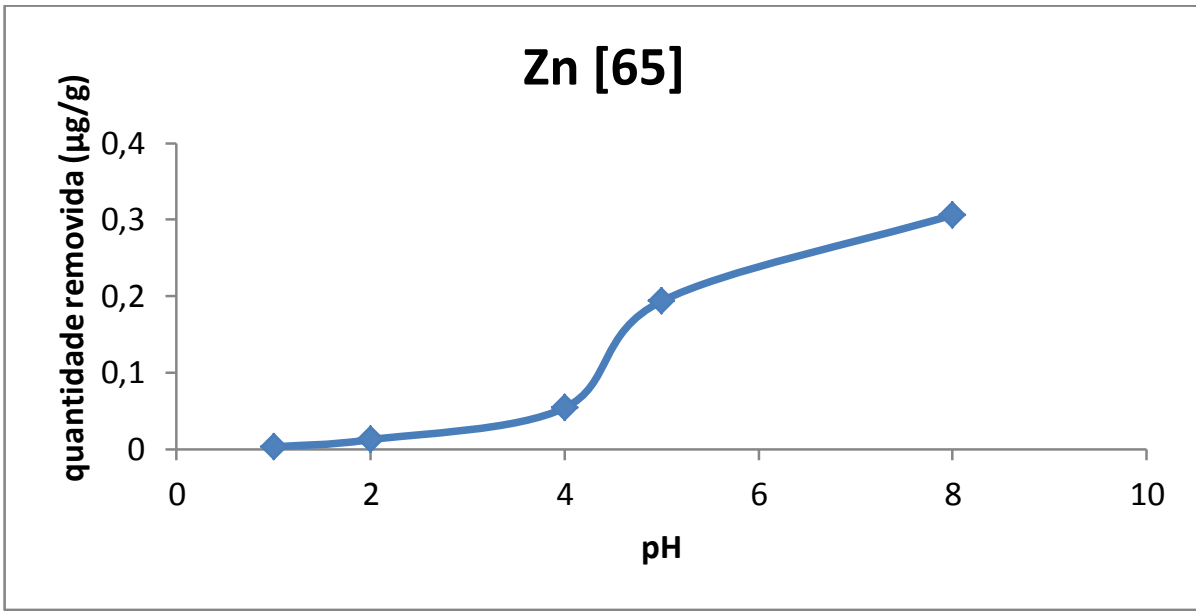

FIGURA 4.21 - Efeito do pH na adsorção do íon de zinco $65 \mathrm{mg} . \mathrm{L}^{-1}$.

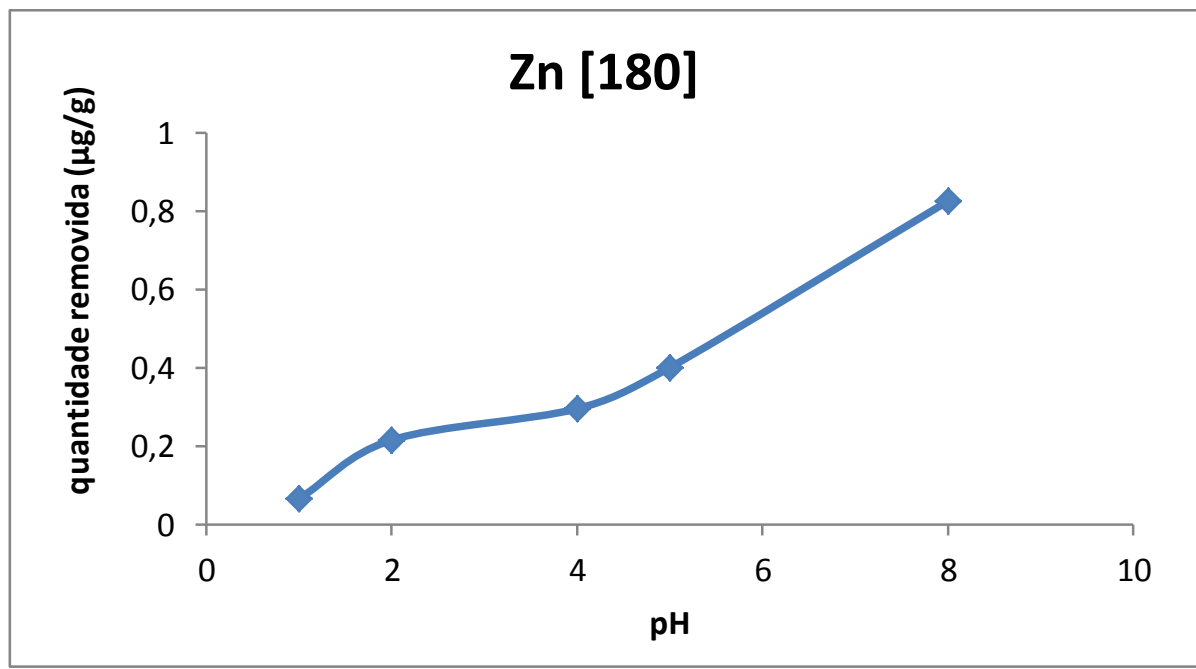

FIGURA 4.22 - Efeito do pH na adsorção do íon de zinco $180 \mathrm{mg} \cdot \mathrm{L}^{-1}$. 


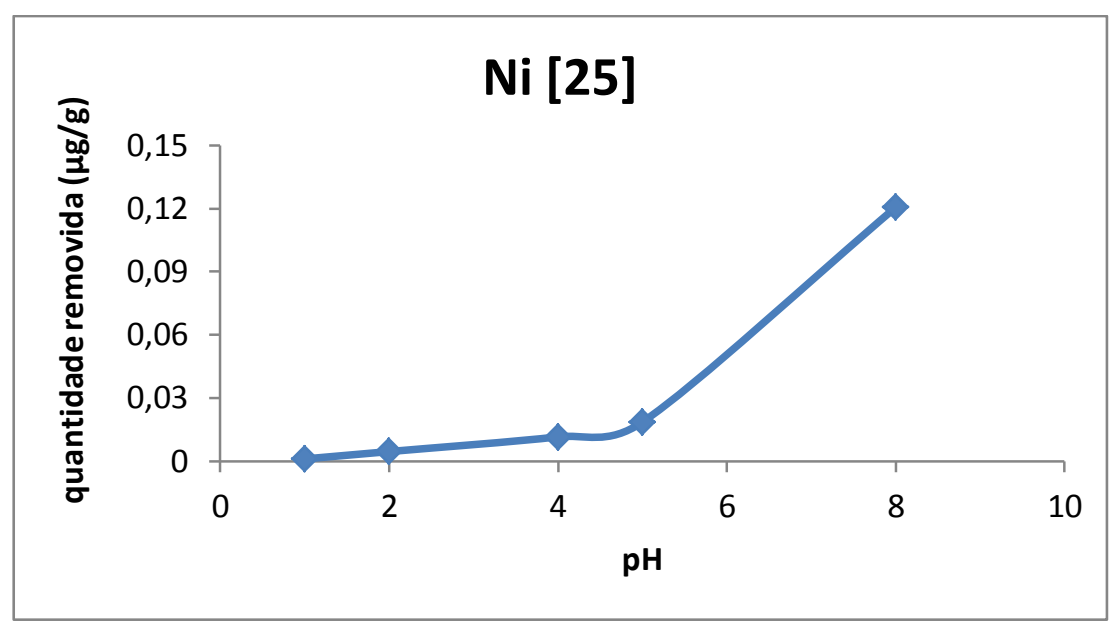

FIGURA 4.23 - Efeito do pH na adsorção do íon de níquel $25 \mathrm{mg} . \mathrm{L}^{-1}$.

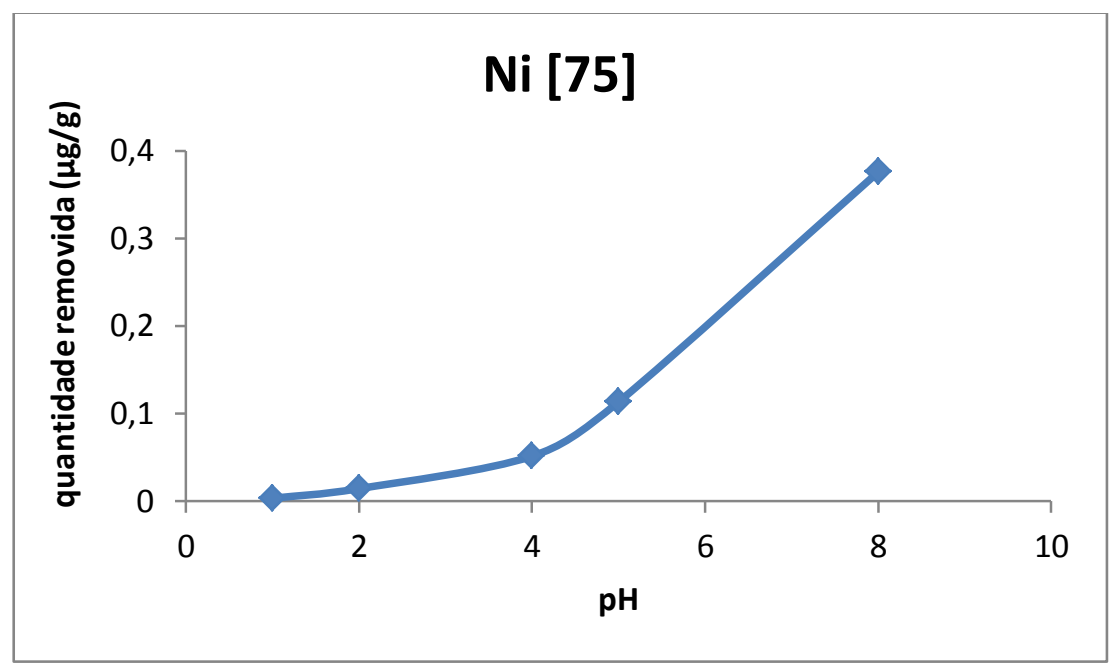

FIGURA 4.24 - Efeito do pH na adsorção do íon de níquel $75 \mathrm{mg} . \mathrm{L}^{-1}$.

Os resultados mostrados nos gráficos apresentados acima, indicam que o $\mathrm{pH}$ é um parâmetro que tem influência na remoção de íons, afetando a carga superficial dos adsorventes. Em pH ácido, o mecanismo de adsorção predominante é eletrostático, já em pH básico, além do mecanismo eletrostático, acredita-se que também ocorra adsorção por ligação de hidrogênio que envolve os sítios Si-OH e Al-OH (RODRIGUES, 2009).

A concentração encontrada no estudo do efeito do $\mathrm{pH}$ para íon cromo $0,1 \mathrm{mg} \cdot \mathrm{L}^{-1}$ (Figura 4.17) ficou abaixo do limite de detecção do equipamento (espectrômetro de emissão óptica com plasma indutivamente acoplado). 
Verificou-se que a máxima adsorção do $\mathrm{Cd}$ com concentração $0,2 \mathrm{mg}$. $\mathrm{L}^{-1}$ ocorreu em pH 5 enquanto que na concentração $8 \mathrm{mg} \cdot \mathrm{L}^{-1}$, a máxima adsorção deste íon ocorreu em pH 8. Para os demais íons, Pb 0,5 mg.L $\mathrm{L}^{-1}, \mathrm{~Pb} 18 \mathrm{mg} \cdot \mathrm{L}^{-1}, \mathrm{Cr}$ 0,1 mg.L $\mathrm{L}^{-1}, \mathrm{Cr}$ 3,5 mg.L ${ }^{-1}$, Cu 12 mg.L $L^{-1}$, Cu 37 mg.L ${ }^{-1}$, Zn 65 mg.L ${ }^{-1}$, Zn 180 mg.L. ${ }^{-1}$, Ni 25 mg.L ${ }^{-1}$, Ni $75 \mathrm{mg} . \mathrm{L}^{-1}$, a máxima adsorção ocorreu em pH 8.

\subsection{3 - EFEITO DO TEMPO DE CONTATO}

Para a análise do efeito do tempo de contato na remoção dos íons metálicos, duas soluções de cada elemento foram escolhidas, consideraram as melhores condições de proporção e pH de cada elemento, estabelecidas nos itens anteriores. As soluções foram tratadas com caulinita por diferentes intervalos de tempo, variando de 5, 10, 20, 30, 60 e 120 minutos.

As curvas de adsorção dos íons Cd (II), Pb (II), Cr (III), Cu (II), Zn (II) e Ni (II), em função do tempo de contato estão representados nas figuras Figuras 4.25, 4.26, 4.27, $4.28,4.29,4.30,4.31,4.32,4.33,4.34,4.35,4.36$, respectivamente.

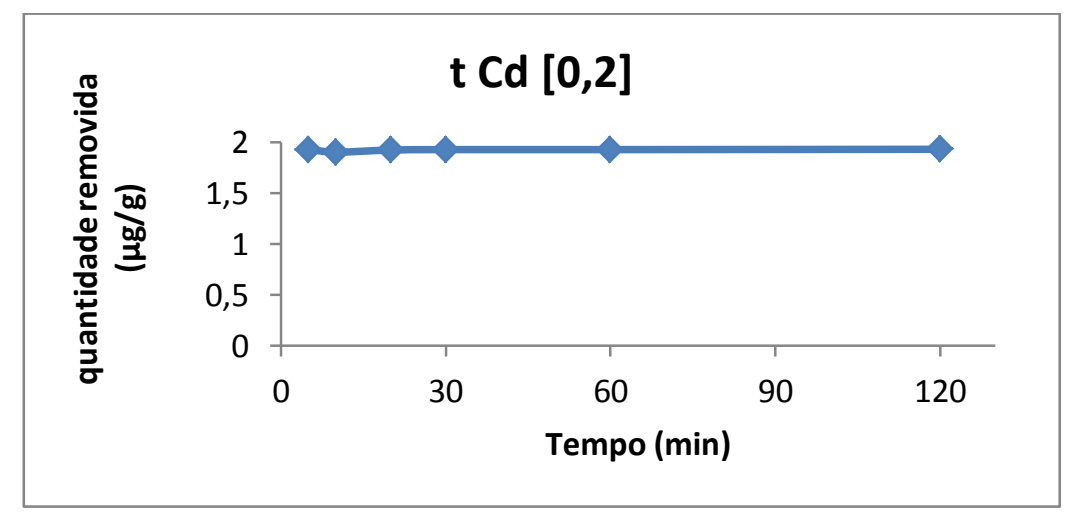

FIGURA 4.25 - Gráfico do efeito do tempo de contato na adsorção do cádmio $0,2 \mathrm{mg} \cdot \mathrm{L}^{-1}$, a $25^{\circ} \mathrm{C}$, na proporção 5:50 e pH = 5. 


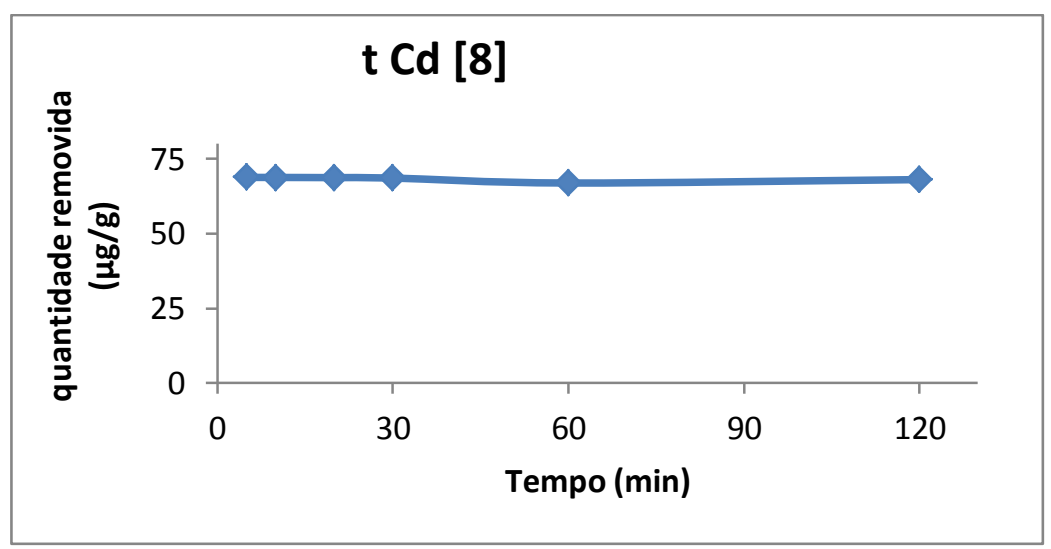

FIGURA 4.26 - Gráfico do efeito do tempo de contato na adsorção do cádmio 8 mg.L ${ }^{1}$, a $25^{\circ} \mathrm{C}$, na proporção 5:50 e $\mathrm{pH}=8$.

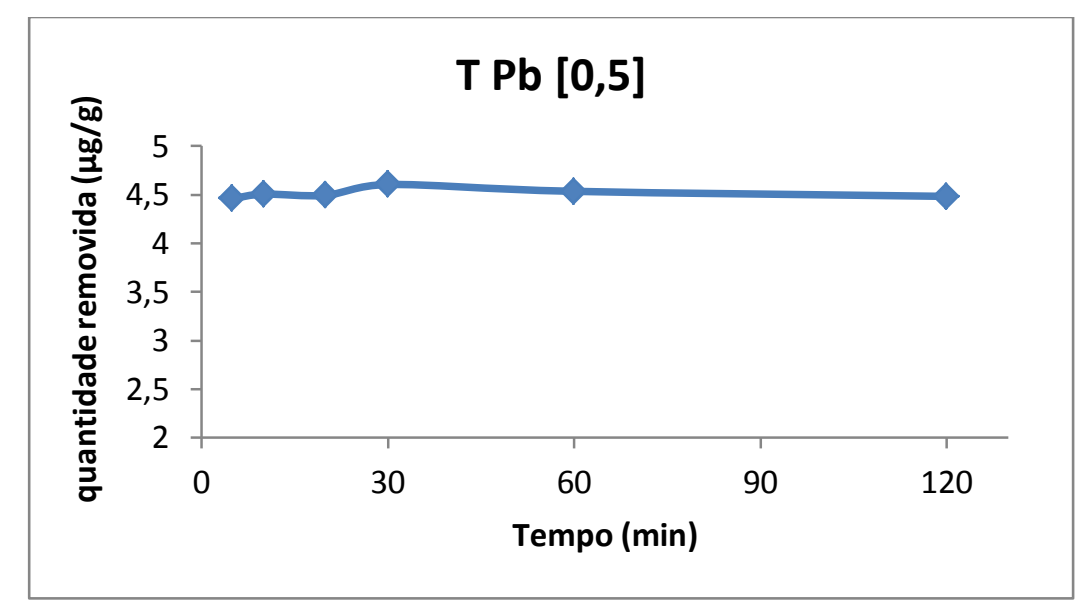

FIGURA 4.27 - Gráfico do efeito do tempo de contato na adsorção do chumbo $0,5 \mathrm{mg} . \mathrm{L}^{-1}$, a $25^{\circ} \mathrm{C}$, na proporção $10: 50$ e $\mathrm{pH}=8$.

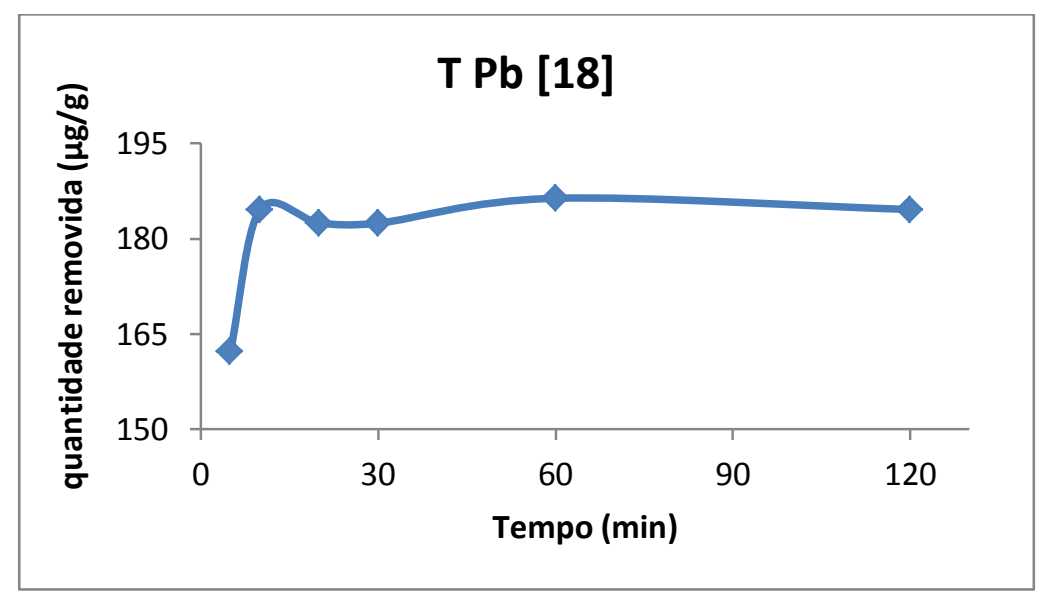

FIGURA 4.28 - Gráfico do efeito do tempo de contato na adsorção do chumbo $18 \mathrm{mg} . \mathrm{L}^{-1}$ a $25^{\circ} \mathrm{C}$, na proporção $10: 50$ e $\mathrm{pH}=8$. 


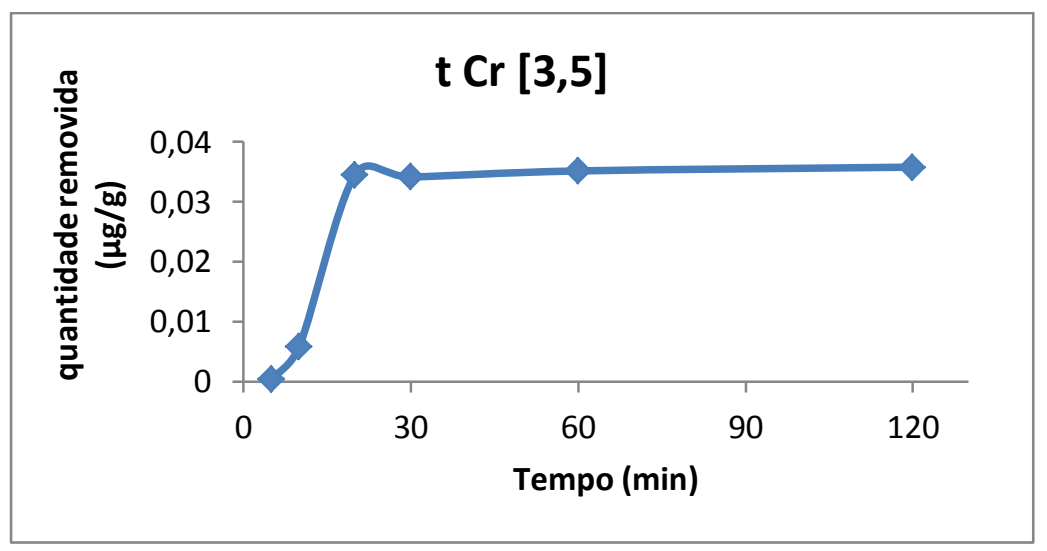

FIGURA 4.29 - Gráfico do efeito do tempo de contato na adsorção do cromo 3,5 mg. $\mathrm{L}^{-1}$, a $25^{\circ} \mathrm{C}$, na proporção 5:50 e pH = 8.

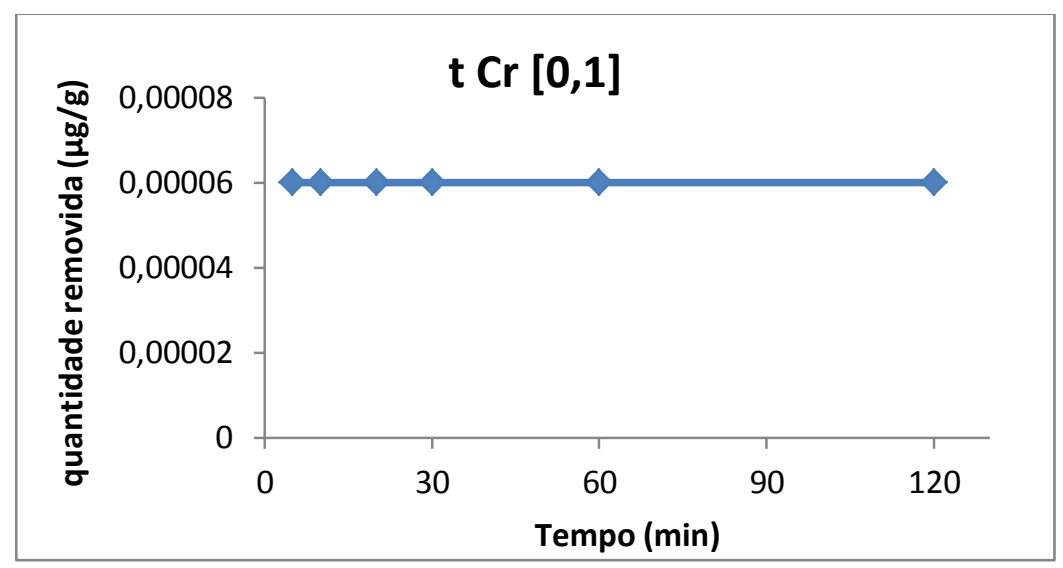

FIGURA 4.30 - Gráfico do efeito do tempo de contato na adsorção do cromo $0,1 \mathrm{mg} \cdot \mathrm{L}^{-1}$, a $25^{\circ} \mathrm{C}$, na proporção 5:50 e $\mathrm{pH}=8$.

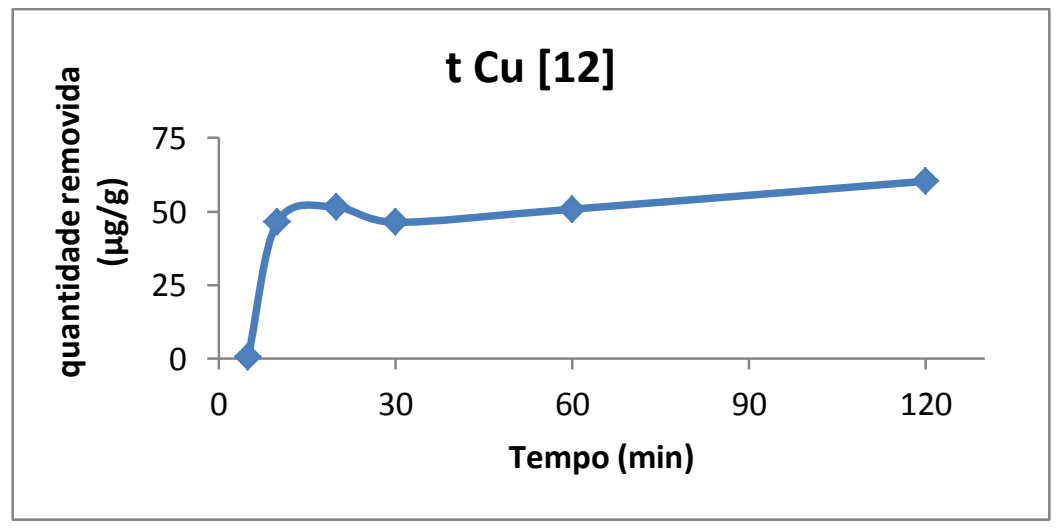

FIGURA 4.31 - Gráfico do efeito do tempo de contato na adsorção do cobre 12 $\mathrm{mg} \cdot \mathrm{L}^{-1}$, a $25^{\circ} \mathrm{C}$, na proporção $10: 50$ e $\mathrm{pH}=8$. 


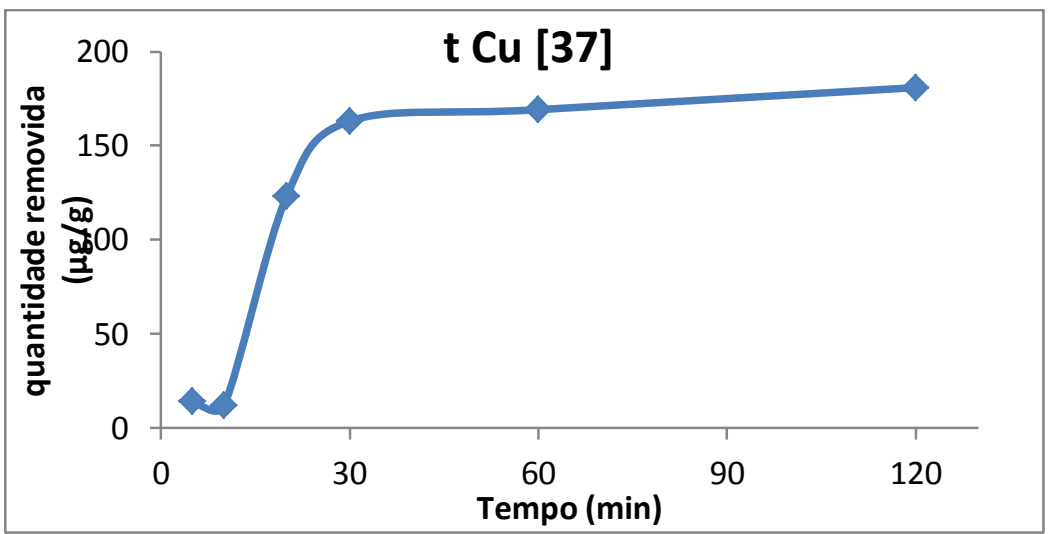

FIGURA 4.32 - Gráfico do efeito do tempo de contato na adsorção do cobre $37 \mathrm{mg} . \mathrm{L}^{-1}$, a $25^{\circ} \mathrm{C}$, na proporção $10: 50$ e $\mathrm{pH}=8$.

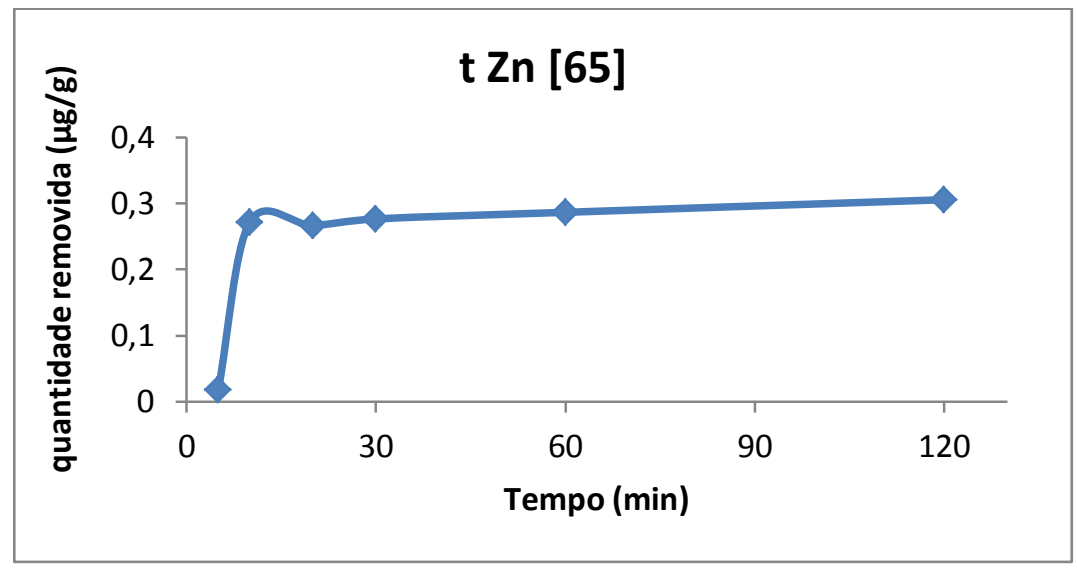

FIGURA 4.33 - Gráfico do efeito do tempo de contato na adsorção do zinco $65 \mathrm{mg} . \mathrm{L}^{-1}$, a $25^{\circ} \mathrm{C}$, na proporção $10: 50$ e $\mathrm{pH}=8$.

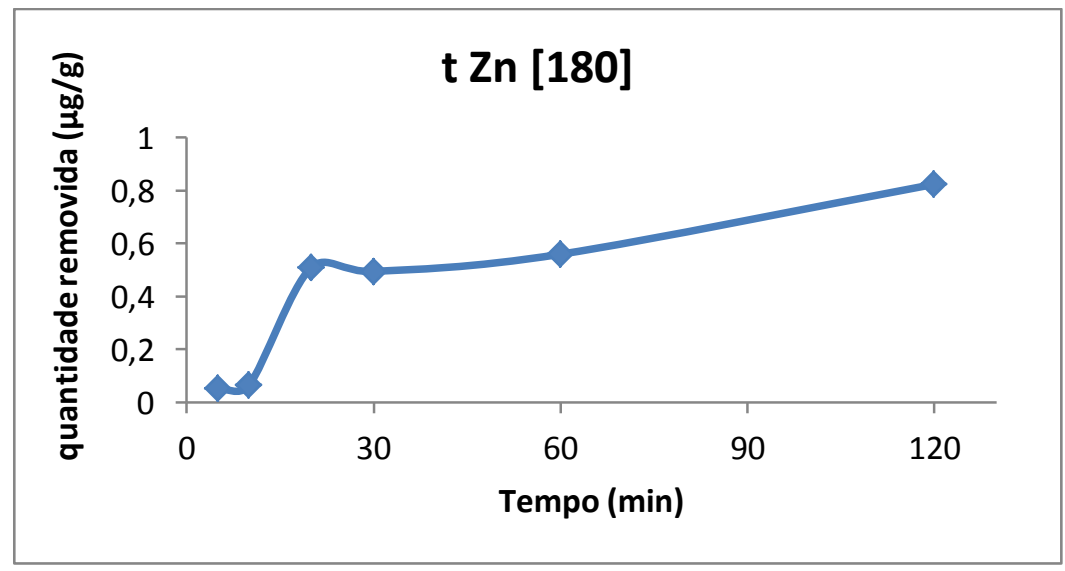

FIGURA 4.34-Gráfico do efeito do tempo de contato na adsorção do zinco 180 mg.L ${ }^{-1}$, a $25^{\circ} \mathrm{C}$, na proporção $10: 50$ e $\mathrm{pH}=8$. 


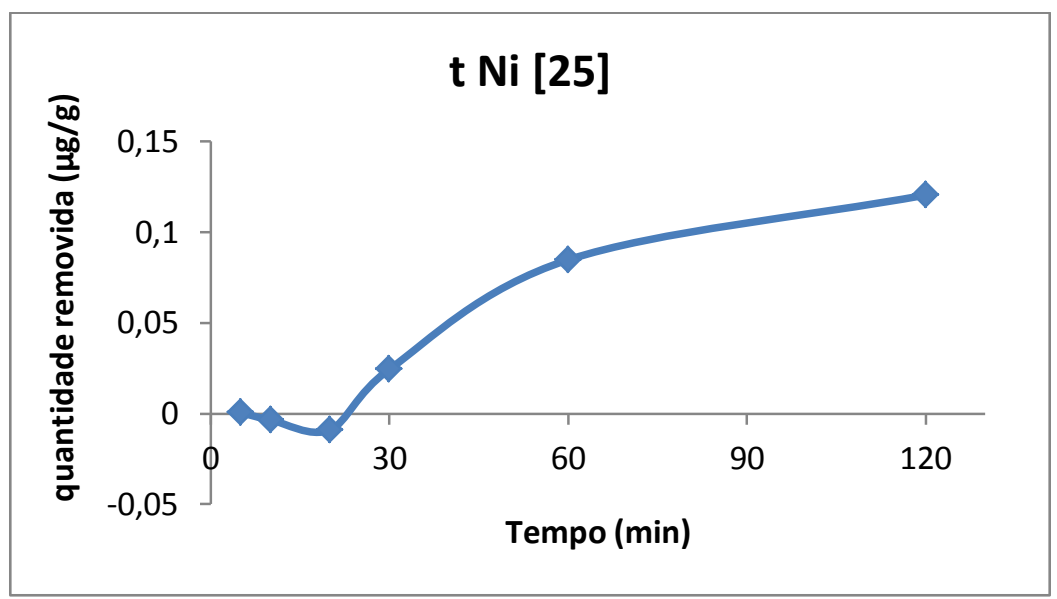

FIGURA 4.35 - Gráfico do efeito do tempo de contato na adsorção do níquel $25 \mathrm{mg} . \mathrm{L}^{-1}$, a $25^{\circ} \mathrm{C}$, na proporção $10: 50$ e $\mathrm{pH}=8$.

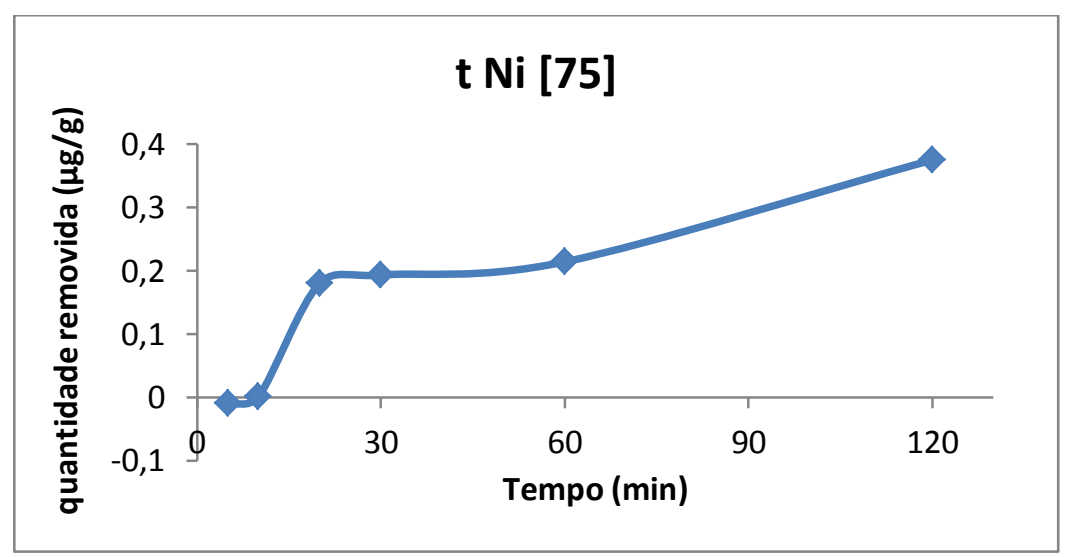

FIGURA 4.36 - Gráfico do efeito do tempo de contato na adsorção do níquel $75 \mathrm{mg} . \mathrm{L}^{-1}$, a $25^{\circ} \mathrm{C}$, na proporção $10: 50$ e $\mathrm{pH}=8$.

O equilíbrio de adsorção foi atingido para todos os íons, exceto para o Ni. Para o Cd 0,2 e 8,0 mg.L $\mathrm{L}^{-1}$, Pb 0,5 mg. $\mathrm{L}^{-1}$ e Cr 0,1 mg.L $\mathrm{L}^{-1}$ o equilíbrio foi atingido a partir dos 5 minutos de contato, para o $\mathrm{Pb} 18 \mathrm{mg} . \mathrm{L}^{-1}$ a partir de 10 minutos. Aos 20 minutos o equilíbrio de adsorção foi atingido para os íons Cr 3,5 mg.L ${ }^{-1}$, Zn 65 mg.L $\mathrm{L}^{-1}$ e Zn 180 mg.L. ${ }^{-1}$. Os íons de Cu $12 \mathrm{mg} . \mathrm{L}^{-1}$ e $\mathrm{Cu} 37 \mathrm{mg} . \mathrm{L}^{-1}$ atingiram o equilíbrio somente após 30 minutos de contato entre a solução e o adsorvente. Na Tabela 4.6, estão representados os tempos necessários para cada espécie atingir o equilíbrio de adsorção. 
TABELA 4.6 - Íons com os respectivos tempos de equilíbrio.

\begin{tabular}{cc}
\hline Íon $\left(\mathrm{mg}^{-L^{-1}}\right)$ & Tempo para Equilíbrio (minutos) \\
\hline $\mathrm{Cd} 0,5$ & 5 \\
$\mathrm{Cd} 8,0$ & 5 \\
$\mathrm{~Pb} 0,5$ & 5 \\
$\mathrm{~Pb} 18$ & 10 \\
$\mathrm{Cr} 0,1$ & 5 \\
$\mathrm{Cr} 3,5$ & 20 \\
$\mathrm{Zn} 65$ & 20 \\
$\mathrm{Zn} 180$ & 20 \\
$\mathrm{Cu} 12$ & 30 \\
$\mathrm{Cu} 37$ & 30 \\
$\mathrm{Ni} 25$ & Equilíbrio não atingido \\
$\mathrm{Ni} 75$ & Equilíbrio não atingido \\
\hline
\end{tabular}

\subsection{4 - ISOTERMAS DE LANGMUIR, FREUNDLICH E DUBININ- RADUSHKEVICH (D-R)}

Nas Figuras 4.37, 4.38, 4.39, 4.40, 4.41 e 4.42, observa-se o comportamento das isotermas de Langmuir, Freundlich e Dubinin-Radushkevich (D-R), obtidas para os íons estudados nas melhores condições de proporção, $\mathrm{pH}$ e tempo de contato, para os íons $\mathrm{Cd}$ (II), $\mathrm{Pb}$ (II), $\mathrm{Cr}$ (III), $\mathrm{Cu}$ (II), Zn (II) e $\mathrm{Ni}$ (II), respectivamente. 

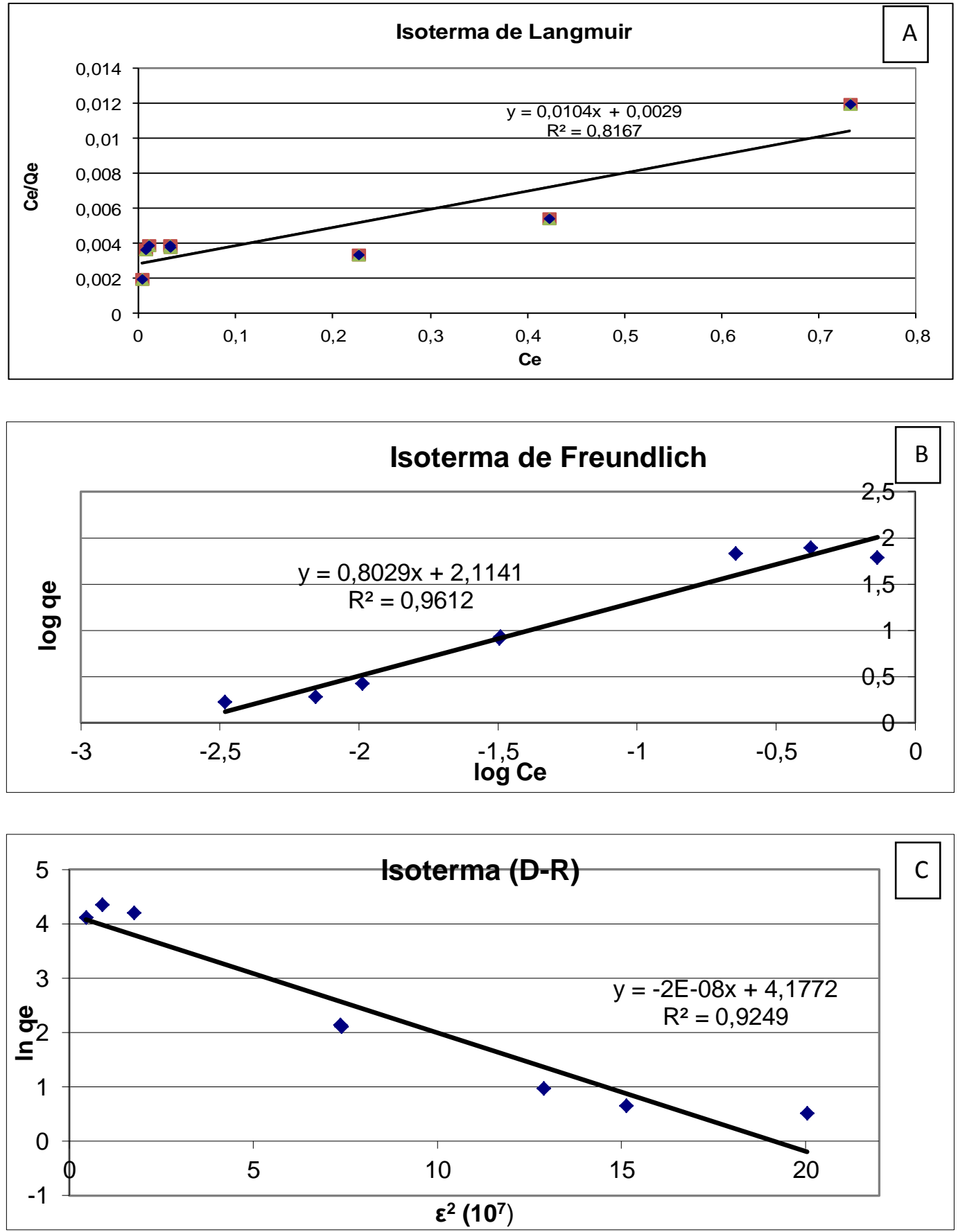

FIGURA 4.37 - Isotermas de Langmuir (A), Freundlich (B) e Dubinin-Radushkevich (C), para o íon cádmio. 

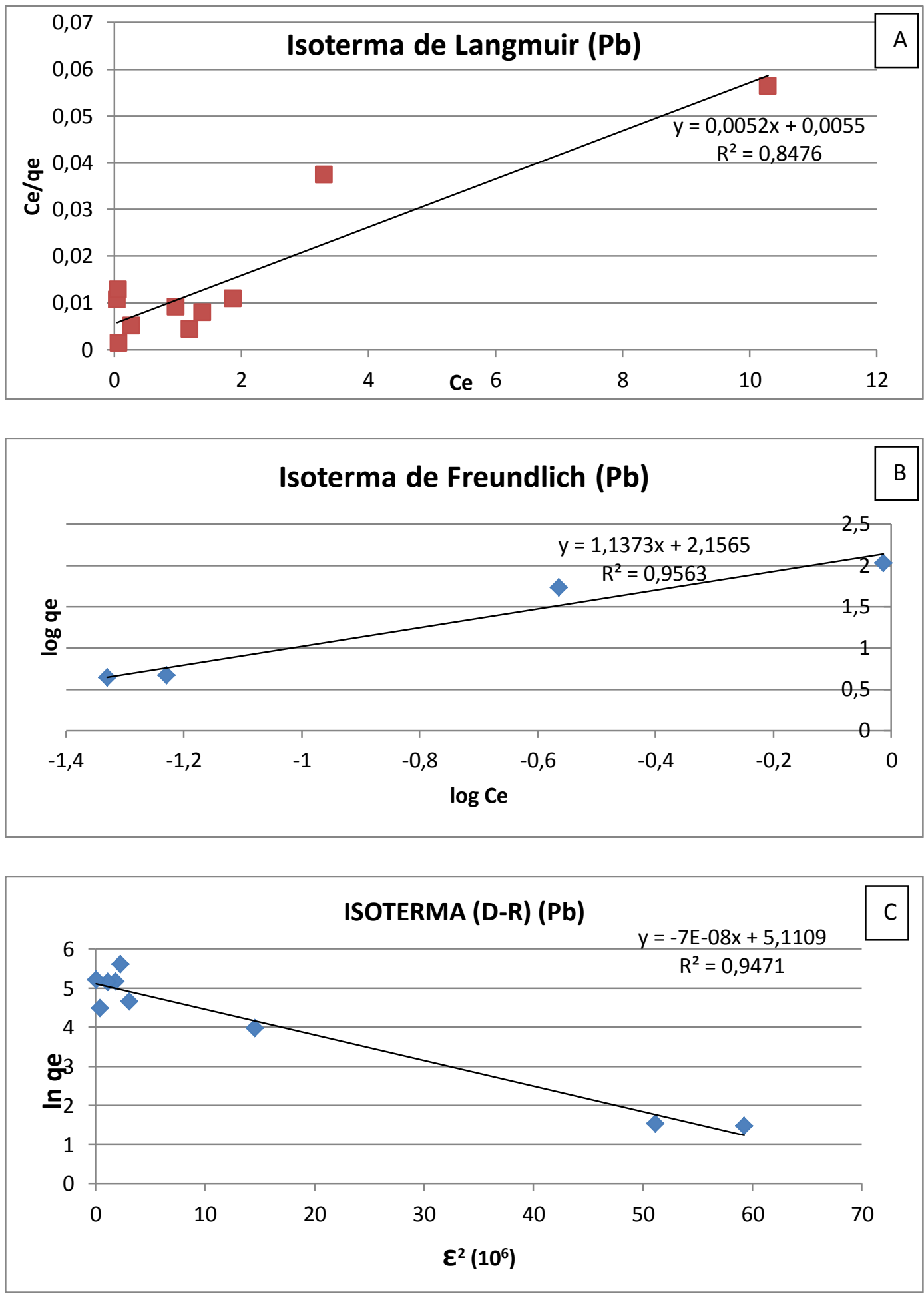

FIGURA 4.38 - Isotermas de Langmuir (A), Freundlich (B) e Dubinin-Radushkevich (C), para o íon chumbo. 

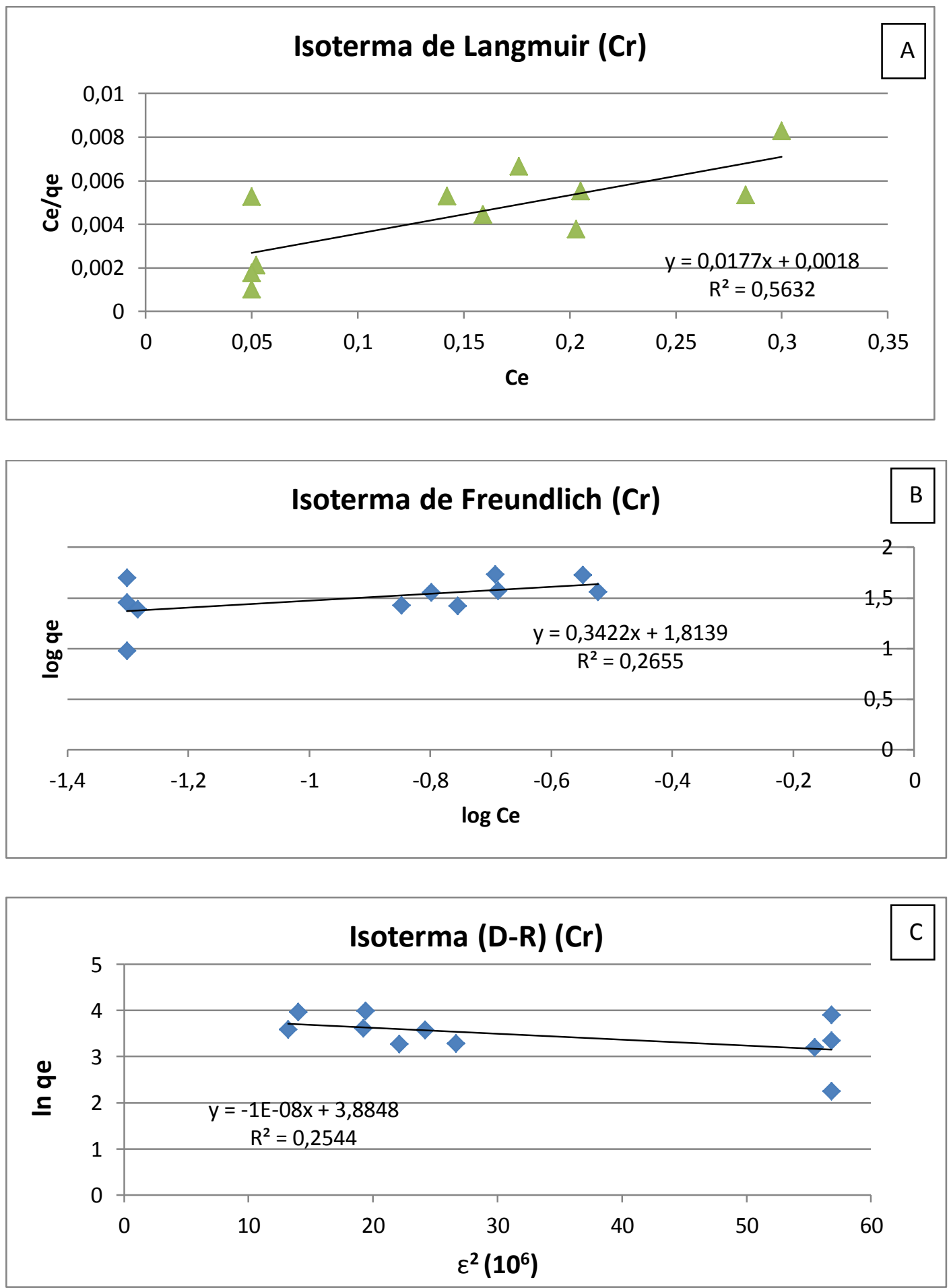

FIGURA 4.39 - Isotermas de Langmuir (A), Freundlich (B) e Dubinin-Radushkevich (C), para o íon cromo. 

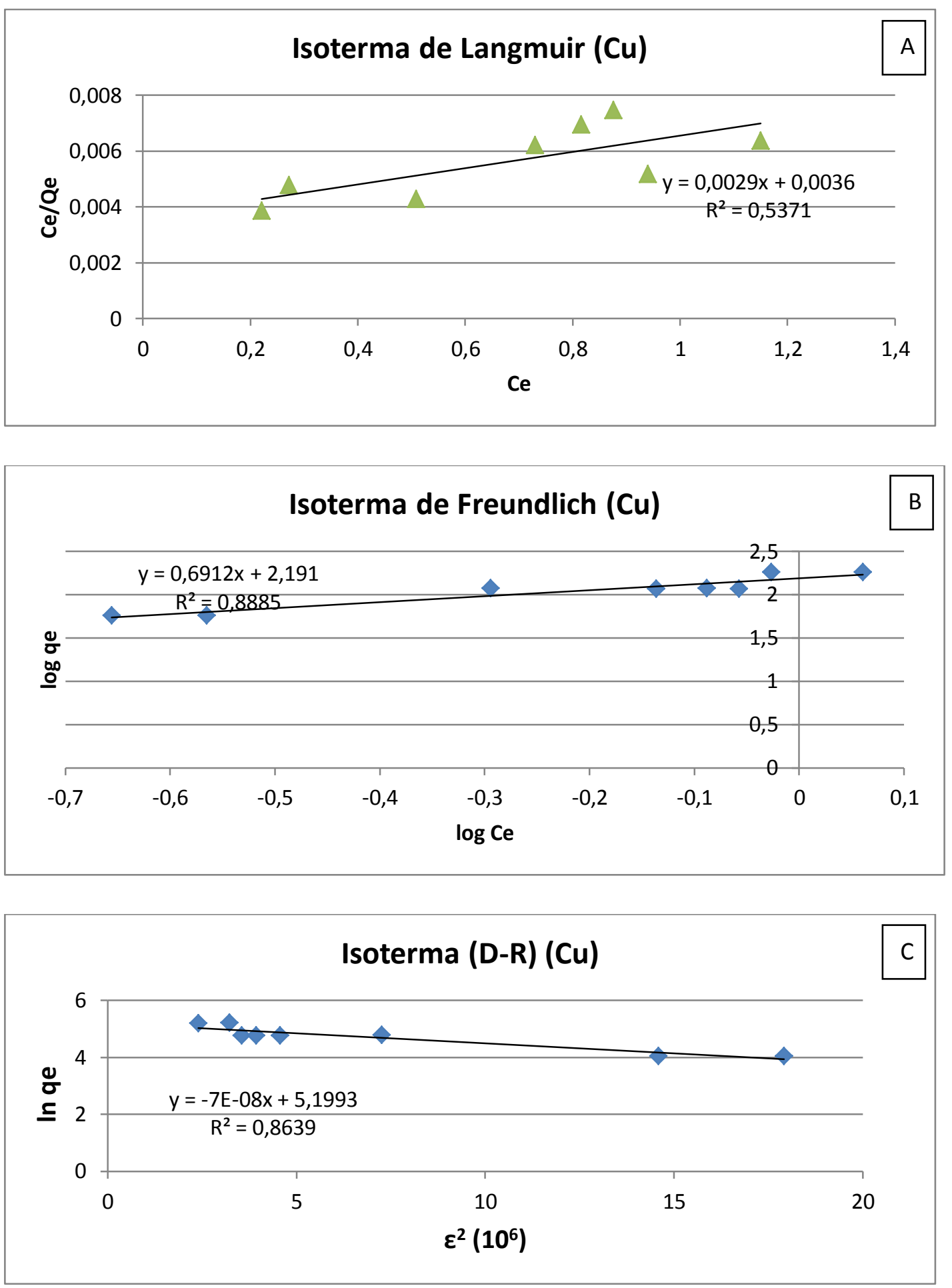

FIGURA 4.40 - Isotermas de Langmuir (A), Freundlich (B) e Dubinin-Radushkevich (C), para o íon cobre. 

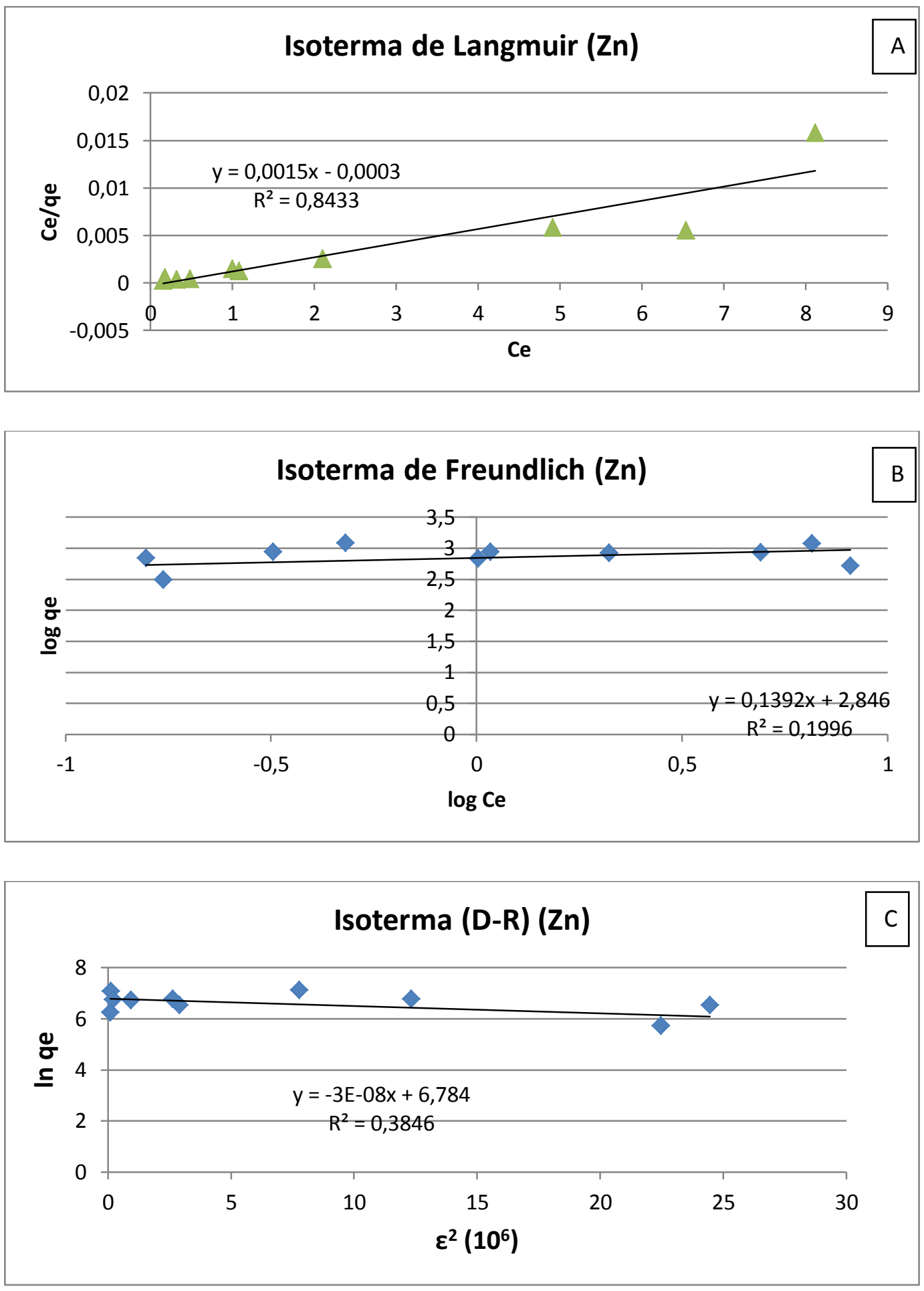

FIGURA 4.41 - Isotermas de Langmuir (A), Freundlich (B) e Dubinin-Radushkevich (C), para o íon zinco. 

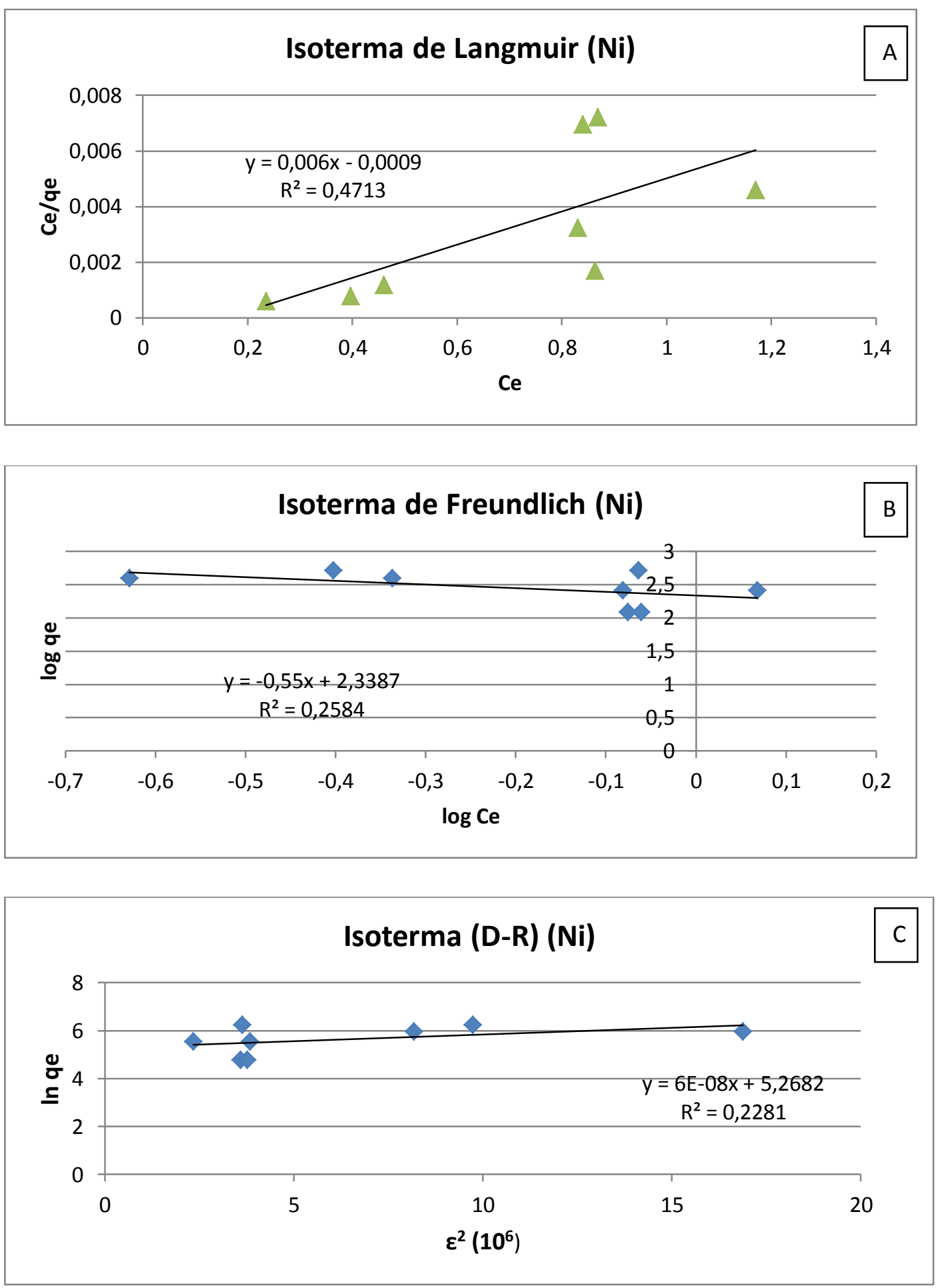

FIGURA 4.42 - Isotermas de Langmuir (A), Freundlich (B) e Dubinin-Radushkevich (C), para o íon níquel.

$\mathrm{Na}$ tabela 4.7, são apresentadas as constantes experimentais obtidas para os modelos de adsorção. 
TABELA 4.7 - Constantes das isotermas obtidas com os dados experimentais.

\begin{tabular}{|c|c|c|c|c|c|c|c|c|c|c|}
\hline \multirow{2}{*}{ Íon } & \multicolumn{3}{|c|}{$\begin{array}{l}\text { Isoterma de } \\
\text { Langmuir }\end{array}$} & \multicolumn{3}{|c|}{ Isoterma de Freundlich } & \multicolumn{4}{|c|}{ Isoterma D-R } \\
\hline & $\begin{array}{c}Q_{0} \\
\left(\mu \mathrm{g} . \mathrm{g}^{-1}\right)\end{array}$ & $\begin{array}{c}\mathbf{K}_{\mathbf{L}} \\
\left(\mathbf{L} \cdot \mathbf{m g}^{-1}\right)\end{array}$ & $\mathbf{R}^{2}$ & $\mathbf{n}$ & $\underset{\left(\mu \mathrm{g} \cdot \mathrm{g}^{-1}\right)}{\mathrm{K}_{\mathrm{f}}}$ & $\mathbf{R}^{2}$ & $\begin{array}{c}\mathbf{q}_{\max } \\
\left(\mu{\left.\mathrm{g} . \mathrm{g}^{-1}\right)}\right.\end{array}$ & $\begin{array}{c}\boldsymbol{\beta} \\
\left(\mathrm{mol}^{2} . \mathrm{kJ}^{2}\right)\end{array}$ & $\begin{array}{c}\mathbf{E} \\
\left(\mathrm{kJ} . \mathrm{mol}^{-1}\right)\end{array}$ & $\mathbf{R}^{2}$ \\
\hline Cd & 96,15 & 3,586 & 0,8167 & 1,25 & 130 & 0,961 & 4,177 & $-0,0006$ & 5,00 & 0,9249 \\
\hline $\mathbf{P b}$ & 192,3 & 0,945 & 0,8476 & 0,88 & 143 & 0,956 & 5,111 & $-0,0023$ & 2,67 & 0,9471 \\
\hline $\mathbf{C u}$ & 344,82 & 0,805 & 0,537 & 1,45 & 155 & 0,888 & 5,199 & $-0,0023$ & 2,67 & 0,8639 \\
\hline $\mathbf{Z n}$ & 667 & 5,00 & 0,8433 & 7,18 & 701 & 0,199 & 6,784 & $-0,001$ & 4,08 & 0,3846 \\
\hline $\mathbf{N i}$ & 166,66 & 6,667 & 0,4713 & 1,82 & 218 & 0,258 & 5,268 & 0,002 & 2,88 & 0,2281 \\
\hline $\mathrm{Cr}$ & 56,49 & 9,834 & 0,5632 & 2,92 & 65,14 & 0,265 & 3,884 & $-0,0003$ & 7,07 & 0,2544 \\
\hline
\end{tabular}

As constantes $K_{F}$ da equação de Freundlich e $Q_{0}$ da equação de Langmuir, sugerem, empiricamente, a capacidade de adsorção dos íons na caulinita. De acordo com as constantes relacionadas na tabela 4.6, observa-se, para os íons $\mathrm{Cd}, \mathrm{Zn}, \mathrm{Ni}$ e $\mathrm{Cr}$, maior capacidade de adsorção para o modelo de Freundlich, sendo que, para os íons $\mathrm{Pb}$ e $\mathrm{Cu}$, o modelo de Langmuir aponta para maior adsorção.

O elevado valor $\mathrm{K}_{\mathrm{F}}$, observado para quatro $(\mathrm{Cd}, \mathrm{Zn}$, Ni e $\mathrm{Cr})$ dos seis íons estudados (apenas $\mathrm{Pb}$ e $\mathrm{Cu}$ apresentaram valor de $\mathrm{Q}_{0}>\mathrm{K}_{\mathrm{F}}$ ), comprova o modelo de Freundlich, em que a adsorção não tem limite e tende a infinito quando a concentração aumenta. Por sua vez a constante $\mathrm{Q}_{0}$ do modelo de Langmuir indica a máxima adsorção quando uma monocamada cobre totalmente a superfície do sorvente (CAROLINA, 2007).

Avaliando-se apenas a isoterma de Langmuir, a constante $\mathrm{Q}_{0}$, aponta para a seguinte seletividade da argila em relação aos metais em estudo, $\mathrm{Zn}$ (II) $>\mathrm{Cu}$ (II) $>\mathrm{Pb}$ (II) $>\mathrm{Ni}(\mathrm{II})>\mathrm{Cd}(\mathrm{II})>\mathrm{Cr}(\mathrm{II})$. Avaliando a constante $\mathrm{K}_{\mathrm{F}}$ da isoterma de Freundlich, a seguinte seletividade é encontrada: $\mathrm{Zn}(\mathrm{II})>\mathrm{Ni}(\mathrm{II})>\mathrm{Cu}(\mathrm{II})>\mathrm{Pb}(\mathrm{II})>\mathrm{Cd}(\mathrm{II})>\mathrm{Cr}$ (II).

A constante relacionada à energia de adsorção $\mathrm{K}_{\mathrm{L}}$, apresentou os valores de 9,834 L.mg ${ }^{-1}$; 6,667 L.mg ${ }^{-1}$; 5,00 L.mg ${ }^{-1}$; 3,586 L.mg ${ }^{-1}$; 0,945 L.mg ${ }^{-1}$ e 0,805 L.mg ${ }^{-1}$ para o $\mathrm{Cr}(\mathrm{II}), \mathrm{Ni}(\mathrm{II}), \mathrm{Zn}(\mathrm{II}), \mathrm{Cd}(\mathrm{II}), \mathrm{Pb}(\mathrm{II})$ e $\mathrm{Cu}(\mathrm{II})$, respectivamente. Os resultados apontam, que os valores de $\mathrm{K}_{\mathrm{L}}$ independem da preferência de adsorção $\mathrm{Q}_{0}$. De acordo com Gupta e Bhattacharyya (2008), os maiores valores de $\mathrm{K}_{\mathrm{L}}$ indicam que a formação do complexo adsorvato/adsorvente ocorre com interações mais fortes. Jiang et. al. (2010), ao estudarem a adsorção dos íons $\mathrm{Pb}(\mathrm{II}), \mathrm{Cd}(\mathrm{II})$ e Cu(II) em caulinita natural, 
obtiveram a seguinte sequência de seletividade $\mathrm{Pb}(\mathrm{II})>\mathrm{Cu}(\mathrm{II})>\mathrm{Cd}(\mathrm{II})$, e $\mathrm{K}_{\mathrm{L}}$ de 0,374 L.mg ${ }^{-1}$, 0,234 L.mg ${ }^{-1}$ e 0,073 L.mg ${ }^{-1}$, para $\mathrm{Pb}, \mathrm{Cd}$ e Cu, respectivamente.

A constante $1 / \mathrm{n}$ indica se a adsorção é favorável ou desfavorável, de acordo com os valores apresentados na tabela 4.7 , com exceção do $\mathrm{Pb}(\mathrm{II})(\mathrm{n}=0,88)$, todos os outros íons apresentam valores de $1<\mathrm{n}<10$, indicando condições favoráveis de adsorção.

O modelo DR descreve o processo como um efeito de preenchimento de poros, relacionado à energia livre de adsorção, o valor da energia de adsorção média, E, apresentado na tabela 4.7, indica, segundo o modelo, que todas as interações são físicas, uma vez que, todos os valores encontrados são menores que $8 \mathrm{~kJ} \mathrm{~mol}^{-1}$.

De acordo com os resultados obtidos, os melhores ajustes, ocorreram para os íons $\mathrm{Cd}(\mathrm{II}), \mathrm{Pb}(\mathrm{II})$ e $\mathrm{Cu}(\mathrm{II})$, segundo o modelo de Freundlich. Indicando, uma adsorção reversível heterogênea, uma vez que não restringe a uma monocamada de cobertura de adsorvente. De acordo com o modelo de Langmuir, os melhores ajustes ocorreram para o $\mathrm{Cd}(\mathrm{II}), \mathrm{Pb}(\mathrm{II})$ e o $\mathrm{Zn}(\mathrm{II})$.

De acordo com os resultados obtidos pode-se concluir que a caulinita estudada pode ser aplicada à remoção dos íons em solução de acordo com a seguinte ordem decrescente $\mathrm{Zn}(\mathrm{II})>\mathrm{Cu}(\mathrm{II})>\mathrm{Pb}(\mathrm{II})>\mathrm{Ni}(\mathrm{II})>\mathrm{Cd}(\mathrm{II})>\mathrm{Cr}(\mathrm{III})$. 


\section{5 - CONCLUSÃO}

Foi avaliada a capacidade de remoção de íons metálicos em solução com a utilização de caulinita comercial. Três amostras, denominadas CA, CB e CC, foram caracterizadas quanto a sua composição mineralógica, química e capacidade de troca catiônica.

Quanto à caracterização mineralógica das amostras, verificou-se que a amostra CA, possui grande quantidade de quartzo e uma pequena quantidade de caulinita. A amostra CB é composta por pirofilita, enquanto que a amostra $\mathrm{CC}$ apresentou um grau de cristalinidade maior que as demais.

Quanto à composição química, determinada por fluorescência de raios-x e análise por ativação neutrônica, constatou-se uma variação considerável entre as três amostras. As amostras $\mathrm{CA}$ e $\mathrm{CB}$ apresentaram teores de $\mathrm{SiO}_{2}, \mathrm{MgO}$ e $\mathrm{CaO}$, superiores aos encontrados na amostra da caulinita CC, indicando provavelmente a presença do argilomineral montmorillonita. A relação molar $\mathrm{SiO}_{2} / \mathrm{Al}_{2} \mathrm{O}_{3}$ encontrada para a amostra CC foi de 1,15, semelhante à da caulinita teórica 1,09, para as amostras CA e CB esta relação foi de 3,26 e 1,79, respectivamente. Teores superiores de sílica e altas quantidades de $\mathrm{Fe}, \mathrm{K}$ e Ti apontam para a presença de impurezas nas amostras $\mathrm{CA}$ e $\mathrm{CB}$, indicando que a amostra $\mathrm{CC}$ apresenta teor de pureza superior às demais. $\mathrm{Na}$ análise de elementos menores e traços, foram encontradas concentrações mais elevadas nas amostras CA e CB.

Com os resultados de CTC, obtidos nas análises da amostra sem tratamento, com tratamento por ativação térmica e química, pode-se concluir que os tratamentos não causaram modificações significativas na estrutura das amostras, assim, não houve melhora na sua capacidade de troca cationnica. A amostra CC foi a que apresentou a maior CTC 9,00 meq/100g, na condição sem tratamento. Assim, a caulinita CC foi escolhida para continuidade no estudo de adsorção.

No estudo da adsorção, ficou comprovado que este é um processo que depende relativamente da proporção argila:solução. Quatro $(\mathrm{Cu}, \mathrm{Ni}, \mathrm{Zn}$ e $\mathrm{Pb})$ dos seis metais estudados apresentaram melhores resultados para a maior proporção argila:solução (10:50), enquanto que apenas dois ( $\mathrm{Cd}$ e $\mathrm{Cr}$ ) apresentaram melhores resultados com uma proporção menor (5:50), no entanto, é necessário ainda uma avaliação custo 
benefício (econômicas e ambiental) da utilização de uma maior proporção. Obs. (a questão está resolvida, pois não houve um estudo do processo e sim avaliação da capacidade de adsorção).

A análise da variação do pH das soluções contendo os íons metálicos apontou que este parâmetro tem influência significativa na adsorção. Para todos os metais estudados, com exceção do $\mathrm{Cd}$ 0,2 mg.L $\mathrm{L}^{-1}$ ( $\mathrm{pH}$ 5), a maior adsorção foi verificada em $\mathrm{pH} 8$.

No estudo da influência do tempo de contato argila:solução para determinação do tempo de equilíbrio verificou-se que este foi alcançado variando de 5 a 30 minutos para todos os íons, exceto para o Ni. Pode-se concluir desta forma, que o tempo de contato para a obtenção do equilíbrio é dependente da concentração inicial dos íons em solução.

De acordo com os resultados obtidos, em função da análise das isotermas de adsorção, as maiores capacidades de remoção de íons metálicos em soluções monoelementares, como as estudadas neste trabalho, foram encontradas para os íons Zn (II), $\mathrm{Cu}$ (II) e $\mathrm{Pb}$ (II). Assim, a amostra CC, pode ser utilizada para remoção destes íons de soluções aquosas com finalidade de reuso ou descarte. 


\section{REFERÊNCIAS}

ABOLLINO, O.; GIACOMINO, A.; MALANDRINO, M.; MENTASTI, E. Interaction of metal ions with montmorillonite and vermiculite. Applied Clay Science. 38, 227236, 2008.

ADRIANO, D.C. Trace elements in the terrestrial environment. New York, Springer-Veriag, 1986.

AGUiAR, M. R.M.; NOVAES, A.C.; GUARINO, A.W.S. Remoção de Metais Pesados de Efluentes Industriais por Aluminossilicatos. Química Nova, v. 25, n. 6B, 1145-1154, 2002.

AJA, S.U. The sorption of the rare earth element, $\mathbf{N d}$, onto kaolinite at $25^{\circ} \mathrm{C}$. Clays and Clay Minerals 46(1), 1998.

AKAR, S. T.; AKAR, T.; KAYNAK, Z.; ANILAN, B.; CABUK, A.; TABAK, Ö.; DEMIR, T. A.; GEDKBEY, T. Removal of copper (II) ions from synthetic solution and real wastewater by the combined action of dried Trametes versicolor cells and montmorillonite. Hydrometallurgy 97:p. 98-104, 2009.

AL-JLIL, S. A.; ALSEWAILEM F. D. Saudi Arabian clays for lead removal in wastewater. Applied Clay Science 42, 671-674, 2009.

ALlOWAY, B. J. Cadmium. In: ALLOWAY, B. J (ed.). Heavy metals in soils. 2ed. London: Blackie Academic, p. 122 - 151, 1995 b.

ARAGÃO, D.M.; ARGUELHO, M.L.P.M.; ALVES, J.P.H.; PRADO, C.M.O. Estudo comparativo da adsorção de $\mathrm{Pb}$ (II), Cd (II) e $\mathrm{Cu}$ (II) em argila natural caulinítica e contendo Montmorilonita. Orbital: The Electronic Journal of Chemistry: Volume 5, Número 3, 2013. 
ARAÚJO, C.S.; SILVA, R.D. Influência da calcinação sobre a remoção de ferro da caulinita e ilita e seus efeitos sobre a acidez. Química Nova, São Paulo, v. 26, n. ${ }^{\circ}$, p. 161 - 164, março/abril, 2003.

ATKINS, P.W.; PAULA, J. Físico-química: v.1, 8. Ed, LTC, Rio de Janeiro, 2008.

BARBIER, F.; DUC, G.; PETIT-RAMEL, M. Colloids and Surfaces A: Physicochem. Eng. Aspects 2000, 166, 153.

BASCETIN, E.; HAZNEDAROGLU, H.; ERKOL, A.Y. The adsorption behavior of cesium on sílica gel. Applied Radiation and Isotopes. V.59, p. 5-9, 2003.

BATTEY, M.H. Mineralogy for Students, Second edition, London and New York, Long-man, 1981.

BHATTACHARYYA, K. G.; GUPTA, S. S. Adsorption of a few heavy metals on natural and modified kaolinite and montmorillonite: a review. Adv. Colloid Interface Science. 140 (2), 114-31, 2008.

BEATY, R.D.; KEBER, J.D. Concepts, Instrumentations and Techiniques in Atomic Absorption Spectrophotometry: Perkin Elmer, USA, 1993

BERTELLA, F.; SCHWANKE, A.J; LOPES, C.W.W.; PENHA, F.G. Estudo da ativação ácida de uma argila bentonita. Perspectiva, 34, 105 - 110, 2010.

BRACCINI, C.F. Estudo de sorção de césio e estrôncio em argilas nacionais para sua utilização como barreira em repositórios de rejeitos radioativos. Comissão Nacional de Energia Nuclear - Programa de Pós Graduação em Ciência e Tecnologia das Radiações, Minerais e Materiais, 2007.

BRADL, H.B. Adsorption of heavy metal íons on soils and soils constituents. Journal of Colloid and Interface Science, v. 277, p. 1-18, 2004.

BRINDLEY, G.W.; KAO, C.; HARRISON, J.L.; LIPSICAS, M \& RAYTHATHA, R. The relation between structural disorder and other characteristics of kaolinite and dickite. Clays Clay Miner, 239-249, 1986. 
BOSTELMANN, E. Avaliação da concentração de metais em amostras de sedimento do Reservatório Billings, Braço Rio Grande. São Paulo, Brasil. Dissertação (Mestrado) - Instituto de Pesquisas Energéticas Nucleares, São Paulo, 2006.

CASANOVA, F.J. O ensaio de azul de metileno na caracterização de solos lateríticos. Reunião anual de pavimentação, Salvador, v.2, p. 279 - 286, 1986.

CAVALCANTI, J.E. Manual de tratamento de efluentes industriais, $2^{\text {a }}$ Ed., 2012.

CIRRA - CENTRO INTERNACIONAL DE REFERÊNCIA EM REUSO DE ÁGUA. Reuso de água. Universidade de São Paulo, 2002.

CONSELHO NACIONAL DO MEIO AMBIENTE. Resolução nº 357, de 17 de março de 2005. Diário Oficial da União, 18 de março de 2005.

CONSELHO NACIONAL DO MEIO AMBIENTE. Resolução ${ }^{\circ}$ 430, de 13 de maio de 2011. Diário Oficial da União, 16 de maio de 2011.

DEER, W.A.; HOWIE, R.A.; ZUSSMAN, J. Minerais Constituintes das Rochas Uma Introdução. London: Calouste Gulbenkian, 1966.

DIAS, F.R.V.; SANTOS, P.S. Studies on the acid activation of Brazilian smectitic clays. Química Nova, São Paulo, v.24, n.3, p. 345-353, maio/junho, 2001.

DUBININ, M.M.; ZAVERINA, E.D.; RADUSHKEVICH, L.V. Sorption and structure of active carbons. I. Adsorption of organic vapors. Zh. Fiz. Khim, v. 21, 1351-1362, 1947.

ELLINGSEN, D.G; Horn N, Aaseth J. Copper. In Nordberg GF, Fowler BA, Nordberg M, Friberg LT, (Ed)RS. Handbook on the Toxicology of Metals. 3rd Ed. San Diego: Elsevier; Chap 26, 2007.

ERDEM, B.; OZCAN, A.; GOK, O.; OZCAN, A.S. Immobilization of 2, 2-dipyridyl onto bentonite and its adsorption behaviour of copper (II) íons. Journal Hazardous Materials, v.163, 418-426, 2009. 
FEI, T.; DEHONG, L.; FENGQUN, Z.; JUNHUA, L.; HUA, T.; XIANGZHONG, K. Determination of trace elements in Chinese medicinal plants by instrumental neutron activation analysis. Journal of Radioanalytical and Nuclear Chemistry, v. 284, p. 507-511, 2010.

FERREIRA, M.J.D. Argilominerais puro e quimicamente modificados como adsorventes para corantes catiôncos. Dissertação de mestrado em Química. Universidade Federal da Paraíba, 2009.

FREIRE, C.B. Estudo de sorção de césio e estrôncio em argilas naturais para sua utilização como barreira em repositórios de rejeitos radioativos. Dissertação (Ciência e Tecnologia das Radiações), Centro de Tecnologia Nuclear, Belo Horizonte, 2007.

GARDOLINSKI, J. E.; FILHO, H. P. M. F.; WYPYCH, F. Comportamento térmico da caulinita hidratada. Química Nova, v. 26, p. 30-35, 2003.

GOLDBERG, S. Adsorption models incorporated into chemical equilibrium models. Soil Science Society of America Special Publication, n.42, p. 75-93, 1995.

GOMES, C.F; Argilas - O que são e para que servem. Fundação Calouste Gulbenkian, Lisboa, 1986.

GRIM, R.E. Clay Mineralogy. $2^{\text {a }}$ Ed. Editora McGraw-Hill Book Company, Estados Unidos, 1 - 596, 1968.

GRUN, E. Caracterização de argilas provenientes de Canelinhas/SC e estudo de formulações de massas cerâmicas. Dissertação (Mestrado em Ciência e Engenharia de Materiais), Universidade do Estado de Santa Catarina, 2007.

GU, B.; SCHMITT, J.; CHEN, Z.; LIANG, L.; MCCARTHY, J.F. Adsorption and desorption of natural organic matter on iron oxide: mechanisms and models. Environmental Science \& Technology, v. 28, p. 38-46, 1994.

GUIDOLIN, J. C. Reuso de efluentes. Brasília: Secretaria de Recusrsos Hídricos, Ministério do Meio Ambiente, 2000. 
GUPTA, S. S.; BHATTACHARYYA, K. G. J. Removal of Cd (II) from aqueous solution by kaolinite, montmorillonite and their poly (oxozirconium) and tetrabutylammonium derivatives. Journal of Hazardous Materials. V. 128, 247-257, 2006.

HARRIS, D.C. Análise Química Quantitativa, New York: LTC - Livros Técnicos e Científicos Editora S.A, 2005.

HESPANHOL, I. Potencial de Reuso de água no Brasil: Agricultura, Indústria, Municípios, Recarga de Aquíferos. Revista Brasileira de Recursos Hídricos, Volume 7, número 4, outubro/dezembro, 75-95, 2002.

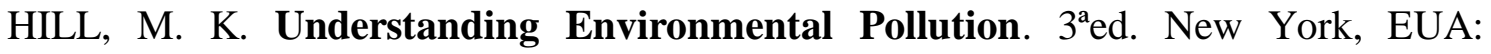
Cambrudge University Press, 585 p., 2010.

HILL, R. J.; MADSEN, I.C. Sample preparation, instrument selection and data collection. In: DAVID, W. I. F.; SHANKLAND, K.; McCUSKER, L. B.; BAERLOCHER, Ch. (Eds.) Structure determination from powder diffraction data. Oxford, UK: Oxford University Press, p. 98-117, 2006.

IAEA - INTERNATIONAL ATOMIC ENERGY AGENCY. Use of research reactors for nêutron activation analysis. (IAEA - TECDOC 1215), 2001.

INGV, INSTITUTO NAZIONALE DI GEOFISICA E VULCANOLOGIA. Disponível em: http://www.pa.ingv.it/laboratori/tracce/elementi.html, acessado em 01/02/2015.

JIANG, M.; JIN, X.; LU, X.; CHEN, Z. Adsorption of Pb (II), Cd (II), Ni (II) and Cu (II) onto natural kaolinite Clay. Desalination v. 252, p.33-39, 2010.

KABATA-PENDIAS, A.; PENDIAS, H. Trace elements in soil and plants. 3ed. Boca Raton: CRC Press, 331p, 2001.

KAKALI, G.; PERRAKI, T.; TSIVILIS, S. e BADOGIANNIS, E. Thermal treatment of kaolin: the effect of mineralogy on the pozzolanic activity. Applied Clay Science, v. 20, 73-80, 2001. 
KRAEPIEL, A. M. L.; KELlER, K.; MOREL, F. M. M. A model fro metal adsorption on montmorillonite. Journal of Colloid and Interface Science. 210, 43-54, 1999.

LAVRADOR FILHO, J. Contribuição para o entendimento do reuso planejado da água e algumas considerações sobre suas possibilidades no Brasil. Dissertação de Mestrado POLI/USP. São Paulo, 1987.

LEE, J. D - Química Inorgânica não tão concisa. São Paulo, 5ªed. 2006.

LENARDA, M.; STORARO, L.; TALONA, A; MORETTI, E.; RIELLO, P. Solid acid catalysts from clays: Preparation of mesoporous catalysts by chemical activation of metakaolin under acid conditions. Journal of Colloid and Interface, Science, v. 311, p. 537-543, 2007.

MALAVOLTA, E. Fertilizantes e seu impacto ambiental: micronutrientes e metais pesados, mitos, mistificação e fatos. São Paulo: ProduQuímica, 1994.

MALIK, P.K. Dye removal from wastewater using activated carbon developed from sawdust: adsorption equilibrium and kinetics. Journal of Hazardous Materials, v. 113, p. 81-88, 2004.

MANNING, T.J.; GROW, W.R. Inductively Coupled Plasma-Atomic Emission Spectrometry. 2 (1) Springer-V Erla G, New York, 1997.

MARQUES, F.A.; CALEGARI, M.R.; VIDAL-TORRADO, P.; BUURMAN, P. Relationship between soil oxidizable carbon and physical, chemical and mineralogical properties of umbric Ferralsols. Revista Brasileira de Ciência do Solo, Viçosa, v. 35, n.1, 25-40, jan/fev. 2011.

MARTINS E.C. Caracterização e quantificação mineralógica da fração argila do horizonte Bi de cambissolo da região de Irati, Paraná, pelo método de Rietveld. Dissertação (Mestrado) - Universidade Estadual de Ponta Grossa, Ponta Grossa, 2010. 
MEIRELLES, V.S. Desenvolvimento de método para a determinação de irídio, paládio, platina e rádio por ICP OES em sílica mesoporosa para uso catalítico. Dissertação (Mestrado) - Universidade de São Paulo, São Paulo, 2012.

MESTER, Z.; STURGEON, R. Comprehensive analytical chemistry: sample preparation for trace element analysis, Ottawa, 2003.

MEYERS, R.A. Encyclopedia of Analytical Chemistry. Chichester, U.K.: John Wiley \& Sons Ltd, 2000.

MIRANDA-TREVINO, J.C.; COLES, C.A. Kaolinite properties, structure and influence of metal retention on pH. Applied Clay Science, 23, 133-139, 2003.

MORAES, E.P.; MACHADO, N.R.C.F.; PERGHER, S.B.C. Síntese da zeólita a partir de um caulim termicamente ativado. Acta Scientiarum Technology, Maringá, v. 25 , p. $63-69,2003$.

MOREIRA, E.G. Preparo e caracterização de um material de referência de mexilhão perna perna (Linnaeus, 1975). Tese Doutorado, Instituto de Pesquisas Energéticas e Nucleares, São Paulo, 2010.

MOREIRA, H.S.; SAIKI, M.; VASCONCELLOS, M. B. A. Análise por ativação com nêutrons de fitoterápicos obtidos de plantas medicinais. International Nuclear Atlantic Conference, Santos, SP, Brazil, September 30 to October 5, 2007.

MORONTA, A.; FERRER, V.; QUERO, J.; ARTEAGA, G.; CHOREN, E. Influence of preparation method on the catalytic properties of acid-activated tetramethylammonium exchanged clays. Applied Catalysis A: General, Amsterdam, v. 230, n.1/2, p. $127-135$, abr. 2002.

MOTTA, J.F.M.; LUZ, A.B.; BALTAR, C.A.M.; BEZERRA, M.S.; CABRAL JÚNIOR, M.; COELHO, J.M. Argila plástica para cerâmica branca. In: Rochas e Minerais Industriais. Rio de Janeiro, Luz, A.B; Lins, F.A.T, Capítulo 34, p. 771-791, 2008. 
MURRAY, H.; BUNDY, W.; HARVEY, C. Kaolin Genesis and Utilization. The Clay Minerals Society, 1993.

NEUMANN, R.; SCHNEIDER, C.L.; ALCOVER NETO, A. Caracterização Tecnológica de Minérios. Capítulo 3, p. 55-109. Rio de Janeiro, 2004.

OKIEL, K.; EL-SAYED, M.; EL-KADY, M.Y. Treatment of oil-water emulsions by adsorption onto activated carbon, bentonite and deposited carbon. Egyptian Journal of Petroleum, v. 20, p. 9-15, 2011.

OUADJENIA, F.; MAROUF, R.; SCHOTT, J.; YAHIAOUI, A. Removal of Cu (II), Cd (II), and Cr (III) íons from Aqueous Solution by Dam Silt. Arabian Journal of Chemistry. 6:401-406, 2010.

OZCAN, A.; ONCU, E.M.; OZCAN, A.S. Kinetics, isotherm and thermodynamic studies of adsorption of Acid Blue 193 from aqueous solutions onto natural sepiolite. Colloid Surf. A 277, 90-97, 2006.

PEREIRA, K.R.O. Estudo, em escala de laboratório, do uso de argilas do tipo bofe na obtenção de argilas organofílicas e ativadas. Tese (Doutorado) - Escola Politécnica, São Paulo, 2008.

RODRIGUES, O.M.S. Estudos de Flotação de Caulinita. 95 p. Dissertação (Mestrado em Engenharia Metalúrgica e de Minas) - Universidade Federal de Minas Gerais, Belo Horizonte, 2009.

SALLES, P.F - Estudo dos tratamentos químico e térmico e a influência na remoção de contaminantes em efluentes de mineração. Dissertação (Mestrado) Universidade Federal de Lavras, Minas Gerais, 2011.

SALTALI, K.; SARI, A.; AYDIN, M. Removal of ammonium ion from aqueous solution by natural Turkish (Yildizeli) zeolite for environmental quality. Journal Hazardous Materials, v. 141, 258-263, 2007.

SANTOS, P.S. Ciência e tecnologia de argilas. São Paulo, $2^{\mathrm{a} e d . ~ V o l u m e ~ 1, ~ p . ~} 242$ 2501975 . 
SANTOS, S.V.; Utilização de resíduos siderúrgicos no tratamento de efluentes contendo emulsões oleosas. Dissertação (Mestrado em Saneamento) Universidade Federal de Minas Gerais, Belo Horizonte, 2013.

SILVA, P.S.C. Caracterização química e radiológica dos sedimentos do estuário de Santos, São Vicente e Baía de Santos. Tese (Doutorado) - Instituto de Pesquisas e Energéticas e Nucleares, São Paulo, 2004.

SKOOG, D. A.; HOLleR, F. J.; NIEMAN, T. A. Principles of Instrumental Analysis, 5th edition. Saunders College Publishing, EUA. 0-03-002078-6, 1998.

SINGH, S.P.; MA, L.Q.; HARRIS, W.G. Heavy metal interaction with phosphatic clay: sorption and desorption behavior. Journal of Environmental Quality 30 (6), 1961-1968, 2001.

SOARES, M.R. Coeficiente de distribuição (Kd) de metais pesados em solos do Estado de São Paulo. Tese de Doutorado - Escola Superior de Agricultura "Luiz de Queiroz”, Universidade de São Paulo, 2004.

SODRE, F.F.; LENZI, E.; COSTA, A.C.S. Utilização de modelos físico-químicos de adsorção no estudo do comportamento do cobre em solos argilosos. Química Nova. V. 24, n. 3, p. 324-330, 2001.

SOMASUNDARAN, P., MALTESH, C. Hydrocarbon and alcohol effects on sulfonate adsorption on alumina. Colloids and Surfaces A: Physicochemical and Engineering Aspects, v. 112, p. 55-62, 1996.

TARASEVICH, Y.I, KLIMOVA, G.M. Complexforming adsorbents based on kaolinite, aluminium oxide and polyphosphates for the extraction and concentration of heavy metal ions from water solutions. Applied Clay Science. 19: 95-101, 2001.

TARI, G.; BOBOS, I.; GOMES, C.S.F. e FERREIRA, J.M.F. Modification of surface

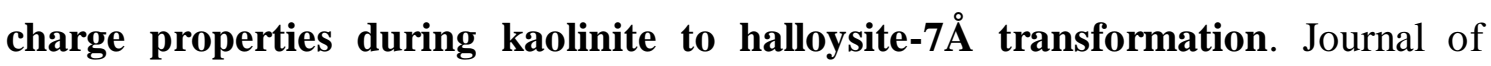
Colloid and Interface Science, v. 210, 360-366, 1999. 
WANG, T.; LU, X.; YAN, Y. Synthesis, characterization and crystallization mechanism of SAPOs from natural kaolinite. Microporous and Mesoporous Materials, Amsterdam, v. 136, n. 1/3, p. 138 - 147, 2010.

WHITTIG, L.D. X-Ray diffraction techniques for mineral identification and mineralogical composition. In: BLACK, C. A; DINAUER, R. C.; EVANS, D. D.; WHITE, J. L.; ENSMINGER, L. E.; CLARK, F. E. (Eds.) Methods of soil analysis. Part 1: Physical and mineralogical properties, including statistics of measurement and sampling. 2 ed. Madison: American Society of Agronomy, p. 671-696, 1965.

ZATTA, L. Caulinita e Haloisita "in-natura" e ativadas com ácidos minerais como catalisadores heterogêneos para esterificação (M) etílica de ácidos graxos. Dissertação Mestrado - Universidade Federal do Paraná, 2010.

ZHENG, H.; WANG, Y.; ZHENG, Y.; ZHENG, H.; LIANG, S.; LONG, M. Equilibrium, kinetic and thermodynamic studies on the sorption of 4hydroxyphenol on Cr-bentonite. Chemical Engineering Journal. V. 143, 117-123, 2008 . 


\section{ANEXO A}

\begin{tabular}{|c|c|c|c|c|c|c|c|c|c|c|c|}
\hline \multicolumn{4}{|c|}{ PROPORÇÃO } & \multicolumn{4}{|c|}{ PROPORÇÃO } & \multicolumn{4}{|c|}{ PROPORÇÃO } \\
\hline \multicolumn{4}{|c|}{$\mathbf{Z n}$} & \multicolumn{4}{|c|}{$\mathbf{N i}$} & \multicolumn{4}{|c|}{$\mathrm{Cu}$} \\
\hline Ref. & $\mathbf{C i}$ & Cf/T1 & $q \mu \mathrm{g} / \mathrm{g}$ & Ref. & $\mathbf{C i}$ & Cf/T1 & $q \mu \mathrm{g} / \mathrm{g}$ & Ref. & $\mathbf{C i}$ & Cf/T1 & $q \mu \mathrm{g} / \mathrm{g}$ \\
\hline 5 & 5,73 & 5,28 & 5280 & 2 & 2,11 & 1,93 & 1930 & 1 & 0,953 & 0,5 & 500 \\
\hline 65 & 70,8 & 57,4 & 57400 & 25 & 26,6 & 24,8 & 24800 & 12 & 12,7 & 12,4 & 12400 \\
\hline 125 & 111 & 101,4 & 101400 & 50 & 50,3 & 47,9 & 47900 & 25 & 25,7 & 23,6 & 23600 \\
\hline 180 & 174 & 160 & 160000 & 75 & 77,0 & 76,0 & 76000 & 37 & 36,8 & 31,2 & 31200 \\
\hline 250 & 244 & 29,3 & 29300 & 100 & 100,9 & 99,6 & 99600 & 50 & 50 & 48,7 & 48700 \\
\hline Ref. & $\mathbf{C i}$ & Cf/T2 & $q \mu \mathrm{g} / \mathrm{g}$ & Ref. & $\mathbf{C i}$ & Cf/T2 & $q \mu \mathrm{g} / \mathrm{g}$ & Ref. & $\mathbf{C i}$ & $\mathrm{Cf} / \mathrm{T} 2$ & $q \mu \mathrm{g} / \mathrm{g}$ \\
\hline 5 & 5,73 & 0,5 & 500 & 2 & 2,11 & 0,5 & 500 & 1 & 0,953 & 0,5 & 500 \\
\hline 65 & 70,8 & 42,5 & 42500 & 25 & 26,6 & 25,0 & 25000 & 12 & 12,4 & 2,37 & 2370 \\
\hline 125 & 111 & 91,1 & 91100 & 50 & 50,3 & 30,0 & 30000 & 25 & 25,7 & 12,27 & 12270 \\
\hline 180 & 174 & 0,5 & 500 & 75 & 77,0 & 72,3 & 72300 & 37 & 36,8 & 17,7 & 17700 \\
\hline 250 & 244 & 13 & 13000 & 100 & 100,9 & 49,6 & 49600 & 50 & 50 & 47,3 & 47300 \\
\hline Ref. & $\mathbf{C i}$ & Cf/T3 & $q \mu \mathrm{g} / \mathrm{g}$ & Ref. & $\mathbf{C i}$ & Cf/T3 & $q \mu \mathrm{g} / \mathrm{g}$ & Ref. & $\mathbf{C i}$ & Cf/T3 & $q \mu \mathrm{g} / \mathrm{g}$ \\
\hline 5 & 5,73 & 0,5 & 500 & 2 & 2,11 & 0,5 & 500 & 1 & 0,953 & 0,5 & 500 \\
\hline 65 & 70,8 & 57 & 57000 & 25 & 26,6 & 24,0 & 24000 & 12 & 12,4 & 0,5 & 500 \\
\hline 125 & 111 & 8,12 & 8120 & 50 & 50,3 & 11,0 & 11000 & 25 & 25,7 & 0,5 & 500 \\
\hline 180 & 174 & 4,91 & 4910 & 75 & 77,0 & 49,0 & 49000 & 37 & 36,8 & 4,43 & 4430 \\
\hline 250 & 244 & 34,5 & 34500 & 100 & 100,9 & 2,53 & 2530 & 50 & 50 & 2,77 & 2770 \\
\hline
\end{tabular}




\section{ANEXO A}

\begin{tabular}{|c|c|c|c|c|c|c|c|c|c|c|c|}
\hline \multicolumn{4}{|c|}{ PROPORÇÃO } & \multicolumn{4}{|c|}{ PROPORÇÃO } & \multicolumn{4}{|c|}{ PROPORÇÃO } \\
\hline \multicolumn{4}{|c|}{$\mathrm{Cr}$} & \multicolumn{4}{|c|}{ Cd } & \multicolumn{4}{|c|}{$\mathbf{P b}$} \\
\hline Ref. & $\mathbf{C i}$ & Cf/T1 & $q \mu g / g$ & Ref. & $\mathbf{C i}$ & Cf/T1 & $q \mu \mathrm{g} / \mathrm{g}$ & Ref. & $\mathbf{C i}$ & Cf/T1 & $q \mu g / g$ \\
\hline 0,1 & 0,1 & 0,086 & 86 & 0,2 & 0,17026 & 0,1688 & 168,8 & 0,5 & 0,522 & 0,1746 & 174,6 \\
\hline 1,0 & 1 & 0,95 & 950 & 1 & 0,88257 & 0,8638 & 863,8 & 6,0 & 5,603 & 4,522 & 4522 \\
\hline 2,5 & 2,5 & 1,75 & 1750 & 5 & 4,4000 & 4,2635 & 4263,5 & 12 & 12,1499 & 4,7525 & 4752,5 \\
\hline 3,5 & 2,9 & 2,37 & 2370 & 8 & 6,83977 & 6,5159 & 6515,9 & 18 & 19,092 & 9,014 & 9014 \\
\hline 5,0 & 5 & 4,85 & 4850 & 10 & 8,61143 & 8,36 & 8360 & 25 & 28,53 & 21,735 & 21735 \\
\hline Ref. & $\mathbf{C i}$ & $\mathrm{Cf} / \mathrm{T} 2$ & $q \mu \mathrm{g} / \mathrm{g}$ & Ref. & $\mathbf{C i}$ & $\mathrm{Cf} / \mathrm{T} 2$ & $q \mu \mathrm{g} / \mathrm{g}$ & Ref. & $\mathbf{C i}$ & $\mathrm{Cf} / \mathrm{T} 2$ & $q \mu \mathrm{g} / \mathrm{g}$ \\
\hline 0,1 & 0,1 & 0,05 & 50 & 0,2 & 0,17026 & 0,0033 & 3,3 & 0,5 & 0,522 & 0,059 & 59 \\
\hline 1,0 & 1 & 0,05 & 50 & 1 & 0,88257 & 0,0323 & 32,3 & 6,0 & 5,603 & 0,07541 & 75,41 \\
\hline 2,5 & 2,5 & 0,052 & 52 & 5 & 4,4000 & 0,7274 & 727,4 & 12 & 12,1499 & 3,3048 & 3304,8 \\
\hline 3,5 & 2,9 & 0,05 & 50 & 8 & 6,83977 & 0,7316 & 731,6 & 18 & 19,092 & 1,873 & 1873 \\
\hline 5,0 & 5 & 0,05 & 50 & 10 & 8,61143 & 8,5785 & 8578,5 & 25 & 28,53 & 10,2875 & 10287,5 \\
\hline Ref. & $\mathbf{C i}$ & Cf/T3 & $q \mu g / g$ & Ref. & $\mathbf{C i}$ & Cf/T3 & $q \mu \mathrm{g} / \mathrm{g}$ & Ref. & $\mathbf{C i}$ & Cff/T3 & $q \mu \mathrm{g} / \mathrm{g}$ \\
\hline 0,1 & 0,1 & 0,05 & 50 & 0,2 & 0,17026 & 0,0027 & 2,7 & 0,5 & 0,522 & 0,02498 & 24,98 \\
\hline 1,0 & 1 & 0,05 & 50 & 1 & 0,88257 & 0,3925 & 392,5 & 6,0 & 5,603 & 0,01154 & 11,54 \\
\hline 2,5 & 2,5 & 0,05 & 50 & 5 & 4,4000 & 0,91729 & 917,29 & 12 & 12,1499 & 0,04559 & 45,585 \\
\hline 3,5 & 2,9 & 0,05 & 50 & 8 & 6,83977 & & & 18 & 19,092 & 1,5958 & 1595,8 \\
\hline 5,0 & 5 & 0,05 & 50 & 10 & 8,61143 & 4,4828 & 4482,8 & 25 & 28,53 & 0,3179 & 317,9 \\
\hline
\end{tabular}


ANEXO B

\section{EFEITO DO pH}

\section{Zn}

$\begin{array}{cccc}\text { Ref.[65] } & \text { Ci } & \mathbf{C f / T 3} & \mathbf{q ~} \boldsymbol{\mu g} / \mathbf{g} \\ \text { pH 1 } & 61,4 & 60,8 & 0,003 \\ \text { pH 2 } & 61,4 & 58,9 & 0,013 \\ \text { pH 4 } & 61,4 & 50,6 & 0,054 \\ \text { pH 5 } & 61,4 & 22,7 & 0,1935 \\ \text { pH 8 } & 61,4 & 0,173 & 0,3061 \\ & & & \\ \text { Ref.[180] } & \text { Ci } & \mathbf{C f / T 3} & \mathbf{q ~} \boldsymbol{\mu g} / \mathbf{g} \\ \text { pH 1 } & 167 & 154 & 0,065 \\ \text { pH 2 } & 167 & 124 & 0,215 \\ \text { pH 4 } & 167 & 108 & 0,295 \\ \text { pH 5 } & 167 & 87 & 0,4 \\ \text { pH 8 } & 167 & 2,1 & 0,8245\end{array}$

\section{EFEITO DO pH}

Ni

$\begin{array}{cccc}\text { Ref.[25] } & \mathbf{C i} & \mathbf{C f} / \mathbf{T 3} & \mathbf{q} \boldsymbol{\mu \mathbf { g } / \mathbf { g }} \\ \text { pH 1 } & 25,1 & 24,9 & 0,001 \\ \text { pH 2 } & 25,1 & 24,2 & 0,0045 \\ \text { pH 4 } & 25,1 & 22,8 & 0,0115 \\ \text { pH 5 } & 25,1 & 21,4 & 0,0185 \\ \text { pH 8 } & 25,1 & 0,99 & 0,1205 \\ & & & \\ \text { Ref.[75] } & \text { Ci } & \mathbf{C f} / \mathbf{T 3} & \mathbf{q} \boldsymbol{\mu \mathbf { g } / \mathbf { g }} \\ \text { pH 1 } & 76,1 & 75,4 & 0,0035 \\ \text { pH 2 } & 76,1 & 73,2 & 0,0145 \\ \text { pH 4 } & 76,1 & 65,8 & 0,0515 \\ \text { pH 5 } & 76,1 & 53,4 & 0,1135 \\ \text { pH 8 } & 76,1 & 0,99 & 0,3755\end{array}$

EFEITO DO pH

$\mathrm{Cu}$

$\begin{array}{cccc}\text { Ref.[12] } & \text { Ci } & \mathbf{C f} / \mathbf{T 3} & \mathbf{q} \boldsymbol{\mu g} / \mathbf{g} \\ & & & \\ \text { pH 2 } & 12,4 & 12,0 & 0,0020 \\ \text { pH 4 } & 12,4 & 10 & 0,0120 \\ \text { pH 5 } & 12,4 & 1,9 & 0,0525 \\ \text { pH 8 } & 12,4 & 0,333 & 0,0603 \\ & & & \\ \text { Ref.[37] } & \text { Ci } & \mathbf{C f} / \mathbf{T 3} & \mathbf{q} \boldsymbol{\mu g} / \mathbf{g} \\ & & & \\ & & & \\ \text { pH 4 } & 36,8 & 33,9 & 0,0145 \\ \text { pH 5 } & 36,8 & 9,03 & 0,1388 \\ \text { pH 8 } & 36,8 & 0,628 & 0,1808\end{array}$




\section{ANEXO B}

EFEITO DO pH

$\mathrm{Cr}$

\begin{tabular}{cccc}
\hline Ref.[0,1] & Ci & Cf/T2 & $\mathbf{q} \boldsymbol{\mu g} / \mathbf{g}$ \\
pH 1 & 0,106 & 0,1 & $6,00 \mathrm{E}-05$ \\
pH 2 & 0,106 & 0,1 & $6,00 \mathrm{E}-05$ \\
pH 4 & 0,106 & 0,1 & $6,00 \mathrm{E}-05$ \\
pH 5 & 0,106 & 0,1 & $6,00 \mathrm{E}-05$ \\
pH 8 & 0,106 & 0,1 & $6,00 \mathrm{E}-05$ \\
& & & \\
Ref.[3,5] & Ci & $\mathbf{C f} / \mathbf{T 2}$ & $\mathbf{q ~} \boldsymbol{\mu g} / \mathbf{g}$ \\
pH 1 & 3,74 & 3,25 & 0,0049 \\
pH 2 & 3,74 & 3,15 & 0,0059 \\
pH 4 & 3,74 & 3,11 & 0,0063 \\
pH 5 & 3,74 & 0,35 & 0,0339 \\
pH 8 & 3,74 & 0,159 & 0,0358
\end{tabular}

EFEITO DO pH

Cd
EFEITO DO pH

$\mathbf{P b}$

$\begin{array}{cccc}\text { Ref.[0,5] } & \mathbf{C i} & \mathbf{C f} / \mathbf{T 3} & \mathbf{q} \boldsymbol{\mu g} / \mathbf{g} \\ \text { pH 1 } & - & - & - \\ \text { pH 2 } & 0,342 & 0,281 & 0,607 \\ \text { pH 4 } & 0,342 & 0,236 & 1,055 \\ \text { pH 5 } & 0,342 & 0,098 & 2,434 \\ \text { pH 8 } & 0,342 & 0,042 & 2,994 \\ & & & \\ \text { Ref.[18] } & \text { Ci } & \mathbf{C f} / \mathbf{T 3} & \mathbf{q ~} \boldsymbol{\mu g} / \mathbf{g} \\ \text { pH 1 } & 15,978 & 15,198 & 7,796 \\ \text { pH 2 } & 15,978 & 15,369 & 6,092 \\ \text { pH 3 } & - & - & - \\ \text { pH 5 } & 15,978 & 4,867 & 111,111 \\ \text { pH 8 } & 15,978 & 0,930 & 150,479\end{array}$


ANEXO C

TEMPO DE CONTATO

$$
\mathbf{Z n}
$$

$\begin{array}{cccc}\text { Ref.[65] } & \mathbf{C i} & \mathbf{C f} / \mathbf{T 3} & \mathbf{q} \boldsymbol{\mu \mathbf { g }} / \mathbf{g} \\ 5 \mathrm{~min} & 61,4 & 58 & 0,017 \\ 10 \mathrm{~min} & 61,4 & 7 & 0,272 \\ 20 \mathrm{~min} & 61,4 & 8 & 0,267 \\ 30 \mathrm{~min} & 61,4 & 6 & 0,277 \\ 60 \mathrm{~min} & 61,4 & 4 & 0,287 \\ 120 \mathrm{~min} & 61,4 & 0,173 & 0,306 \\ & & & \\ \text { Ref.[180] } & \mathbf{C i} & \mathbf{C f} / \mathbf{T 3} & \mathbf{q} \boldsymbol{\mu \mathbf { g }} / \mathbf{g} \\ 5 \mathrm{~min} & 167 & 156 & 0,055 \\ 10 \mathrm{~min} & 167 & 154 & 0,065 \\ 20 \mathrm{~min} & 167 & 65 & 0,51 \\ 30 \mathrm{~min} & 167 & 68 & 0,495 \\ 60 \mathrm{~min} & 167 & 55 & 0,56 \\ 120 \mathrm{~min} & 167 & 2,1 & 0,824\end{array}$

TEMPO DE CONTATO

$\mathrm{Ni}$

\begin{tabular}{cccc}
\multicolumn{4}{c}{$\mathbf{N i}$} \\
Ref.[25] & $\mathbf{C i}$ & $\mathbf{C f} / \mathbf{T 3}$ & $\mathbf{q} \boldsymbol{\mu g} / \mathbf{g}$ \\
$5 \mathrm{~min}$ & 25,1 & 25 & 0,0005 \\
$10 \mathrm{~min}$ & 25,1 & 25,8 & $-0,0035$ \\
$20 \mathrm{~min}$ & 25,1 & 26,9 & $-0,009$ \\
$30 \mathrm{~min}$ & 25,1 & 20,2 & 0,0245 \\
$60 \mathrm{~min}$ & 25,1 & 8,13 & 0,0848 \\
$120 \mathrm{~min}$ & 25,1 & 0,99 & 0,1205 \\
& & & \\
Ref.[75] & $\mathbf{C i}$ & $\mathbf{C f} / \mathbf{T 3}$ & $\mathbf{q} \boldsymbol{\mu g} / \mathbf{g}$ \\
$5 \mathrm{~min}$ & 76,1 & 78 & $-0,0095$ \\
$10 \mathrm{~min}$ & 76,1 & 75,8 & 0,0015 \\
$20 \mathrm{~min}$ & 76,1 & 40 & 0,1805 \\
$30 \mathrm{~min}$ & 76,1 & 37,4 & 0,1935 \\
$60 \mathrm{~min}$ & 76,1 & 33,22 & 0,2144 \\
$120 \mathrm{~min}$ & 76,1 & 0,99 & 0,3755
\end{tabular}

TEMPO DE CONTATO

$\mathrm{Cu}$

$\begin{array}{cccc}\text { Ref.[12] } & \mathbf{C i} & \mathbf{C f} / \mathbf{T 3} & \mathbf{q} \boldsymbol{\mu g} / \mathbf{g} \\ 5 \mathrm{~min} & 12,4 & 12,3 & 0,5 \\ 10 \mathrm{~min} & 12,4 & 3,1 & 46,5 \\ 20 \mathrm{~min} & 12,4 & 2,09 & 51,55 \\ 30 \mathrm{~min} & 12,4 & 3,12 & 46,4 \\ 60 \mathrm{~min} & 12,4 & 2,23 & 50,85 \\ 120 \mathrm{~min} & 12,4 & 0,333 & 60,33 \\ & & & \\ \text { Ref.[37] } & \mathbf{C i} & \mathbf{C f} / \mathbf{T 3} & \mathbf{q} \boldsymbol{\mu g} / \mathbf{g} \\ 5 \mathrm{~min} & 36,8 & 33,9 & 14,5 \\ 10 \mathrm{~min} & 36,8 & 34,4 & 12 \\ 20 \mathrm{~min} & 36,8 & 12,14 & 123,3 \\ 30 \mathrm{~min} & 36,8 & 4,2 & 163 \\ 60 \mathrm{~min} & 36,8 & 2,97 & 169,15 \\ 120 \mathrm{~min} & 36,8 & 0,628 & 180,86\end{array}$




\section{ANEXO C}

TEMPO DE CONTATO

$\mathrm{Cr}$

$\begin{array}{cccc}\text { Ref.[0,1] } & \mathbf{C i} & \mathbf{C f} / \mathbf{T 2} & \mathbf{q} \boldsymbol{\mu g} / \mathbf{g} \\ 5 \mathrm{~min} & 0,106 & 0,1 & 6,00 \mathrm{E}-05 \\ 10 \mathrm{~min} & 0,106 & 0,1 & 6,00 \mathrm{E}-05 \\ 20 \mathrm{~min} & 0,106 & 0,1 & 6,00 \mathrm{E}-05 \\ 30 \mathrm{~min} & 0,106 & 0,1 & 6,00 \mathrm{E}-05 \\ 60 \mathrm{~min} & 0,106 & 0,1 & 6,00 \mathrm{E}-05 \\ 120 \mathrm{~min} & 0,106 & 0,1 & 6,00 \mathrm{E}-05\end{array}$

$\begin{array}{cccc}\text { Ref.[3,5] } & \mathbf{C i} & \mathbf{C f} / \mathbf{T} 2 & \mathbf{q} \boldsymbol{\mu} \mathbf{g} / \mathbf{g} \\ 5 \mathrm{~min} & 3,74 & 3,7 & 0,0004 \\ 10 \mathrm{~min} & 3,74 & 3,15 & 0,0059 \\ 20 \mathrm{~min} & 3,74 & 0,286 & 0,0345 \\ 30 \mathrm{~min} & 3,74 & 0,322 & 0,0342 \\ 60 \mathrm{~min} & 3,74 & 0,222 & 0,0352 \\ 120 \mathrm{~min} & 3,74 & 0,159 & 0,0358\end{array}$

TEMPO DE CONTATO

Cd

$\begin{array}{cccc}\text { Ref.[0,2] } & \mathbf{C i} & \mathbf{C f} / \mathbf{T} 2 & \mathbf{q} \boldsymbol{\mu g} / \mathbf{g} \\ 5 \mathrm{~min} & 0,198 & 0,0046 & 1,934 \\ 10 \mathrm{~min} & 0,198 & 0,0073 & 1,907 \\ 20 \mathrm{~min} & 0,198 & 0,0052 & 1,928 \\ 30 \mathrm{~min} & 0,198 & 0,0048 & 1,932 \\ 60 \mathrm{~min} & 0,198 & 0,0048 & 1,932 \\ 120 \mathrm{~min} & 0,198 & 0,0045 & 1,935\end{array}$

$\begin{array}{cccc}\text { Ref.[8,0] } & \mathbf{C i} & \mathbf{C f} / \mathbf{T 2} & \mathbf{q} \boldsymbol{\mu g} / \mathbf{g} \\ 5 \mathrm{~min} & 6,932 & 0,0488 & 68,832 \\ 10 \mathrm{~min} & 6,932 & 0,0499 & 68,821 \\ 20 \mathrm{~min} & 6,932 & 0,0556 & 68,764 \\ 30 \mathrm{~min} & 6,932 & 0,0704 & 68,616 \\ 60 \mathrm{~min} & 6,932 & 0,2363 & 66,957 \\ 120 \mathrm{~min} & 6,932 & 0,1227 & 68,093\end{array}$

TEMPO DE CONTATO

$\mathbf{P b}$

$\begin{array}{cccc}\text { Ref.[0,5] } & \mathbf{C i} & \mathbf{C f} / \mathbf{T 3} & \mathbf{q} \boldsymbol{\mu g} / \mathbf{g} \\ 5 \mathrm{~min} & 0,4848 & 0,0386 & 4,462 \\ 10 \mathrm{~min} & 0,4848 & 0,0341 & 4,507 \\ 20 \mathrm{~min} & 0,4848 & 0,0354 & 4,494 \\ 30 \mathrm{~min} & 0,4848 & 0,0242 & 4,606 \\ 60 \mathrm{~min} & 0,4848 & 0,0312 & 4,536 \\ 120 \mathrm{~min} & 0,4848 & 0,0364 & 4,484 \\ & & & \\ \text { Ref.[18] } & \mathbf{C i} & \mathbf{C f} / \mathbf{T 3} & \mathbf{q} \boldsymbol{\mu g} / \mathbf{g} \\ 5 \mathrm{~min} & 18,944 & 2,7296 & 162,144 \\ 10 \mathrm{~min} & 18,944 & 0,4884 & 184,556 \\ 20 \mathrm{~min} & 18,944 & 0,6964 & 182,476 \\ 30 \mathrm{~min} & 18,944 & 0,6986 & 182,454 \\ 60 \mathrm{~min} & 18,944 & 0,3066 & 186,374 \\ 120 \mathrm{~min} & 18,944 & 0,4835 & 184,605\end{array}$


ANEXO D

\begin{tabular}{ccccc}
\multicolumn{5}{c}{ ISOTERMA - LANGMUIR } \\
\hline Ref. & Co & Ce & qe $\boldsymbol{\mu g} / \mathbf{g}$ & $\mathbf{C e} / \mathbf{q e}$ \\
{$[0,2]$} & 0,198 & 0,007 & 1,91 & 0,00366 \\
{$[1,0]$} & 0,851 & 0,032 & 8,19 & 0,00391 \\
{$[8,0]$} & 6,932 & 0,226 & 67,06 & 0,00337 \\
{$[10,0]$} & 8,177 & 0,422 & 77,55 & 0,00544 \\
T2 [0,2] & 0,170 & 0,0033 & 1,67 & 0,00198 \\
T2 [1,0] & 0,883 & 0,0323 & 8,50 & 0,0038 \\
T2 [8,0] & 6,840 & 0,7316 & 61,08 & 0,01198 \\
pH 8 [0,2] & 0,274 & 0,0103 & 2,64 & 0,00391
\end{tabular}

ISOTERMA-FREUNDLICH

\begin{tabular}{ccccccc}
\multicolumn{7}{c}{$\mathbf{C d}$} \\
\hline Ref. & Co & $\mathbf{C e}$ & $\mathbf{q e} \boldsymbol{\mu g} / \mathbf{g}$ & $\mathbf{C e} / \mathbf{q e}$ & $\log \mathbf{q e}$ & $\log \mathbf{C e}$ \\
{$[0,2]$} & 0,198 & 0,007 & 1,91 & 0,00366 & 0,28103 & $-2,1549$ \\
{$[1,0]$} & 0,851 & 0,032 & 8,19 & 0,00391 & 0,91328 & $-1,4949$ \\
{$[8,0]$} & 6,932 & 0,226 & 67,06 & 0,00337 & 1,82646 & $-0,6459$ \\
{$[10,0]$} & 8,177 & 0,422 & 77,55 & 0,00544 & 1,88958 & $-0,3747$ \\
T2 [0,2] & 0,170 & 0,0033 & 1,67 & 0,00198 & 0,22261 & $-2,4815$ \\
T2 [1,0] & 0,883 & 0,0323 & 8,50 & 0,0038 & 0,92956 & $-1,4908$ \\
T2 [8,0] & 6,840 & 0,7316 & 61,08 & 0,01198 & 1,78591 & $-0,1357$ \\
pH 8 [0,2] & 0,274 & 0,0103 & 2,64 & 0,00391 & 0,42111 & $-1,9872$
\end{tabular}

\section{ISOTERMA - D-R}

\begin{tabular}{cccccc}
\multicolumn{7}{c}{ Cd } \\
\hline Ref. & Co & $\mathbf{C e}$ & $\mathbf{q e} \boldsymbol{\mu g} / \mathbf{g}$ & $\mathbf{l n} \mathbf{q e}$ & $\boldsymbol{\varepsilon}$ \\
{$[0,2]$} & 0,198 & 0,007 & 1,91 & 0,6471 & $1,5 \mathrm{E}+08$ \\
{$[1,0]$} & 0,851 & 0,032 & 8,19 & 2,10291 & $7,4 \mathrm{E}+07$ \\
{$[8,0]$} & 6,932 & 0,226 & 67,06 & 4,20559 & $1,8 \mathrm{E}+07$ \\
{$[10,0]$} & 8,177 & 0,422 & 77,55 & 4,35092 & 9050121 \\
T2 [0,2] & 0,170 & 0,0033 & 1,67 & 0,51258 & $2 \mathrm{E}+08$ \\
T2 [1,0] & 0,883 & 0,0323 & 8,50 & 2,14038 & $7,4 \mathrm{E}+07$ \\
T2 [8,0] & 6,840 & 0,7316 & 61,08 & 4,11221 & 4552111 \\
pH $8[0,2]$ & 0,274 & 0,0103 & 2,64 & 0,96964 & $1,3 \mathrm{E}+08$
\end{tabular}


ANEXO D

\begin{tabular}{ccccc}
\multicolumn{5}{c}{ ISOTERMA - LANGMUIR } \\
\hline Ref. & Co & Ce & $\mathbf{q e} \boldsymbol{\mu} \mathbf{g} / \mathbf{g}$ & $\mathbf{C e} / \mathbf{q e}$ \\
{$[0,5]$} & 0,4848 & 0,0468 & 4,38 & 0,01068 \\
{$[6,0]$} & 5,603 & 0,2726 & 53,304 & 0,00511 \\
{$[12]$} & 11,552 & 0,9688 & 105,832 & 0,00915 \\
{$[18]$} & 18,944 & 1,3868 & 175,572 & 0,0079 \\
{$[25]$} & 28,53 & 1,1904 & 273,524 & 0,00435 \\
T2 [0,5] & 0,522 & 0,059 & 4,63 & 0,01274 \\
T2 [6,0] & 5,603 & 0,0754 & 55,276 & 0,00136 \\
T2 [12] & 12,1499 & 3,3048 & 88,451 & 0,03736 \\
T2 [18] & 19,092 & 1,873 & 172,190 & 0,01088 \\
T2 [25] & 28,53 & 10,2875 & 182,425 & 0,05639
\end{tabular}

ISOTERMA-FREUNDLICH

\begin{tabular}{ccccccc}
\multicolumn{7}{c}{$\mathbf{P b}$} \\
\hline Ref. & $\mathbf{C o}$ & $\mathbf{C e}$ & $\mathbf{q e} \boldsymbol{\mu g} / \mathbf{g}$ & $\mathbf{C e} / \mathbf{q e}$ & $\log \mathbf{q e}$ & $\log \mathbf{C e}$ \\
{$[0,5]$} & 0,4848 & 0,0468 & 4,38 & 0,01068 & 0,64147 & $-1,3298$ \\
{$[6,0]$} & 5,603 & 0,2726 & 53,304 & 0,00511 & 1,72676 & $-0,5645$ \\
{$[12]$} & 11,552 & 0,9688 & 105,832 & 0,00915 & 2,02462 & $-0,0138$ \\
$\mathrm{~T} 2[0,5]$ & 0,522 & 0,059 & 4,63 & 0,01274 & 0,66558 & $-1,2291$
\end{tabular}

ISOTERMA - D-R

\begin{tabular}{cccccc}
\multicolumn{7}{c}{ ISOTERMA - D-R } \\
\hline Ref. & Co & Ce & qe $\boldsymbol{\mu g} / \mathbf{g}$ & ln qe & $\boldsymbol{\varepsilon}$ \\
{$[0,5]$} & 0,4848 & 0,0468 & 4,38 & 1,47705 & $5,9 \mathrm{E}+07$ \\
{$[6,0]$} & 5,603 & 0,2726 & 53,304 & 3,97601 & $1,5 \mathrm{E}+07$ \\
{$[12]$} & 11,552 & 0,9688 & 105,832 & 4,66185 & 3083725 \\
{$[18]$} & 18,944 & 1,3868 & 175,572 & 5,16805 & 1807847 \\
{$[25]$} & 28,53 & 1,1904 & 273,524 & 5,61139 & 2280353 \\
T2 [0,5] & 0,522 & 0,059 & 4,63 & 1,53256 & $5,1 \mathrm{E}+07$ \\
T2 [6,0] & 5,603 & 0,0754 & 55,276 & 4,01234 & $4,3 \mathrm{E}+07$ \\
T2 [12] & 12,1499 & 3,3048 & 88,451 & 4,48245 & 428557 \\
T2 [18] & 19,092 & 1,873 & 172,190 & 5,1486 & 1122399 \\
T2 [25] & 28,53 & 10,2875 & 182,425 & 5,20634 & 52773,5
\end{tabular}


ANEXO D

\section{ISOTERMA - LANGMUIR}

\begin{tabular}{ccccc}
\multicolumn{5}{c}{$\mathbf{C r}$} \\
Ref. & $\mathbf{C o}$ & $\mathbf{C e}$ & $\mathbf{q e} \boldsymbol{\mu \mathbf { g } / \mathbf { g }}$ & $\mathbf{C e} / \mathbf{q}$ \\
{$[2,5]$} & 2,82 & 0,142 & 26,78 & 0,0053 \\
{$[2,5]$} & 2,82 & 0,176 & 26,44 & 0,00666 \\
{$[3,5]$} & 3,92 & 0,3 & 36,2 & 0,00829 \\
{$[3,5]$} & 3,92 & 0,205 & 37,15 & 0,00552 \\
{$[5,0]$} & 5,58 & 0,203 & 53,77 & 0,00378 \\
{$[5,0]$} & 5,58 & 0,283 & 52,97 & 0,00534 \\
$\mathrm{~T} 2[1,0]$ & 1 & 0,05 & 9,5 & 0,00526 \\
$\mathrm{~T} 2[2,5]$ & 2,5 & 0,052 & 24,48 & 0,00212 \\
$\mathrm{~T} 2[3,5]$ & 2,9 & 0,05 & 28,5 & 0,00175 \\
$\mathrm{~T} 2[5,0]$ & 5 & 0,05 & 49,5 & 0,00101 \\
$\mathrm{pH} 8[3,5]$ & 3,74 & 0,159 & 35,81 & 0,00444 \\
120 min $[3,5]$ & 3,74 & 0,159 & 35,81 & 0,00444
\end{tabular}

ISOTERMA-FREUNDLICH

\section{$\mathrm{Cr}$}

\begin{tabular}{ccccccc}
\hline Ref. & Co & $\mathbf{C e}$ & $\mathbf{q e} \boldsymbol{\mu g} / \mathbf{g}$ & $\mathbf{C e} / \mathbf{q e}$ & $\log \mathbf{q e}$ & $\log \mathbf{C e}$ \\
{$[2,5]$} & 2,82 & 0,142 & 26,78 & 0,0053 & 1,42781 & $-0,8477$ \\
{$[2,5]$} & 2,82 & 0,176 & 26,44 & 0,00666 & 1,42226 & $-0,7545$ \\
{$[3,5]$} & 3,92 & 0,3 & 36,2 & 0,00829 & 1,55871 & $-0,5229$ \\
{$[3,5]$} & 3,92 & 0,205 & 37,15 & 0,00552 & 1,56996 & $-0,6882$ \\
{$[5,0]$} & 5,58 & 0,203 & 53,77 & 0,00378 & 1,73054 & $-0,6925$ \\
{$[5,0]$} & 5,58 & 0,283 & 52,97 & 0,00534 & 1,72403 & $-0,5482$ \\
$\mathrm{~T} 2[1,0]$ & 1 & 0,05 & 9,5 & 0,00526 & 0,97772 & $-1,301$ \\
$\mathrm{~T} 2[2,5]$ & 2,5 & 0,052 & 24,48 & 0,00212 & 1,38881 & $-1,284$ \\
$\mathrm{~T} 2[3,5]$ & 2,9 & 0,05 & 28,5 & 0,00175 & 1,45484 & $-1,301$ \\
$\mathrm{~T} 2[5,0]$ & 5 & 0,05 & 49,5 & 0,00101 & 1,69461 & $-1,301$ \\
$\mathrm{pH} 8[3,5]$ & 3,74 & 0,159 & 35,81 & 0,00444 & 1,554 & $-0,7986$ \\
$120 \min [3,5]$ & 3,74 & 0,159 & 35,81 & 0,00444 & 1,554 & $-0,7986$
\end{tabular}




\section{ANEXO D}

\section{ISOTERMA - D-R}

\begin{tabular}{cccccc}
\multicolumn{7}{c}{$\mathbf{C r}$} \\
\hline Ref. & Co & $\mathbf{C e}$ & $\mathbf{q e ~} \boldsymbol{\mu g} / \mathbf{g}$ & $\mathbf{l n} \mathbf{q e}$ & $\boldsymbol{\varepsilon}$ \\
{$[2,5]$} & 2,82 & 0,142 & 26,78 & 3,28766 & $2,7 \mathrm{E}+07$ \\
{$[2,5]$} & 2,82 & 0,176 & 26,44 & 3,27488 & $2,2 \mathrm{E}+07$ \\
{$[3,5]$} & 3,92 & 0,3 & 36,2 & 3,58906 & $1,3 \mathrm{E}+07$ \\
{$[3,5]$} & 3,92 & 0,205 & 37,15 & 3,61496 & $1,9 \mathrm{E}+07$ \\
{$[5,0]$} & 5,58 & 0,203 & 53,77 & 3,98472 & $1,9 \mathrm{E}+07$ \\
{$[5,0]$} & 5,58 & 0,283 & 52,97 & 3,96973 & $1,4 \mathrm{E}+07$ \\
$\mathrm{~T} 2[1,0]$ & 1 & 0,05 & 9,5 & 2,25129 & $5,7 \mathrm{E}+07$ \\
$\mathrm{~T} 2[2,5]$ & 2,5 & 0,052 & 24,48 & 3,19786 & $5,5 \mathrm{E}+07$ \\
$\mathrm{~T} 2[3,5]$ & 2,9 & 0,05 & 28,5 & 3,34990 & $5,7 \mathrm{E}+07$ \\
$\mathrm{~T} 2[5,0]$ & 5 & 0,05 & 49,5 & 3,90197 & $5,7 \mathrm{E}+07$ \\
$\mathrm{pH} 8[3,5]$ & 3,74 & 0,159 & 35,81 & 3,57823 & $2,4 \mathrm{E}+07$ \\
120 min $[3,5]$ & 3,74 & 0,159 & 35,81 & 3,57823 & $2,4 \mathrm{E}+07$
\end{tabular}




\section{ANEXO D}

\begin{tabular}{ccccc}
\multicolumn{5}{c}{ ISOTERMA - LANGMUIR } \\
\hline Ref. & Co & Ce & $\mathbf{q e ~} \boldsymbol{\mu g} / \mathbf{g}$ & $\mathbf{C e} / \mathbf{q e}$ \\
{$[12]$} & 11,66 & 0,272 & 56,94 & 0,00478 \\
{$[12]$} & 11,66 & 0,221 & 57,20 & 0,00386 \\
{$[25]$} & 24,2 & 0,730 & 117,35 & 0,00622 \\
{$[25]$} & 24,2 & 0,508 & 118,46 & 0,00429 \\
{$[37]$} & 24,3 & 0,876 & 117,12 & 0,00748 \\
{$[37]$} & 24,3 & 0,816 & 117,42 & 0,00695 \\
{$[50]$} & 37,2 & 1,15 & 180,25 & 0,00638 \\
{$[50]$} & 37,2 & 0,94 & 181,30 & 0,00518
\end{tabular}

ISOTERMA-FREUNDLICH

\begin{tabular}{ccccccc}
\multicolumn{7}{c}{$\mathbf{C u}$} \\
\hline Ref. & Co & Ce & qe $\boldsymbol{\mu g} / \mathbf{g}$ & $\mathbf{C e} / \mathbf{q e}$ & $\log \mathbf{q e}$ & $\log \mathbf{C e}$ \\
{$[12]$} & 11,66 & 0,272 & 56,94 & 0,00478 & 1,75542 & $-0,5654$ \\
{$[12]$} & 11,66 & 0,221 & 57,20 & 0,00386 & 1,75736 & $-0,6556$ \\
{$[25]$} & 24,2 & 0,730 & 117,35 & 0,00622 & 2,06948 & $-0,1367$ \\
{$[25]$} & 24,2 & 0,508 & 118,46 & 0,00429 & 2,07357 & $-0,2941$ \\
{$[37]$} & 24,3 & 0,876 & 117,12 & 0,00748 & 2,06863 & $-0,0575$ \\
{$[37]$} & 24,3 & 0,816 & 117,42 & 0,00695 & 2,06974 & $-0,0883$ \\
{$[50]$} & 37,2 & 1,15 & 180,25 & 0,00638 & 2,25588 & 0,0607 \\
{$[50]$} & 37,2 & 0,94 & 181,30 & 0,00518 & 2,2584 & $-0,0269$
\end{tabular}

\section{ISOTERMA - D-R}

\begin{tabular}{cccccc}
\multicolumn{5}{c}{$\mathbf{C u}$} \\
\hline Ref. & $\mathbf{C o}$ & $\mathbf{C e}$ & $\mathbf{q e} \boldsymbol{\mu g} / \mathbf{g}$ & $\mathbf{l n} \mathbf{q e}$ & $\boldsymbol{\varepsilon}$ \\
{$[12]$} & 11,66 & 0,272 & 56,94 & 4,042 & $1,5 \mathrm{E}+07$ \\
{$[12]$} & 11,66 & 0,221 & 57,20 & 4,04647 & $1,8 \mathrm{E}+07$ \\
{$[25]$} & 24,2 & 0,730 & 117,35 & 4,76516 & 4565488 \\
{$[25]$} & 24,2 & 0,508 & 118,46 & 4,77458 & 7260036 \\
{$[37]$} & 24,3 & 0,876 & 117,12 & 4,7632 & 3556393 \\
{$[37]$} & 24,3 & 0,816 & 117,42 & 4,76576 & 3924549 \\
{$[50]$} & 37,2 & 1,15 & 180,25 & 5,19434 & 2400906 \\
{$[50]$} & 37,2 & 0,94 & 181,30 & 5,20015 & 3219492
\end{tabular}




\section{ANEXO D}

\begin{tabular}{ccccc}
\multicolumn{5}{c}{ ISOTERMA - LANGMUIR } \\
\hline Ref. & Co & Ce & $\mathbf{q e ~} \boldsymbol{\mu g} / \mathbf{g}$ & $\mathbf{C e} / \mathbf{q e}$ \\
{$[125]$} & 137,1 & 0,157 & 684,715 & 0,00023 \\
{$[125]$} & 137,1 & 1,01 & 680,45 & 0,00148 \\
{$[180]$} & 174 & 1,08 & 864,6 & 0,00125 \\
{$[180]$} & 174 & 0,32 & 868,4 & 0,00037 \\
{$[250]$} & 244 & 6,54 & 1187,3 & 0,00551 \\
{$[250]$} & 244 & 0,48 & 1217,6 & 0,00039 \\
T3 [125] & 111 & 8,12 & 514,4 & 0,01579 \\
T3 [180] & 174 & 4,91 & 845,45 & 0,00581 \\
pH 8 [65] & 61,4 & 0,173 & 306,135 & 0,00057 \\
pH 8 [180] & 167 & 2,1 & 824,5 & 0,00255 \\
120 min [65] & 61,4 & 0,173 & 306,135 & 0,00057 \\
120 min [180] & 167 & 2,1 & 824,5 & 0,00255
\end{tabular}

\begin{tabular}{ccccccc}
\multicolumn{7}{c}{ ISOTERMA-FREUNDLICH } \\
\hline Ref. & Co & Ce & qe $\boldsymbol{\mu g} / \mathbf{g}$ & $\mathbf{C e} / \mathbf{q e}$ & log qe & log Ce \\
{$[125]$} & 137,1 & 0,157 & 684,715 & 0,00023 & 2,83551 & $-0,8041$ \\
{$[125]$} & 137,1 & 1,01 & 680,45 & 0,00148 & 2,8328 & 0,00432 \\
{$[180]$} & 174 & 1,08 & 864,6 & 0,00125 & 2,93682 & 0,03342 \\
{$[180]$} & 174 & 0,32 & 868,4 & 0,00037 & 2,93872 & $-0,4949$ \\
{$[250]$} & 244 & 6,54 & 1187,3 & 0,00551 & 3,07456 & 0,81558 \\
{$[250]$} & 244 & 0,48 & 1217,6 & 0,00039 & 3,0855 & $-0,3188$ \\
T3 [125] & 111 & 8,12 & 514,4 & 0,01579 & 2,7113 & 0,90956 \\
T3 [180] & 174 & 4,91 & 845,45 & 0,00581 & 2,92709 & 0,69108 \\
pH 8 [65] & 61,4 & 0,173 & 306,135 & 0,00057 & 2,48591 & $-0,762$ \\
pH 8 [180] & 167 & 2,1 & 824,5 & 0,00255 & 2,91619 & 0,32222 \\
120 min [65] & 61,4 & 0,173 & 306,135 & 0,00057 & 2,48591 & $-0,762$ \\
120 min [180] & 167 & 2,1 & 824,5 & 0,00255 & 2,91619 & 0,32222
\end{tabular}




\section{ANEXO D}

\section{ISOTERMA - D-R}

\begin{tabular}{cccccc}
\multicolumn{7}{c}{ Zn } \\
\hline Ref. & Co & Ce & $\mathbf{q e} \boldsymbol{\mu g} / \mathbf{g}$ & $\mathbf{l n} \mathbf{q e}$ & $\boldsymbol{\varepsilon}$ \\
{$[125]$} & 137,1 & 0,157 & 684,715 & 6,529 & $2,4 \mathrm{E}+07$ \\
{$[125]$} & 137,1 & 1,01 & 680,45 & 6,52275 & 2904318 \\
{$[180]$} & 174 & 1,08 & 864,6 & 6,76227 & 2634247 \\
{$[180]$} & 174 & 0,32 & 868,4 & 6,76665 & $1,2 \mathrm{E}+07$ \\
{$[250]$} & 244 & 6,54 & 1187,3 & 7,07944 & 124152 \\
{$[250]$} & 244 & 0,48 & 1217,6 & 7,10464 & 7775352 \\
T3 [125] & 111 & 8,12 & 514,4 & 6,243 & 82717,2 \\
T3 [180] & 174 & 4,91 & 845,45 & 6,73987 & 210728 \\
pH 8 [65] & 61,4 & 0,173 & 306,135 & 5,72403 & $2,2 \mathrm{E}+07$ \\
pH 8 [180] & 167 & 2,1 & 824,5 & 6,71478 & 930188 \\
120 min [65] & 61,4 & 0,173 & 306,135 & 5,72403 & $2,2 \mathrm{E}+07$ \\
120 min [180] & 167 & 2,1 & 824,5 & 6,71478 & 930188
\end{tabular}




\section{ANEXO D}

\begin{tabular}{ccccc}
\multicolumn{5}{c}{ ISOTERMA - LANGMUIR } \\
\hline Ref. & Co & Ce & $\mathbf{q e} \boldsymbol{\mu} \mathbf{g} / \mathbf{g}$ & $\mathbf{C e} / \mathbf{q e}$ \\
{$[25]$} & 25 & 0,869 & 120,655 & 0,0072 \\
{$[25]$} & 25 & 0,84 & 120,8 & 0,00695 \\
{$[50]$} & 52,2 & 1,17 & 255,15 & 0,00459 \\
{$[50]$} & 52,2 & 0,83 & 256,85 & 0,00323 \\
{$[75]$} & 78,3 & 0,235 & 390,325 & 0,0006 \\
{$[75]$} & 78,3 & 0,46 & 389,2 & 0,00118 \\
{$[100]$} & 103 & 0,863 & 510,685 & 0,00169 \\
{$[100]$} & 103 & 0,396 & 513,02 & 0,00077
\end{tabular}

\section{ISOTERMA-FREUNDLICH}

\begin{tabular}{ccccccc}
\multicolumn{7}{c}{$\mathbf{N i}$} \\
\hline Ref. & Co & Ce & qe $\boldsymbol{\mu g} / \mathbf{g}$ & $\mathbf{C e} / \mathbf{q e}$ & $\log \mathbf{q e}$ & $\log \mathbf{C e}$ \\
{$[25]$} & 25 & 0,869 & 120,655 & 0,0072 & 2,08155 & $-0,061$ \\
{$[25]$} & 25 & 0,84 & 120,8 & 0,00695 & 2,08207 & $-0,0757$ \\
{$[50]$} & 52,2 & 1,17 & 255,15 & 0,00459 & 2,4068 & 0,06819 \\
{$[50]$} & 52,2 & 0,83 & 256,85 & 0,00323 & 2,40968 & $-0,0809$ \\
{$[75]$} & 78,3 & 0,235 & 390,325 & 0,0006 & 2,59143 & $-0,6289$ \\
{$[75]$} & 78,3 & 0,46 & 389,2 & 0,00118 & 2,59017 & $-0,3372$ \\
{$[100]$} & 103 & 0,863 & 510,685 & 0,00169 & 2,70815 & $-0,064$ \\
{$[100]$} & 103 & 0,396 & 513,02 & 0,00077 & 2,71013 & $-0,4023$
\end{tabular}

\section{ISOTERMA - D-R}

\begin{tabular}{cccccc}
\multicolumn{7}{c}{$\mathbf{N i}$} \\
\hline Ref. & $\mathbf{C o}$ & $\mathbf{C e}$ & $\mathbf{q e} \boldsymbol{\mu g} / \mathbf{g}$ & $\mathbf{l n} \mathbf{q e}$ & $\boldsymbol{\varepsilon}$ \\
{$[25]$} & 25 & 0,869 & 120,655 & 4,79294 & 3596525 \\
{$[25]$} & 25 & 0,84 & 120,8 & 4,79414 & 3770496 \\
{$[50]$} & 52,2 & 1,17 & 255,15 & 5,54185 & 2340037 \\
{$[50]$} & 52,2 & 0,83 & 256,85 & 5,54849 & 3833524 \\
{$[75]$} & 78,3 & 0,235 & 390,325 & 5,96698 & $1,7 \mathrm{E}+07$ \\
{$[75]$} & 78,3 & 0,46 & 389,2 & 5,96409 & 8180360 \\
{$[100]$} & 103 & 0,863 & 510,685 & 6,23575 & 3631485 \\
{$[100]$} & 103 & 0,396 & 513,02 & 6,24031 & 9735150
\end{tabular}

